\title{
International Capital Flows and Debt Dynamics
}

\author{
Martin D. D. Evans \\ Department of Economics, Georgetown University; \\ the NBER; and Research Department, IMF*
}

June 27, 2012

\begin{abstract}
This paper presents a new model for studying international capital flows and debt dynamics. The model emphasizes the role of expectations concerning future trade flows and returns as the determinants of a country's foreign asset and liability positions, and how revisions in these expectations drive gross and net capital flows. I use the model to estimate the drivers of the U.S. external position and capital flows between 1973 and 2008. The estimates show that most of the secular rise in U.S. international indebtedness is attributable to growing optimism about future returns on U.S. holdings of foreign equity and FDI assets. Expectations concerning future returns are also the most important determinant of net capital flows, but the flows themselves are not important drivers of the U.S. external position. My estimates also show that the transformation of world savings into risky assets by the U.S. had little effect on its external position, but the expected real depreciation of the dollar allowed the U.S. to sustain a much higher level of international debt after the 1990s.
\end{abstract}

Keywords: Capital Flows, External Imbalances, International Debt, International Solvency, Exorbitant Privilege

JEL Codes: F31, F32, F34

\footnotetext{
*Email: evansmdd@gmail.com. This paper is a revised and extended version of an earlier paper entitled "Understanding the Dynamics of the US External Position". I thank Alberto Fuertes for his assistance in updating the data set used here. The paper was written while the author was visiting the Research Department of the IMF. The views expressed here are solely those of the author and should not be reported as representing the views of the IMF. I am very grateful to the Research Department for their hospitality and financial support.
} 


\section{Introduction}

The past quarter century has witnessed a dramatic change in world financial markets. The liberalization of capital accounts and globalization of financial transactions has been accompanied by a rapid increase in the size of the gross foreign asset and liability positions of many countries. In the two decades preceding the 2008 crisis, gross capital flows were typically larger than current account gaps in industrialized countries, and grew at a faster rate than international trade flows. The precrisis period also witnessed a marked increase in current account imbalances across the globe, with numerous countries running persistent surpluses or deficits. Most notably, the U.S. continued to run large current account deficits in the face of a growing level of international debt.

These developments provide a challenge to both researchers and policymakers. Traditional macro models focus on the behavior of the current account driven by national savings and investment decisions rather than the financial decisions that govern the size and composition of gross capital flows (see, e.g., Obstfeld and Rogoff, 1995). The limit on a country's ability to run current account deficits in such models is largely determined by the prospects for future surpluses whereas actual limits also depend on the prospective future returns on foreign assets relative to liabilities. As a result, persistent current account deficits may be more sustainable than a traditional macro-based evaluation would suggest. Conversely, a country without a history of current account deficits may find itself in an unsustainable position if the composition of foreign assets and liabilities make its net foreign asset position vulnerable to unexpected asset-price movements. Existing models provide little guidance on how to assess such balance sheet considerations.

In this paper I develop a new model for studying the dynamics of a country's foreign asset and liability positions. The model provides an integrated framework for examining the real and financial factors that affect the evolution of any country's external position. In particular, the empirical model I build on this framework allows me to estimate the factors driving variations in U.S. foreign asset and liability positions, and their associated capital flows before the 2008 financial crisis. In so doing, I shed new light on the source and importance of the so-called "exorbitant privilege" enjoyed by the U.S. over the past quarter century.

The model is built around the consolidated budget constraint that links the evolution of a country's foreign assets and liabilities to exports, imports and returns. This accounting identity is usually used to relate a country's current net asset position to the history of current account balances and the capital gains on past asset and liability holdings. Here I combined it with a no-Ponzi condition to derive the international solvency constraint that places an upper limit on a country's international borrowing. This solvency constraint lies at the heart of the model. Specifically, I derive a set of present value expressions that link a country's current asset and liability positions to expectations concerning the future course of exports, imports, the returns on foreign assets and liabilities. These expressions also determine gross and net capital flows. I combine the position and flow equations 
with estimates of a Vector Autogression (VAR) to empirically study the factors driving the U.S. external positions and capital flows.

The economic logic underlying the model is simple. Consider a situation where a country with a negative net foreign asset position wants to run a current account deficit to facilitate intertemporal consumption smoothing. Clearly, this is only possible if the country can finance the deficit via the accumulation of foreign liabilities or through the sale of foreign assets. Either way, in the absence of Ponzi schemes, the country's creditors must expect that the additional net debt will ultimately be repaid using the proceeds from future net exports and/or the return differential between foreign assets and liabilities. Any variation in a country's net foreign asset position must therefore be accompanied by a revision in expectations concerning future trade flows and/or returns. Similarly, changes in gross asset or liability positions must reflect revisions in the expected future returns on the underlying securities or the dividend flows they produce financed by trade flows. These links between expectations and positions lie at the heart of the model and are the focus of the empirical analysis.

The rapid rise in the gross foreign asset and liability positions of many countries in recent decades presents a challenge for anyone developing a model of international asset positions. In the case of the U.S., gross assets and liabilities have grown much faster than exports, imports, GDP or estimates of U.S. wealth. Gourinchas and Rey (2007b) accommodate this feature by focusing on the process of international adjustment around slow-moving trends in the ratios of assets, liabilities, exports and imports to wealth (under the assumption that the trends represent structural changes related to trade and financial globalization). I adopt a fundamentally different approach. Instead of detrending the data, I adjust exports and imports by the addition of a common trend that maintains the integrity of the consolidated budget constraint. These adjustments allow me to derive equations for total foreign asset and liability positions from an accurate log-approximation to the consolidated budget constraint. As a consequence, my model accommodates the prominent trends observed in international data.

My empirical analysis of the U.S. data produces three sets of results. The first set concerns the evolution of the U.S. foreign asset and liability positions. I find that the expectations of future trade flows and returns identified by the model estimates account for approximately 97 percent of the quarterly variations in the U.S. net external position between 1973:I and 2007:IV. Furthermore, the estimates imply that revisions in the expected future return differential between foreign assets and liabilities are the dominant driver of the U.S. external position, contributing more than 75 percent to the sample variance in the baseline version of the model. These estimates of the valuation component are roughly twice the size of those reported by Gourinchas and Rey (2007b). They reflect the fact that the low-frequency swings in the U.S. external position are more closely related to changes in expected return differentials than to changes in expected future trade flows. I also find that expectations concerning future trade flows and returns had asymmetric affects on the dynamics of gross foreign asset and liability positions. A rise in expected future export growth 
induced the accumulation of liabilities, while a rise in expected future import growth produced a fall in foreign asset holdings. Changes in expected future returns had similarly asymmetric effects: higher expected returns on assets increased asset holdings, while higher expected returns on liabilities lowered liability holdings.

My second set of results concerns capital flows. I find that changes in expected future return differentials between foreign asset and liability portfolios are an empirically important driver of U.S. net capital flows; indeed they are a good deal more important than changes in expected future trade flows. At the same time, net capital flows have played a rather minor role as the driver of changes in the U.S. external position; making a variance contribution of just 10 percent over a ten year horizon. In contrast, gross capital flows are primarily driven by a common component that reflects international capital deepening driven by the expected growth in average net income from asset and liabilities relative to returns. Flows are also an important driver of gross position changes, accounting for approximately 50 percent of their variance over a ten year horizon.

I also use the model estimates to evaluate the idea that the U.S. has enjoyed an "exorbitantprivilege" from issuing a reserve currency and transforming world savings into risky capital. I find that while the asymmetric composition of U.S. foreign asset and liability portfolios affected the behavior of realized return differentials, it did not materially affect the long-horizon forecasts of future returns that determine the valuation component. As a consequence, my results indicate that the U.S. did not benefit significantly from the concentration of its asset holdings in equity and FDI and its liabilities in debt. On the other hand, the U.S. did benefit from the return differentials on equity and FDI. Persistent and predicable variations in these differentials are the main drivers of the valuation component. I also find that the historical variations in the valuation component embedded significant expectations concerning the future real depreciation of the dollar. In particular, much of the marked deterioration in the U.S. external position between 1998 and 2003 appears to be attributable to expectations of a future real dollar depreciation that was associated with higher expected future return differentials on equity and FDI.

This paper is closely related to Gourinchas and Rey (2007b) in its focus on the link between a country's external position and forecasts of future trade flows and returns. However, I go beyond their analysis in three key respects: First, the model I develop accommodates the trends in gross asset and liability positions so I can examine the dynamics of total positions rather than their cyclical components. Second, I examine the dynamics of both gross and net positions and their associated capital flows. Third, I use the model to quantify how composition effects and variations in the international value of dollar contribute to the U.S. exorbitant privilege via their implications for the international solvency constraint.

My results are also related to a larger literature on international returns. Early papers in this literature (Obstfeld and Rogoff, 2005; Lane and Milesi-Ferretti, 2005; Meissner and Taylor, 2006 and Gourinchas and Rey, 2007a) estimated that the return on U.S. foreign assets was on average 
approximately 3 percent per year higher than the return on foreign liabilities. Subsequent papers by Curcuru, Dvorak, and Warnock (2007) and Lane and Milesi-Ferretti (2009) argued that these estimates were biased upward because of inaccuracies in data. The data on returns I use avoids this bias and has similar sample properties to the returns used in Curcuru, Dvorak, and Warnock (2007) and Forbes (2009). More importantly, I show that persistent variations in expected future return differentials played a dominant role in the evolution of the U.S. external position even though average return differentials are very small. In other words, the economic relevance of return differentials for a country's external position depends on the behavior expected future differentials conditioned on real-time information, rather than on the size of unconditional expected return differentials. Finally, my analysis concerning the drivers of capital flows relates to the large literature studying the effects of capital controls (see, Magud, Reinhart, and Rogoff, 2011, for a recent survey). The distinctive feature of the paper with respect to this literature is that I study the determinants of capital flows in a dynamic, intertemporal setting.

The remainder of the paper is structured as follows: Section 2 describes the links between the balance of payments accounts and the consolidated budget constraint that lies at the heart of the model. Section 3 presents the model. I describe the data and model estimates in Section 4. Section 5 uses the model estimates to study the evolution of U.S. external positions and capital flows. The source of the U.S. exorbitant privilege is studied in Section 6. Section 7 concludes.

\section{International Assets, Liabilities, Returns and Trade Flows}

I begin by establishing the links between the balance of payments accounts and the consolidated budget constraint that governs the evolution of a country's foreign asset and liability positions. I then examine the role of expectations, capital gains and portfolio choices in the determination of net foreign asset positions and capital flows. This analysis sets the stage for the development of the model in Section 3.

\subsection{The Balance of Payments and Consolidated Budget Constraint}

Consider the accounting identity that links the change in foreign asset and liability holdings to the balance of the payments. Let $A_{j, t}$ and $L_{i, t}$ denote domestic agents' holdings of foreign asset $j$ and liability $i$ at the end of period $t$, respectively. Changes in the aggregate asset and liability holdings during period $t$ are related to the balance of payments accounts by

$$
\sum_{j} P_{j, t}^{\mathrm{A}} \Delta A_{j, t}-\sum_{i} P_{i, t}^{\mathrm{L}} \Delta L_{i, t}=C A_{t}+K A_{t}+E O_{t}
$$

where $\Delta$ is the first-difference operator (i.e., $\Delta Z_{t}=Z_{t}-Z_{t}$ ), and the relative prices of asset $j$ and liability $i$, measured relative to the domestic price level, are $P_{j, t}^{\mathrm{A}}$ and $P_{i, t}^{\mathrm{L}}$, respectively. The term 
on the left-hand-side identifies the period $-t$ net real capital flow. This flow is equal to the current account balance, $C A_{t}$, plus capital account transfers, $K A_{t}$, and the errors and omissions term, $E O_{t}$, from the balance of payments at the end of period $t$, all measured in real terms. The right-hand-side of (1) may be further decomposed by writing the current account in terms of its main components:

$$
C A_{t}=\mathfrak{X}_{t}-\mathfrak{M}_{\mathfrak{t}}+U T_{t}^{\mathrm{A}}-U T_{t}^{\mathrm{L}}+I Y_{t}^{\mathrm{A}}-I Y_{t}^{\mathrm{L}},
$$

where $\mathfrak{X}_{\mathfrak{t}}-\mathfrak{M}_{t}$ denotes the difference between the real flows of exports $\mathfrak{X}_{t}$ and imports $\mathfrak{M}_{t}$ (i.e. real net exports) during period $t ; U T_{t}^{\mathrm{A}}$ and $U T_{t}^{\mathrm{L}}$ denote the real value of unilateral transfers (including compensation of employees) that add to asset and liability holdings; while $I Y_{t}^{\mathrm{A}}$ and $I Y_{t}^{\mathrm{L}}$ identify the real investment income from assets and liabilities held at the end of period $t-1$.

We can derive an equation for the evolution of the country's external position from (1) and (2) in three steps. First, let $F A_{t}=\sum_{j} P_{j, t}^{\mathrm{A}} A_{j, t}$ and $F L_{t}=\sum_{i} P_{i, t}^{\mathrm{L}} L_{i, t}$ define the real value of foreign asset and liability holdings at the end of period $t$. Changes in the value of these holdings are given by

$$
\begin{aligned}
& \Delta F A_{t}=\sum_{j} P_{j, t}^{\mathrm{A}} \Delta A_{j, t}+\sum_{j} \Delta P_{j, t}^{\mathrm{A}} A_{j, t-1}=\sum_{j} P_{j, t}^{\mathrm{A}} \Delta A_{j, t}+F A_{t-1} \sum_{j} \alpha_{j, t-1}^{\mathrm{A}} \kappa_{j, t}^{\mathrm{A}}, \\
& \Delta F L_{t}=\sum_{i} P_{i, t}^{\mathrm{L}} \Delta L_{i, t}+\sum_{i} \Delta P_{i, t}^{\mathrm{L}} L_{i, t-1}=\sum_{i} P_{i, t}^{\mathrm{L}} \Delta L_{i, t}+F L_{t-1} \sum_{i} \alpha_{i, t-1}^{\mathrm{L}} \kappa_{i, t}^{\mathrm{L}},
\end{aligned}
$$

where $\alpha_{j, t}^{\mathrm{A}}=P_{j, t}^{\mathrm{A}} A_{j, t} / F A_{t}$ and $\alpha_{i, t}^{\mathrm{L}}=P_{i, t}^{\mathrm{L}} L_{i, t} / F A_{t}$ are the shares of assets $j$ and liabilities $i$ in the portfolios of assets and liabilities, with $\sum_{j} \alpha_{j, t}=1$ and $\sum_{i} \alpha_{i, t}=1$. $\kappa_{j, t}^{\mathrm{A}}$ and $\kappa_{i, t}^{\mathrm{L}}$ are the period $-t$ real capital grain on asset $j$ and loss on liability $i$, equal to $\Delta P_{j, t}^{\mathrm{A}} / P_{j, t-1}^{\mathrm{A}}$ and $\Delta P_{j, t}^{\mathrm{L}} / P_{j, t-1}^{\mathrm{L}}$, respectively. Thus the change in real value of assets comprises the gross capital flow, $\sum_{j} P_{j, t}^{\mathrm{A}} \Delta A_{j, t}$, and $F A_{t-1}$ times the weighted average of capital gains on individual assets, $\sum_{j} \alpha_{j, t-1} \kappa_{j, t}^{\mathrm{A}}$. The gross flow in liabilities, $\sum_{i} P_{i, t}^{\mathrm{L}} \Delta L_{i, t}$ and $F L_{t-1}$ times the weighted average of capital losses on individual liabilities, $\sum_{i} \alpha_{i, t-1} \kappa_{i, t}^{\mathrm{L}}$, similarly determine the change in the real value of foreign liabilities.

Next, we link the investment income, transfers and capital adjustments to assets and liabilities in the form of "dividends". In particular, the dividend rates, $D_{j, t}$ and $D_{i, t}$ for asset $j$ and liability $i$ identify the portion of these flows accruing to the holders of existing asset and liabilities such that

$$
\begin{aligned}
& I Y_{t}^{\mathrm{A}}+U T_{t}^{\mathrm{A}}+K A_{t}^{\mathrm{A}}=\sum_{j} D_{j, t}^{\mathrm{A}} A_{j, t-1}=F A_{t-1} \sum_{j} \alpha_{j, t-1} \lambda_{j, t}^{\mathrm{A}}, \quad \text { and } \\
& I Y_{t}^{\mathrm{L}}+U T_{t}^{\mathrm{L}}+K A_{t}^{\mathrm{L}}=\sum_{i} D_{i, t}^{\mathrm{L}} L_{i, t-1}=F L_{t-1} \sum_{j} \alpha_{j, t-1} \lambda_{j, t}^{\mathrm{L}},
\end{aligned}
$$

with $\lambda_{j, t}^{\mathrm{A}}=D_{j, t}^{\mathrm{A}} / P_{j, t-1}^{\mathrm{A}}$ and $\lambda_{i, t}^{\mathrm{L}}=D_{i, t}^{\mathrm{L}} / P_{i, t-1}^{\mathrm{L}}$. Here $K A_{t}^{\mathrm{A}}$ and $K A_{t}^{\mathrm{L}}$ denote the asset and liability transfers in the capital account: i.e., $K A_{t}=K A_{t}^{\mathrm{A}}-K A_{t}^{\mathrm{L}}$. 
In the absence of transfers and adjustments, $D_{j, t}$ and $D_{i, t}$ would be determined by the cash flow associated with each asset or liability. For example, in the case of a domestic coupon-paying bond liability, $D_{i, t}$ would be determined by the coupon rate. Similarly, if a long-term foreign bond is held as a foreign asset, $D_{j, t}$ would be determined by the bond's coupon rate and the prevailing spot exchange rate that translates coupon payments into domestic currency. Here the dividend rates are also determined by how transfers and adjustments are accrued to individual assets and liabilities.

The final step combines equations (1) - (4) to give

$$
\Delta F A_{t}-\Delta F L_{t}=\mathfrak{X}_{t}-\mathfrak{M}_{\mathrm{t}}+\sum_{j} \alpha_{j, t-1}^{\mathrm{A}}\left(\lambda_{j, t}^{\mathrm{A}}+\kappa_{j, t}^{\mathrm{A}}\right) F A_{t-1}-\sum_{i} \alpha_{i, t}^{\mathrm{L}}\left(\lambda_{i, t}^{\mathrm{L}}+\kappa_{i, t}^{\mathrm{L}}\right) F L_{t-1}+E O_{t}
$$

or, more compactly,

$$
F A_{t}-F L_{t}=\mathfrak{X}_{t}-\mathfrak{M}_{\mathfrak{t}}+R_{t}^{\mathrm{FA}} F A_{t-1}-R_{t}^{\mathrm{FL}} F L_{t-1}+E O_{t}
$$

This is the country's consolidated budget constraint. $R_{t}^{\mathrm{A}}$ and $R_{t}^{\mathrm{L}}$ denote the gross real returns on the portfolios of foreign assets and liabilities defined by

$$
\begin{array}{ll}
R_{t}^{\mathrm{FA}}=\sum_{j} \alpha_{j, t-1}^{\mathrm{A}} R_{j, t}^{\mathrm{FA}} \quad \text { with } \quad R_{j, t}^{\mathrm{A}}=\left(1+\lambda_{j, t}^{\mathrm{A}}+\kappa_{j, t}^{\mathrm{A}}\right)=\left(P_{j, t}^{\mathrm{A}}+D_{j, t}^{\mathrm{A}}\right) / P_{j, t-1}^{\mathrm{A}} \quad \text { and } \\
R_{t}^{\mathrm{FL}}=\sum_{i} \alpha_{i, t-1}^{\mathrm{L}} R_{i, t}^{\mathrm{FL}} \quad \text { with } \quad R_{i, t}^{\mathrm{L}}=\left(1+\lambda_{i, t}^{\mathrm{L}}+\kappa_{i, t}^{\mathrm{L}}\right)=\left(P_{i, t}^{\mathrm{L}}+D_{i, t}^{\mathrm{L}}\right) / P_{i, t-1}^{\mathrm{L}} .
\end{array}
$$

Equation (5) shows that the evolution of a country's foreign asset and liability position reflects four sets of factors. First, decisions concerning international trade in goods and services add to the value of net foreign assets, $N F A_{t}=F A_{t}-F L_{t}$, insofar as they alter net exports, $\mathfrak{X}_{\mathfrak{t}}-\mathfrak{M}_{t}$. Second, decisions concerning the composition of the asset and liabilities portfolios made in period $t-1$ (i.e., $\alpha_{j, t-1}^{\mathrm{A}}$ and $\left.\alpha_{i, t-1}^{\mathrm{L}}\right)$, affect $N F A_{t}$ via their impact on the returns on assets and liabilities realized in period $t$. Third, variations in the dividends and prices of assets (liabilities) expressed in local currency affect the returns on individual assets (liabilities) by changing dividend/price and capital gains components, $\lambda_{j, t}^{\mathrm{A}}$ and $\kappa_{j, t}^{\mathrm{A}}\left(\lambda_{i, t}^{\mathrm{L}}\right.$ and $\left.\kappa_{i, t}^{\mathrm{L}}\right)$. Finally, variations in exchange rates may affect $N F A_{t}$ via their impact on net exports, foreign-currency denominated dividends and securities prices.

\subsection{Trade Flows, Asset Pricing and Portfolio Choice}

The consolidated budget constraint in (5) combines the effects of trade flows, asset-pricing and portfolio choice into a single equation that governs the evolution of a country's external position. To appreciate the role of these factors, it proves informative to consider the link between a country's 
net foreign asset position and the history of its current account balances. For this purpose, I combine (2) with (4) to write

$$
C A_{t}+K A_{t}=\mathfrak{X}_{t}-\mathfrak{M}_{\mathfrak{t}}+\sum_{j} \alpha_{j, t-1}^{\mathrm{A}} \lambda_{j, t}^{\mathrm{A}} F A_{t-1}-\sum_{i} \alpha_{i, t-1} \lambda_{i, t}^{\mathrm{L}} F L_{t-1}
$$

Substituting this expression into (5) and simplifying the result with (6) produces

$$
N F A_{t}=\sum_{s=0}^{t} C A_{s}+\sum_{s=1}^{t}\left(\kappa_{s}^{\mathrm{A}}-\kappa_{s}^{\mathrm{L}}\right) F A_{s-1}+\sum_{s=1}^{t} \kappa_{s}^{\mathrm{L}} N F A_{s-1}+\sum_{s=0}^{t} \zeta_{s},
$$

where $\zeta_{t}=K A_{t}+E O_{t}, \kappa_{t}^{\mathrm{A}}=\sum_{j} \alpha_{j, t-1}^{\mathrm{A}} \kappa_{j, t}^{\mathrm{A}}$ and $\kappa_{t}^{\mathrm{L}}=\sum_{i} \alpha_{i, t-1}^{\mathrm{L}} \kappa_{i, t}^{\mathrm{L}}$.

Equation (7) shows that a country's current net foreign asset position reflects the history of past (real) current account balances, the cumulative effects of capital transfers, errors and omissions, and the effects of past real capital gains and losses via $\kappa_{t}^{\mathrm{A}}$ and $\kappa_{t}^{\mathrm{A}}$ (the weighted averages of the capital gains and losses on individual assets and liabilities, respectively). Notice that capital gains and losses will contribute little to the current external position in countries with a history of small net foreign asset positions and portfolio choices that make $\kappa_{s}^{\mathrm{A}}-\kappa_{s}^{\mathrm{L}}$ close to zero for $s \leq t$. If the cumulative effects of capital transfers, errors and omissions are also small (as is often the case), the current account can be rightly viewed as the dominant determinant of the external position in these countries.

For other countries, the capital gains terms appear to have made a significant historical contribution to the net foreign asset position. For example, in the U.S. case, $N F A_{t}$ has fallen much less than the cumulation of past current account balances implying that the capital gains on foreign assets have far outweighed the capital loss on foreign liabilities. As Figure 1 shows, these effects have been particular significant since the early 1980's. The figure plots the ratios of $N F A_{t}$ and $\sum_{s=0}^{t} C A_{s}$ relative to GDP between 1973:I and 2007:IV, so the vertical distance between the plots represents the cumulative contribution of net capital gains relative to GDP. These plots show the deterioration in the U.S. external position between 1980 and 2002 was significantly cushioned by the cumulative effects of capital gains, but since then the effects have become much larger. Indeed, all of the recent improvement in the U.S. external position is attributable to capital gain effects, accounting for as much as 41 per cent of GDP by the end of $2007 .^{1}$

While capital gains can be an historically important contributor to a country's external position, their presence does not imply that a country can run persistent current account deficits with im-

\footnotetext{
${ }^{1}$ This discussion ignores inaccuracies in the data, which are potentially quite important. For example, direct estimates of the capital gains terms, $\kappa_{s}^{\mathrm{A}}$ and $\kappa_{s}^{\mathrm{L}}$, are unable to reconcile all the difference between $N F A_{t}$ and $\sum_{s=0}^{t} C A_{s}$, see, e.g., Curcuru, Dvorak, and Warnock (2007), Lane and Milesi-Ferretti (2009), and Gohrband and Howell (2010). This backward-looking perspective on the net foreign asset position depends on how returns are split between capital gains and yields. Below I take a forward-looking perspective on the determination of the net foreign asset position that depends on expected future returns. Also, in a similar vein, Hausmann et al. (2006) argue that the positive income balance on U.S. net asset holdings is indicative of mis-measurement in the U.S. net asset position.
} 
Figure 1: Alternative Measures of the U.S. External Position

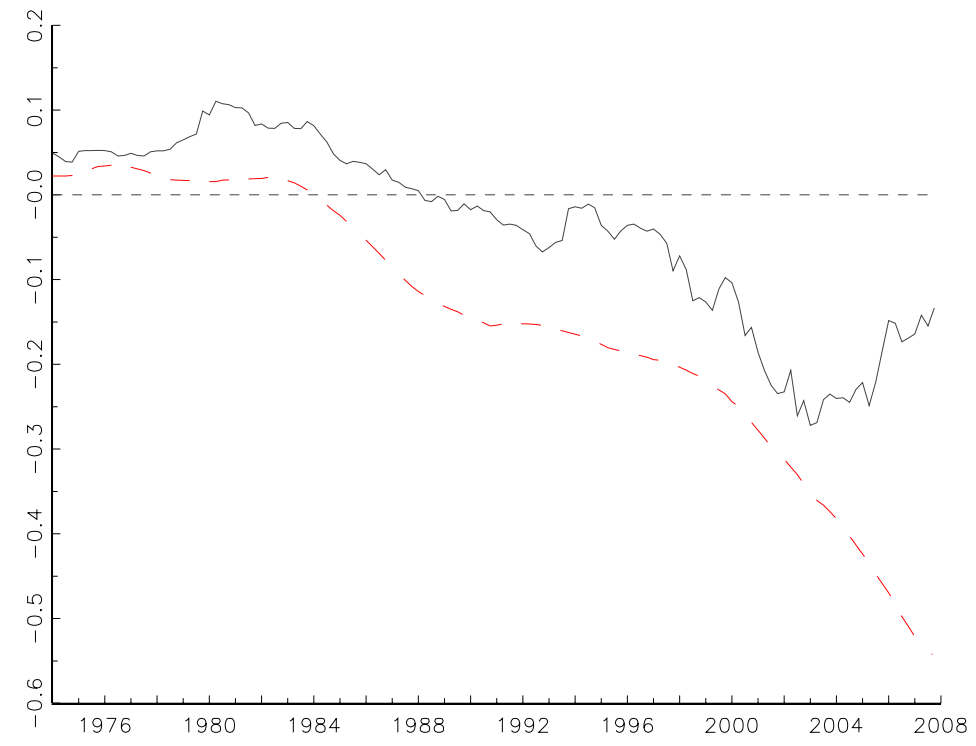

$N F A_{t} / G D P_{t}$ - solid black, $\sum_{s=0} C A_{s} / G D P_{t}$ - dashed red.

punity. Ultimately, the requirements of international solvency place limits on the contributions capital gains and trade flows can make to the evolution of a country's external position. To identify these limits, I re-arranging equation (5) and iterate forward to give

$$
N F A_{t}=-\sum_{i=1}^{\infty} \mathfrak{D}_{t+i}^{-1}\left[\mathfrak{X}_{t+i}-\mathfrak{M}_{\mathfrak{t}+\mathfrak{i}}+\left(R_{t+i}^{\mathrm{FA}}-R_{t+i}^{\mathrm{FL}}\right) F A_{t+i-1}\right]-\lim _{i \rightarrow \infty} \mathfrak{D}_{t+i}^{-1}\left(F L_{t+i}-F A_{t+i}\right),
$$

where $\mathfrak{D}_{t+i}=\prod_{j=1}^{i} R_{t+j}^{\mathrm{FL}}$ is the discount rate.

The first term on the right-hand-side of (8) is the present value of net exports and the excess returns on foreign assets. The second term identifies the present value of the future international indebtedness as the horizon rises without limit. This term must be equal to zero when international investors are unwilling to engage in Ponzi-schemes. For example, if $\lim _{i \rightarrow \infty} \mathfrak{D}_{t+i}^{-1}\left(F L_{t+i}-F A_{t+i}\right)>$ 0 , current indebtedness exceeds the value of the resources available for domestic residents to pay off their international debt in the future so the country would have to borrow ever larger amounts to avoid defaulting. Clearly, foreign investors would never consent to such a Ponzi scheme because it amounts to providing domestic residents with free resources. Alternatively, if $\lim _{i \rightarrow \infty} \mathfrak{D}_{t+i}^{-1}\left(F L_{t+i}-\right.$ $\left.F A_{t+i}\right)<0$ domestic investors would be consenting to an analogous Ponzi-scheme.

Imposing the no-Ponzi condition and taking expectations conditional on period- $t$ information $\Omega_{t}$, that includes the value of $N F A_{t}$, (8) becomes

$$
N F A_{t}=-\mathbb{E}_{t} \sum_{i=1}^{\infty} \mathfrak{D}_{t+i}^{-1}\left[\mathfrak{X}_{t+i}-\mathfrak{M}_{\mathfrak{t}+\mathfrak{i}}+\left(R_{t+i}^{\mathrm{FA}}-R_{t+i}^{\mathrm{FL}}\right) F A_{t+i-1}\right] .
$$


Thus, in a world without international Ponzi-schemes, a country's current external position is limited by expectations about the future paths of exports, imports, and the returns of foreign assets and liabilities. More specifically, (9) implies that any fall in a country's net foreign asset position must be accompanied by expectations of higher future net exports, higher excess returns and/or a lower discount rates $\mathfrak{D}_{t+i}$.

Equations (7) and (9) provide complimentary perspectives on the evolution of a country's external position. (9) shows how the value of foreign assets and liabilities at a point in time embed expectations about future trade flows and returns. As these expectations change through time the corresponding changes in $N F A_{t}$ are apportioned between capital gains and loss and the net real capital flows recorded in the balance of payments accounts. Equation (7) simply cumulates the resulting accounting entries together with the gains and losses. For example, the rise in $N F A_{t}$ for the U.S. after 2004 shown in Figure 1 must have been accompanied by some combination of greater pessimism regarding future net exports, lower excess returns, and/or higher discount rates that accrued in the form of significant net capital gains on existing asset and liability positions.

Capital gains and losses also contribute to capital flows. Equation (3) implies that the change in the net foreign asset position can be written as

$$
\Delta N F A_{t}=F L W_{t}+\kappa_{t}^{\mathrm{A}} F A_{t-1}-\kappa_{t}^{\mathrm{L}} F L_{t-1},
$$

where $F L W_{t}=\sum_{j} P_{j, t}^{\mathrm{A}} \Delta A_{j, t}-\sum_{i} P_{i, t}^{\mathrm{L}} \Delta L_{i, t}$. Combing this expression with (9) produces the following equation for net capital flows during period $t$ :

$$
F L W_{t}=N F A_{t}-\left\{\left(1+\kappa_{t}^{\mathrm{A}}\right) F A_{t-1}-\left(1+\kappa_{t}^{\mathrm{L}}\right) F L_{t-1}\right\}
$$

Here capital flows are determined by the difference between the desired value for $N F A_{t}$ consistent with current expectations, and the net value of pre-existing foreign asset and liability positions (incorporating capital gains and losses).

As a matter of accounting, equation (1) implies that $F L W_{t}=C A_{t}+K A_{t}+E O_{t}$, so for most countries net capital flows simply mirror the current account balance (because $K A_{t}+E O_{t} \cong 0$ ). In contrast, (10) links capital flows to expected future trade flows, returns, and portfolio choices. To illustrate the usefulness of this perspective, suppose the economy is hit by a shock that leads to a downward revision in forecasts of future net exports, but has no effect on future returns. Under these circumstances, equation (9) implies that there must be a rise in $N F A_{t}$, but the effect on the net capital flow could be in either direction. If, for example, the shock produces no capital gains or losses on prior asset and liability holdings, $\kappa_{t}^{\mathrm{A}}=\kappa_{t}^{\mathrm{L}}=0$ so $F L W_{t}=\Delta N F A_{t}$ and the shock will induce a positive net capital flow. In this case, capital flows move in a manner consistent with intertemporal smoothing (i.e., the current account moves into surplus as agents anticipate future deficits). Alternatively, the shock may induce sizable gains and/or loss on existing asset 
and liability positions so that $\kappa_{t}^{\mathrm{A}} F A_{t-1}>\kappa_{t}^{\mathrm{L}} F L_{t-1}$. Under these circumstances the net capital flow could be negative, a result inconsistent with intertemporal smoothing.

Equation (10) also allows us to identify the effects of international portfolio allocations on capital flows. For example, suppose the economy is hit by a shock that raises the expected future excess return on a particular security, say the equity on firms in one sector of the economy. If foreign investors have access to the domestic equity market and are expected to hold some of these securities in the future, the expected future return on foreign liabilities $R_{t+i}^{\mathrm{FL}}$ will rise; and, ceteris paribus, so too will $N F A_{t}$. Once again, the effect on net capital flows depends on foreign investors existing positions and the response of current equity prices. If the news induces a fall in current equity prices (as one would expect), but foreign investors currently hold none of the equities, $\kappa_{t}^{\mathrm{L}} F L_{t-1}$ (and $\kappa_{t}^{\mathrm{A}} F A_{t-1}$ ) are zero so there are no offsetting capital gains or losses on foreign assets and liabilities. In this case the rise in $N F A_{t}$ produces a capital inflow. Alternatively, if foreign investors already hold large positions in the equities, the capital loss they suffer represents a gain to domestic agents because it lowers the value of existing foreign liabilities. In this case $\kappa_{t}^{\mathrm{L}} F L_{t-1}$ is negative, so there will only be a capital inflow if the rise in $N F A_{t}$ dominates (i.e., if $\Delta N F A_{t}+\kappa_{t}^{\mathrm{L}} F L_{t-1}>0$ ). Thus, the response of capital flows to news concerning future returns depends on expected future holdings, returns and realized capital gains/losses on existing holdings.

To summarize, equations (9) and (10) provide perspectives on the determination of a country's external position and net capital flows that emphasize the role of expectations and portfolio choices. These perspectives form the basis for the model of capital flows developed in the next section.

\section{A Model of Capital Flow Dynamics}

This section presents a model of international positions and capital flows that incorporates trade

flows, portfolio choice and the capital gains and losses on foreign assets and liability positions. The model is developed from a log-linear approximation of the country's consolidated budget constraint in equation (5) and a no-Ponzi condition. It produces present value expressions for the country's asset and liability positions, like equation (9), but without the nonlinearities involving future returns, net exports and foreign assets. I combine these expressions with forecasts from a VAR to model the dynamics of external positions and capital flows.

\subsection{Approximating the Consolidated Budget Constraint}

I approximate the country's consolidated budget constraint in equation (5) in several steps: First, notice that (5) can also be written as

$$
F A_{t}-F L_{t}=\mathfrak{X}_{t}^{*}-\mathfrak{M}_{t}^{*}-R_{t}^{\mathrm{FL}} F L_{t-1}+R_{t}^{\mathrm{FA}} F A_{t-1},
$$


with $\mathfrak{X}_{t}^{*}=\mathfrak{X}_{t}+\mathcal{T}_{t}$ and $\mathfrak{M}_{t}^{*}=\mathfrak{M}_{t}+\mathcal{T}_{t}$, where $\mathcal{T}_{t}$ denotes a common trend. ${ }^{2}$ Clearly, adding a common trend to exports and imports has no effect on the consolidated budget constraint because exports and imports only enter as net exports, $\mathfrak{X}_{t}-\mathfrak{M}_{t}$. It does, however, allow me to use ratios involving adjusted exports and imports, $\mathfrak{X}_{t}^{*}$ and $\mathfrak{M}_{t}^{*}$, as approximation points in the steps below. ${ }^{3}$

The next step is to rewrite (11) as

$$
f a_{t}=r_{t}^{\mathrm{FA}}+f a_{t-1}+\ln \left(1-\exp \left(m_{t}^{*}-r_{t}^{\mathrm{FA}}-f a_{t-1}\right)+\Re_{t}\right)
$$

where $\Re_{t}=\left(F L_{t}+\mathfrak{X}_{t}^{*}-R_{t}^{\mathrm{FL}} F L_{t-1}\right) / R_{t}^{\mathrm{FA}} F A_{t-1}$. Here lowercase letters denote natural logs of their uppercase counterparts, e.g., $f a_{t}=\ln F A_{t}$. I now take a first-order Taylor approximation to the last term term on the right-hand-side of (12) around the point where $\Re_{t}=0$ and $1-\left(\mathfrak{M}_{t}^{*} / R_{t}^{\mathrm{FA}} F A_{t-1}\right)=$ $\rho \in(0,1)$. This produces

$$
f a_{t}=r_{t}^{\mathrm{FA}}+f a_{t-1}-\frac{1-\rho}{\rho}\left(m_{t}^{*}-r_{t}^{\mathrm{FA}}-f a_{t-1}\right)+\frac{1}{\rho} \Re_{t}+k,
$$

where $k \equiv \ln (\rho)+\frac{1-\rho}{\rho} \ln (1-\rho)$.

In the second step I approximate the dynamics of foreign liabilities. For this purpose, I rewrite the definition of $\Re_{t}$ as

$$
\exp \left(f l_{t}-r_{t}^{\mathrm{FA}}-f a_{t-1}\right)=\left(1-\exp \left(x_{t}^{*}-r_{t}^{\mathrm{FA}}-f a_{t-1}\right)\right) \exp \left(r_{t}^{\mathrm{FL}}-r_{t}^{\mathrm{FA}}+f l_{t-1}-f a_{t-1}\right)+\Re_{t},
$$

and take logs:

$$
f l_{t}-r_{t}^{\mathrm{FA}}-f a_{t-1}=\ln \left\{\left(1-\exp \left(x_{t}-r_{t}^{\mathrm{FA}}-f a_{t-1}\right)\right) \exp \left(r_{t}^{\mathrm{FL}}-r_{t}^{\mathrm{FA}}+f l_{t-1}-f a_{t-1}\right)+\Re_{t}\right\} .
$$

I then take another first-order Taylor approximation to the term on the right-hand-side around the point where $1-\left(\mathfrak{X}_{t}^{*} / R_{t}^{\mathrm{FL}} F L_{t-1}\right)=\rho, \Re_{t}=0$ and $R_{t}^{\mathrm{FA}} F A_{t-1} / R_{t}^{\mathrm{FL}} F L_{t-1}=1$. After some simplification, this produces

$$
f l_{t}=r_{t}^{\mathrm{FL}}+f l_{t-1}-\frac{1-\rho}{\rho}\left(x_{t}^{*}-r_{t}^{\mathrm{FL}}-f l_{t-1}\right)+\frac{1}{\rho} \Re_{t}+k .
$$

In the final step I combine (13) and (14) to eliminate $\Re_{t}$. For this purpose, it is useful to introduce two new variables: $n f a_{t}=f a_{t}-f l_{t}$, and $r_{t}^{\mathrm{NFA}}=r_{t}^{\mathrm{FA}}-r_{t}^{\mathrm{FL}}$. Recall that $F A_{t}$ and $F L_{t}$ denote the real value of foreign assets and liabilities at the the end of period $t$, while $R_{t}^{\mathrm{FA}}$ and $R_{t}^{\mathrm{FL}}$ are the returns on the asset and liability portfolios between the start of periods $t-1$ and $t$. Thus, $n f a_{t}$ denotes the $\log$ ratio of foreign assets to liabilities at the at the end of period $t$, and $r_{t}^{\mathrm{NFA}}$ denotes the $\log$ excess return on assets over liabilities between start of periods $t-1$ and $t$. Combining (13) and (14)

\footnotetext{
${ }^{2}$ I will ignore the "errors and omissions" term $E O_{t}$ for the sake of clarity. Non-zero values for $E O_{t}$ in actual data will contribute to the approximation error, see Figure 3 below.

${ }^{3}$ Hereafter I drop the term "adjusted" when it is clear that I'm referring to $\mathfrak{X}_{t}^{*}$ and $\mathfrak{M}_{t}^{*}$ rather than $\mathfrak{X}_{t}$ and $\mathfrak{M}_{t}$.
} 
to eliminate $\Re_{t}$ produces

$$
n f a_{t}=\frac{1}{\rho}\left(r_{t}^{\mathrm{NFA}}+n f a_{t-1}\right)+\frac{1-\rho}{\rho}\left(x_{t}^{*}-m_{t}^{*}\right) .
$$

Equation (15) approximates the joint dynamics of foreign assets, liabilities, returns and adjusted exports and imports consistent with the consolidated budget constraint in (11) around the point where $\mathfrak{M}_{t}^{*} / R_{t}^{\mathrm{FA}} F A_{t-1}=\mathfrak{X}_{t}^{*} / R_{t}^{\mathrm{FL}} F L_{t-1}=1-\rho, \Re_{t}=0$ and $R_{t}^{\mathrm{FA}} F A_{t-1}=R_{t}^{\mathrm{FL}} F L_{t-1}$. It is easy to check that this point is where the country is in externally balanced position with net exports equal to zero and the value of foreign assets is equal to the value of foreign liabilities.

Equation (15) differs in an important way from the approximation derived by Gourinchas and Rey (2007b). They start from the consolidated budget constraint in (5) but assume that asset and liability holdings, returns, exports and imports all comprise cyclical and trend components. They then derive an approximation to the dynamics in (5) around a deterministic trend path where solvency is satisfied. More specifically, let $\epsilon_{t}^{\mathrm{A}}, \epsilon_{t}^{\mathrm{L}}, \epsilon_{t}^{\mathrm{X}}$ and $\epsilon_{t}^{\mathrm{M}}$ denote the log deviations of assets, liabilities, exports and imports from trend, respectively. Gourinchas and Rey's approximation can be written as

$$
n f a_{t}^{\mathrm{C}}=\frac{1}{\phi}\left(n f a_{t-1}^{\mathrm{C}}+r_{t-1}^{\mathrm{C}}\right)+\frac{1-\phi}{\phi} n x_{t}^{\mathrm{C}},
$$

with $\phi \in(0,1)$, where $n x_{t}^{\mathrm{C}}=\mu^{\mathrm{x}} \epsilon_{t}^{\mathrm{X}}-\mu^{\mathrm{M}} \epsilon_{t}^{\mathrm{M}}$ and $n f a_{t}^{\mathrm{C}}=\mu^{\mathrm{A}} \epsilon_{t-1}^{\mathrm{A}}-\mu^{\mathrm{L}} \epsilon_{t-1}^{\mathrm{L}}$ for positive constants $\mu^{i}$. Here $r_{t+1}^{\mathrm{C}}$ is proportional to the log deviation of returns on net foreign assets; it increases with the return on foreign assets and decreases with the return on foreign liabilities.

Clearly, approximation in (16) has a similar form to (15), but it applies to the cyclical components of exports, imports and the foreign asset and liability positions rather than the trade flows and positions themselves. This distinction is of little importance when the trends in the trade flows and positions are small, but if the variations are large and persistent, de-trending may remove much of the variation in the data. In such cases, focusing on (estimates of) the cyclical components can only provide an incomplete picture of the factors affecting a country's external position and capital flows. In contrast, (15) can be used to analyze the complete external position and capital flows for any country once we add a common trend to exports and imports. As we shall see, these adjustments are straightforward in the U.S. case.

\subsection{Net Positions and Capital Flows}

I now combine the approximation in (15) with a no-Ponzi condition to derive equations for a country's net external position and capital flows. For this purpose, it proves useful to define some new variables. Let $f a_{t \mid t-1}=r_{t}^{\mathrm{FA}}+f a_{t-1}$ and $f l_{t \mid t-1}=r_{t}^{\mathrm{FL}}+f l_{t-1}$ denote the value of asset and liabilities at the beginning of period $t .{ }^{4}$ Further, let $n x_{t}^{*}=x_{t}^{*}-m_{t}^{*}$ and $x p_{t}=f a_{t \mid t-1}-f l_{t \mid t-1}+n x_{t}^{*}$

\footnotetext{
${ }^{4}$ I use the $t \mid t-1$ subscript to indicate that these are positions chosen in period $t-1$ valued at period $-t$ prices.
} 
so that (15) can be rewritten as

$$
x p_{t}=r_{t}^{\mathrm{NFA}}+\Delta n x_{t}^{*}+\frac{1}{\rho} x p_{t-1}
$$

I use $x p_{t}$ as my measure of a country's current net external position. It combines the log ratio of U.S. assets to liabilities at the beginning of period $t$, with ratio of exports to imports during the period. The external position deteriorates when there is a fall in the log ratio of exports to imports, or a fall in the value of foreign assets relative to liabilities, or some combination of the two. Hereafter, I will refer to $n x_{t}^{*}$ as simply "net exports".

I now use (17) to derive a simple present value equation for the external position. First, I rewrite the equation as

$$
x p_{t}=-\rho r_{t+1}^{\mathrm{NFA}}-\rho \Delta n x_{t+1}+\rho x p_{t+1} .
$$

Recall that the linearization parameter, $\rho$, takes a value between zero and one. Next, I iterate forward and take expectations conditioned on agents' period- $t$ information, which includes the value of $x p_{t}$. This produces

$$
x p_{t}=-\sum_{i=1}^{\infty} \rho^{i} \mathbb{E}_{t}\left[r_{t+i}^{\mathrm{NFA}}+\Delta n x_{t+i}^{*}\right]+\lim _{i \rightarrow \infty} \mathbb{E}_{t} \rho^{i} x p_{t+i}
$$

where $\mathbb{E}_{t}$ denotes expectations conditioned on agents' period- $t$ information. Notice that $\lim _{i \rightarrow \infty} \mathbb{E}_{t} \rho^{i} x p_{t+i}<0$ if the country is expected to simply issue more liabilities in the future to avoid defaulting on its existing international obligations. Similarly, $\lim _{i \rightarrow \infty} \mathbb{E}_{t} \rho^{i} x p_{t+i}>0$ when the country's trading partners are expected to run an analogous Ponzi scheme. I impose the no-Ponzi condition $\lim _{i \rightarrow \infty} \mathbb{E}_{t} \rho^{i} x p_{t+i}=0$ to obtain

$$
x p_{t}=x p_{t}^{\mathrm{TR}}+x p_{t}^{\mathrm{VAL}}
$$

with $\quad x p_{t}^{\mathrm{TR}}=-\mathbb{E}_{t} \sum_{i=1}^{\infty} \rho^{i} \mathbb{E}_{t} \Delta n x_{t+i}^{*} \quad$ and $\quad x p_{t}^{\mathrm{VAL}}=-\mathbb{E}_{t} \sum_{i=1}^{\infty} \rho^{i} r_{t+i}^{\mathrm{NFA}}$.

Equation (18) relates a country's current external position to expectations concerning the future returns on foreign assets, foreign liabilities and the future growth in net exports. Importantly it embeds the central feature of the forward-looking equation for $N F A_{t}$ in (9) without the nonlinearities involving returns, discount rates and future foreign asset holdings. I will refer to $x p_{t}^{\mathrm{TR}}$ and $x p_{t}^{\mathrm{VAL}}$ as the trade and valuation components of the external position.

By definition, the net capital flow during period $t$ is equal to the difference between the net value of foreign asset holdings at the end of period $t$ and their net value at the start of the period: $F L W_{t}=\sum_{j} P_{j, t}^{\mathrm{A}} \Delta A_{j, t}-\sum_{i} P_{i, t}^{\mathrm{L}} \Delta L_{i, t}$. To identify the capital flows consistent with (18), I work with an analogous definition based on log ratios. Specifically, I define the gross log asset (liability) flow during period $t$ as the $\log$ ratio of the end-of-period value of asset (liability) holdings to the 
value of beginning-of-period holdings:

$$
f l w_{t}^{\mathrm{FA}}=f a_{t}-f a_{t \mid t-1} \quad \text { and } \quad f l w_{t}^{\mathrm{FL}}=f l_{t}-f l_{t \mid t-1} .
$$

Notice that positive values for $f l w_{t}^{\mathrm{FA}}$ and $f l w_{t}^{\mathrm{FL}}$ indicate the accumulation of assets and liabilities, respectively. Further, I identify the period $-t$ net log capital flow as the growth differential between foreign assets and liabilities, $f l w_{t}=f l w_{t}^{\mathrm{FA}}-f l w_{t}^{\mathrm{FL}}$. Combining this definition with (15) produces

$$
f l w_{t}=\frac{1-\rho}{\rho}\left(r_{t}^{\mathrm{NFA}}+n f a_{t-1}\right)+\frac{1-\rho}{\rho} n x_{t}^{*}=\frac{1-\rho}{\rho} x p_{t} .
$$

So substituting for $x p_{t}$ from (18) gives

$$
f l w_{t}=-(1-\rho) \sum_{i=1}^{\infty} \rho^{i-1} \mathbb{E}_{t}\left[r_{t+i}^{\mathrm{NFA}}+\Delta n x_{t+i}^{*}\right] .
$$

Equation (19) identifies the period - $t$ net capital flow necessary to keep the value of foreign assets and liabilities at the levels consistent with international solvency. For intuition, suppose that a country enjoys a positive external position because net exports are expected to fall in the future $\mathbb{E}_{t} \Delta n x_{t+i}^{*}<0$ (see equation 18). Under these circumstances, flw $w_{t}$ must also be positive because the country needs to accumulate foreign assets more quickly than foreign liabilities in anticipation of the time when they must be sold to finance future trade deficits. Alternatively, if $x p_{t}>0$ because

expected future return on foreign assets are less than those on liabilities (i.e., $\mathbb{E}_{t} r_{t+i}^{\mathrm{NFA}}<0$ ), the country needs to accumulate foreign assets more quickly in anticipation of lower asset and higher liability prices that would otherwise erode the relative value of its future asset and liability positions to the point of insolvency.

\subsection{Gross Positions and Capital Flows}

Equation (15) can also be used to derive expressions for the value of gross foreign asset and liability positions and their associated capital flows. First, I use the definition in (6a) to write the return on foreign assets as $R_{t}^{\mathrm{FA}}=\left(F A_{t}+Y_{t}^{\mathrm{FA}}\right) / F A_{t-1}$, where $Y_{t}^{\mathrm{FA}}=\sum_{j}\left(A_{j t-1} D_{j t}^{\mathrm{A}}-P_{j} \Delta A_{j, t}\right)$. Recall that $D_{j t}^{\mathrm{A}}$ is the dividend rate for asset $j$, so $A_{j t-1} D_{j t}^{\mathrm{A}}-P_{j} \Delta A_{j, t}$ identifies the difference between the dividend stream and the cost of acquiring a larger position in asset $j$. $Y_{t}^{\mathrm{FA}}$ therefore represents the net income from all foreign assets during period $t$. To relate net income to the log return on foreign assets, I take a first-order log approximation to the return around the point where $Y_{t}^{\mathrm{FA}}=\mathfrak{M}_{t}^{*}$. This produces

$$
r_{t}^{\mathrm{FA}}=\rho f a_{t}-f a_{t-1}+(1-\rho) y_{t}^{\mathrm{FA}}-\rho k,
$$

where $k=\ln (\rho)+\frac{1-\rho}{\rho} \ln (1-\rho)$. 
Next, let $\delta_{t}^{\mathrm{FL}}=f l_{t \mid t-1}-x_{t}^{*}$ denote the log ratio of the value of foreign liabilities at the start of period $t$ to exports during period $t$. Combining this definition with (15) and (20) produces

$$
\delta_{t}^{\mathrm{FL}}=\rho \delta_{t+1}^{\mathrm{FL}}+\rho\left(\Delta x_{t+1}^{*}-r_{t+1}^{\mathrm{FL}}\right)+(1-\rho)\left(y_{t}^{\mathrm{FA}}-m_{t}^{*}\right)-\rho k .
$$

Ultimately, in the absence of Ponzi schemes, there must be an upper limit on the value of a country's foreign liabilities relative to its exports, so $\lim _{i \rightarrow \infty} \mathbb{E}_{t} \rho^{i} \delta_{t+1+i}^{\mathrm{FL}}=0$. Iterating forward and applying this no-Ponzi condition gives

$$
\delta_{t}^{\mathrm{FL}}=\mathbb{E}_{t} \sum_{i=1}^{\infty} \rho^{i}\left[\Delta x_{t+i}^{*}-r_{t+i}^{\mathrm{FL}}\right]+(1-\rho) \mathbb{E}_{t} \sum_{i=0}^{\infty} \rho^{i}\left(y_{t+i}^{\mathrm{FA}}-m_{t+i}^{*}\right)-\frac{\rho k}{1-\rho}
$$

Equation (21) shows how the country's consolidated budget constraint relates the value of foreign liabilities at the start of period $t$ to current exports, expectations of future export growth, liability returns, and the net asset income to import ratio, $y_{t+i}^{\mathrm{FA}}-m_{t+i}^{*}$. For intuition, its useful to think of exports as a dividend payments made to the holders of the country's foreign liabilities. Under this interpretation, the left-hand-side of (21) is simply the log price-to-dividend ratio for foreign liabilities. As in standard asset-pricing, this ratio depends positively on expected future dividend growth and negatively on expected future returns, as shown by the first term on the right-hand-side (see, e.g., Campbell and Shiller, 1987). The last term on the right-hand-side accounts of the effects of foreign asset accumulation. Specifically, if $\mathbb{E}_{t}\left(y_{t+i}^{\mathrm{FA}}-m_{t+i}^{*}\right)>0$, expected future asset income will be available to pay for imports and reduce foreign liabilities. Ceteris paribus, this improves the country's future external position, so the current value of foreign liabilities rises relative to exports consistent with the international solvency constraint in (18).

The gross asset position is identify analogously. Let $\delta_{t}^{\mathrm{FA}}=f a_{t \mid t-1}-m_{t}^{*}$ denote the log ratio of foreign assets to imports. By definition, $x p_{t}=\delta_{t}^{\mathrm{FA}}-\delta_{t}^{\mathrm{FAL}}$ so (18) and (21) imply that

$$
\delta_{t}^{\mathrm{FA}}=\mathbb{E}_{t} \sum_{i=1}^{\infty} \rho^{i}\left[\Delta m_{t+i}^{*}-r_{t+i}^{\mathrm{FA}}\right]+(1-\rho) \mathbb{E}_{t} \sum_{i=0}^{\infty} \rho^{i}\left[y_{t+i}^{\mathrm{FL}}-x_{t+i}^{*}\right]-\frac{\rho k}{1-\rho},
$$

where $y_{t}^{\mathrm{FL}}=y_{t}^{\mathrm{FA}}+x_{t}^{*}-m_{t}^{*}$ is the net income paid to foreign creditors. The intuition behind (22) is analogous to that of equation (21) except that imports now play the role of dividends for foreign assets.

Finally, I identify gross capital flows from the gross positions and net income flows. Specifically, combining (15) and (21) with the definitions of $f l w_{t}^{\mathrm{FA}}, f l w_{t}^{\mathrm{FL}}, \delta_{t}^{\mathrm{FA}}$ and $\delta_{t}^{\mathrm{FL}}$ produces

$$
\begin{aligned}
& f l w_{t}^{\mathrm{FA}}=\frac{1-\rho}{\rho}\left(\delta_{t}^{\mathrm{FA}}-\delta^{\mathrm{FA}}\right)+\frac{1-\rho}{\rho}\left(x_{t}^{*}-y_{t}^{\mathrm{FL}}\right), \\
& f l w_{t}^{\mathrm{FL}}=\frac{1-\rho}{\rho}\left(\delta_{t}^{\mathrm{FL}}-\delta^{\mathrm{FL}}\right)+\frac{1-\rho}{\rho}\left(m_{t}^{*}-y_{t}^{\mathrm{FA}}\right),
\end{aligned}
$$


where $\delta^{\mathrm{FL}}$ and $\delta^{\mathrm{FA}}$ are the steady state values of $\delta_{t}^{\mathrm{FL}}$ and $\delta_{t}^{\mathrm{FA}}$ (equal to $-\rho k /(1-\rho)$ ), respectively. These equations have the intuitive implication that a county accumulates a larger asset and liability position in response to an increase in the (desired) price-to-dividend ratios. Gross asset flows also reflect "excess export earnings" represented by $x_{t}^{*}-y_{t}^{\mathrm{FL}}$, while gross liability flows respond to "excess import costs" represented by $m_{t}^{*}-y_{t}^{\mathrm{FA}}$. Of course, these two expressions also imply that the dynamics of net flows $f l w_{t}=f l w_{t}^{\mathrm{FA}}-f l w_{t}^{\mathrm{FL}}$ are consistent with (19).

\subsection{Equilibrium Positions and Capital Flows}

The equations for the net and gross positions and capital flows derived above represent the implications of a country's consolidated budget constraint and no-Ponzi conditions. As such, they identify the proximate determinants of the external position and capital flows in the form of expectations concerning future trade flows and returns, rather than a full-blown model where these expectations are themselves determined as part of the equilibrium. In this paper I use a VAR to identify the expectations that are the proximate drivers of the external position and capital flows. This approach, inspired by the work of Campbell and Shiller (1987), avoids the complexity of developing a model that adequately represents the complex array of financial instruments used as foreign assets and liabilities by many countries. ${ }^{5}$

Let $\Omega_{t}$ denote a subset of agents information at $t$ that comprises the history of returns on assets and liabilities, export and import growth and the external positions available to the researcher: i.e. $\Omega_{t}=\left\{r_{t-i}^{\mathrm{FA}}, r_{t-i}^{\mathrm{FL}}, \Delta x_{t-i}^{*}, \Delta m_{t-i}^{*}, \delta_{t-i}^{\mathrm{FA}}, \delta_{t-i}^{\mathrm{FL}}\right\}_{i \geq 0}$. By the law of iterated expectations, $\mathbb{E}\left[\mathbb{E}_{t} \Delta n x_{t+i}^{*} \mid \Omega_{t}\right]=$ $\mathbb{E}\left[\Delta n x_{t+i}^{*} \mid \Omega_{t}\right]$ and $\mathbb{E}\left[\mathbb{E}_{t} r_{t+i}^{\mathrm{NFA}} \mid \Omega_{t}\right]=\mathbb{E}\left[r_{t+i}^{\mathrm{NFA}} \mid \Omega_{t}\right]$ for all $i>0$. Thus, taking expectations conditional on $\Omega_{t}$ on both sides of (18) produces

$$
\mathbb{E}\left[x p_{t} \mid \Omega_{t}\right]=-\sum_{i=1}^{\infty} \rho^{i} \mathbb{E}\left[r_{t+i}^{\mathrm{NFA}}+\Delta n x_{t+i}^{*} \mid \Omega_{t}\right]
$$

Since $x p_{t}=\delta_{t}^{\mathrm{FA}}-\delta_{t}^{\mathrm{FL}} \in \Omega_{t}$, the expectation on the left-hand-side is simply equal to $x p_{t}$, so the expression above becomes

$$
x p_{t}=-\sum_{i=1}^{\infty} \rho^{i} \mathbb{E}\left[r_{t+i}^{\mathrm{NFA}}+\Delta n x_{t+i}^{*} \mid \Omega_{t}\right] .
$$

Unlike (18), this equation relates the external position to forecasts for future returns and net export growth that are conditioned on a subset of agents' information, $\Omega_{t}$. It may seem strange that any additional information available to agents at the time has no effect on $x p_{t}$. Surely they have

\footnotetext{
${ }^{5}$ Recall that $r_{t}^{\mathrm{FA}}$ and $r_{t}^{\mathrm{FL}}$ are the $\log$ returns on portfolio of foreign assets and liabilities, so a full-blown DSGE model would need to identify the portfolio choices embedded in these returns. While recent papers by Evans and Hnatkovska (2005 \& 2007), Hnatkovska (2010), Tille and Wincoop (2010), Devereux and Sutherland (2010) and others begin the development of such DSGE models, they have not reached the point where they can be part of an estimable structural model for external positions and capital flows.
} 
information that is useful for forecasting future changes in returns that is not available to the researcher. However, $\Omega_{t}$ is not just any subset of agents' information. Because $\Omega_{t}$ contains the elements that comprise current and past values of $x p_{t}$ as well as the history of returns and the growth in net exports, it effectively contains all the information agents are using to calculate $\mathbb{E}_{t}\left[r_{t+i}^{\mathrm{NFA}}+\right.$ $\left.\Delta n x_{t+i}^{*}\right]$ for $i>0$. For example, if agents have information that leads them to forecast higher growth in net exports twenty quarters ahead than they would based on their observations of $\left\{\Delta n x_{t-i}^{*}\right.$, $\left.r_{t-i}^{\mathrm{NFA}}\right\}_{i \geq 0}$, this information will be reflected in a lower value for $x p_{t}$. Any information set containing $\left\{\delta_{t-i}^{\mathrm{FA}}, \delta_{t-i}^{\mathrm{FL}}, \Delta n x_{t-i}^{*}, r_{t-i}^{\mathrm{NFA}}\right\}_{i \geq 0}$ will therefore capture this extra information affecting $\mathbb{E}_{t}\left[r_{t+i}^{\mathrm{NFA}}+\Delta n x_{t+i}^{*}\right]$. In short, we are using equation (24) to construct a particular subset of agents' information for which the implications of the present value model for the external position remain valid.

Following Campbell and Shiller (1987), we can use (24) to derive restrictions on the joint dynamics of the external position, net exports, and the return differential. First, I compute $\mathbb{E}\left[r_{t+i}^{\mathrm{NFA}}+\Delta n x_{t+i}^{*} \mid \Omega_{t}\right]$ for $i>0$ from a VAR. Let the vector $z_{t}=\left[\begin{array}{llllll}r_{t}^{\mathrm{FA}} & r_{t}^{\mathrm{FL}} & \Delta x_{t}^{*} & \Delta m_{t}^{*} & \delta_{t}^{\mathrm{FA}} & \delta_{t}^{\mathrm{FL}}\end{array}\right]^{\prime}$ follow a $k^{\prime}$ th. order VAR:

$$
z_{t}=a_{1} z_{t-1}+a_{2} z_{t-2}+\ldots . a_{k} z_{t-k}+u_{t}
$$

where $a_{i}$ are matrices of coefficients from each of the VAR equations, and $u_{t}$ is a vector of mean-zero shocks. To compute $\mathbb{E}\left[r_{t+i}^{\mathrm{NFA}}+\Delta n x_{t+i} \mid \Omega_{t}^{*}\right]$, the VAR is written in companion form:

$$
\left[\begin{array}{c}
z_{t} \\
\vdots \\
\vdots \\
z_{t-k+1}
\end{array}\right]=\left[\begin{array}{cccc}
a_{1} & \cdots & \cdots & a_{k} \\
I & & & \\
& \ddots & & \\
& & I & 0
\end{array}\right]\left[\begin{array}{c}
z_{t-1} \\
\vdots \\
\vdots \\
z_{t-k}
\end{array}\right]+\left[\begin{array}{c}
u_{t} \\
0 \\
\vdots \\
0
\end{array}\right]
$$

or, more compactly,

$$
Z_{t}=A Z_{t-1}+U_{t}
$$

Multi-period forecasts are easily computed from (25) as $\mathbb{E}\left[Z_{t+i} \mid Z_{t}\right]=A^{i} Z_{t}$, where $A^{i}$ denotes $i$ multiplications of the $A$ matrix.

Next, consider the implications of equation (24) for the dynamics of $Z_{t}$. Let the vectors

$\imath_{r}=\left[\begin{array}{lllll}1 & -1 & 0 & \cdots & 0\end{array}\right], \quad \imath_{n x}=\left[\begin{array}{lllllll}0 & 0 & 1 & -1 & 0 & \cdots & 0\end{array}\right] \quad$ and $\quad \imath_{x p}=\left[\begin{array}{llll}0 & \cdots & 1 & -1\end{array}\right]$

select $r_{t}^{\mathrm{NFA}}, \Delta n x_{t}$ and $x p_{t}$ from $Z_{t}$. I can now compute the multi-period forecasts of net export growth and the return differential as $\mathbb{E}\left[r_{t+i}^{\mathrm{NFA}} \mid \Omega_{t}\right]=\imath_{r} A^{i} Z_{t}$ and $\mathbb{E}\left[\Delta n x_{t+i} \mid \Omega_{t}^{*}\right]=\imath_{n x} A^{i} Z_{t}$ for all $i>0$. Substituting these forecasts into $(24)$ produces $^{6}$

$$
\imath_{x p} Z_{t}=x p_{t}=-\left(\imath_{r}+\imath_{n x}\right) \sum_{i=1}^{\infty} \rho^{i} A^{i} Z_{t}=-\left(\imath_{r}+\imath_{n x}\right) \rho A(I-\rho A)^{-1} Z_{t} .
$$

\footnotetext{
${ }^{6}$ In deriving the equation I have implicitly assumed that the eigenvalues of $\rho A$ are less than one in absolute value. Since $1>\rho>0$, this condition is satisfied if $z_{t}$ follows a covariance stationary time series process.
} 
This equation must hold for all possible values of the $Z_{t}$ vector, so the companion matrix $A$ from the VAR must satisfy

$$
\imath_{x p}=-\left(\imath_{r}+\imath_{n x}\right) \rho A(I-\rho A)^{-1}
$$

Equation (26) contains a set of restrictions on the VAR coefficients in (25) that represent constraints on the joint dynamics of $r_{t}^{\mathrm{NFA}}, \Delta n x_{t}^{*}$, and $x p_{t}$. They can be empirically examined for particular values of $\rho$ by computing a nonlinear Wald test from estimates of the $A$ matrix computed from OLS estimates of the VAR equations. This is really a test of a joint null hypothesis. In addition to the present value relation in (24) we are also testing the assumption that forecasts of future returns and net export growth can be computed from the VAR as $\left(\imath_{r}+\imath_{n x}\right) A^{i} Z_{t}$. This is not an innocuous assumption. Even if the dynamics of $z_{t}$ can be represented by a $k^{\prime}$ th. order VAR, these forecasts only represent the best forecasts of $r_{t+i}^{\mathrm{NFA}}+\Delta n x_{t+i}^{*}$ that can be computed using linear combinations of the variables in $Z_{t}$. It is possible that forecasts based on both linear and nonlinear combination of the variables in $Z_{t}$ have a lower mean squared forecast error. If this is the case, $\mathbb{E}\left[r_{t+i}^{\mathrm{NFA}}+\Delta n x_{t+i}^{*} \mid \Omega_{t}\right] \neq\left(\imath_{r}+\imath_{n x}\right) A^{i} Z_{t}$ and the restrictions in (26) will not hold true even if the present value relation in $(24)$ is valid.

The VAR can also be used to study gross foreign asset and liability positions. In particular since $\delta_{t}^{\mathrm{FL}}$ is an element in $\Omega_{t}$, we can rewrite $(21)$ as

$$
\delta_{t}^{\mathrm{FL}}=\sum_{i=1}^{\infty} \rho^{i} \mathbb{E}\left[\Delta x_{t+i}^{*}-r_{t+i}^{\mathrm{FL}} \mid \Omega_{t}\right]+(1-\rho) \mathbb{E}_{t} \sum_{i=0}^{\infty} \rho^{i} E\left[y_{t+i}^{\mathrm{FA}}-m_{t+i}^{*} \mid \Omega_{t}\right]-\frac{\rho}{1-\rho} k
$$

Notice that the first term on the right-hand-side can be computed from the VAR, so we can examine the extent to which variations in the gross liability position reflect changes in exports and the present value of future export growth and returns. The one catch here is that agents' forecasts for $\Delta x_{t+i}^{*}-r_{t+i}^{\mathrm{FL}}$ may differ from $\mathbb{E}\left[\Delta x_{t+i}^{*}-r_{t+i}^{\mathrm{FL}} \mid \Omega_{t}\right]$ even though $\delta_{t}^{\mathrm{FL}} \in \Omega_{t}$. The reason is that $\delta_{t}^{\mathrm{FL}}$ may contain agents' private information concerning $y_{t+i}^{\mathrm{FA}}-m_{t+i}^{*}$ as well as $\Delta x_{t+i}^{*}-r_{t+i}^{\mathrm{FL}}$ so the history of $\delta_{t}^{\mathrm{FL}}$ is not necessarily sufficient for capturing all their private information in $\mathbb{E}_{t}\left[\Delta x_{t+i}^{*}-r_{t+i}^{\mathrm{FL}}\right]$. For this reason, I examine the robustness of the estimates for $\mathbb{E}\left[\Delta x_{t+i}^{*}-r_{t+i}^{\mathrm{FL}} \mid \Omega_{t}\right]$ to alternative VAR specifications.

Finally, recall that the period $-t$ net capital flow is related to the external position by $f l w_{t}=\frac{1-\rho}{\rho} x p_{t}$, so taking conditional expectations on both sides of (19) produces

$$
f l w_{t}=-(1-\rho) \sum_{i=1}^{\infty} \rho^{i-1} \mathbb{E}\left[r_{t+i}^{\mathrm{NFA}}+\Delta n x_{t+i}^{*} \mid \Omega_{t}\right] .
$$

This equation provides the basis for studying the drivers of net capital flows using the VAR estimates. The drivers of gross asset and liability flows can also be examined with the VAR using (23) with (27) and (28). 


\section{Data and Estimation}

I use the model to study the U.S. external position and capital flows in quarterly data between 1973:I and 2007:IV. I exclude data from 2008 onwards to avoid confounding the effects of the world financial crisis with normal conditions in world trade and financial markets. This section first describes the data and discusses how I estimate the common trend in exports and imports that is used in my approximation of the consolidated budget constraint. I then present summary statistics and the VAR estimates.

\subsection{Data}

I use an extended version of the data used by Gourinchas and Rey (2007b). They computed the market values for four categories of U.S. foreign asset and liabilities: equity, foreign direct investment (FDI), debt and other, by combining data on international positions with information on the capital gains and losses. I extend their data to 2007:IV following the detailed procedures described in Gourinchas and Rey (2005).

In brief, the positions of asset $j$ and liability $i$ are updated according to

$$
F A_{j, t}=F A_{j, t-1}+\text { Flow }_{j, t}+\text { Dis }_{j, t}, \quad \text { and } \quad F L_{i, t}=F L_{i, t-1}+F l o w_{i, t}+\text { Dis }_{i, t},
$$

where: $F A_{j, t}$ and $F L_{i, t}$ denote the positions at the end of period $t ; F l o w_{j, t}$ and $F l o w_{i, t}$ denote the period- $t$ flows that enter the balance of payments; while $D i s_{j, t}$ and $D i s_{i, t}$ are the discontinuities reflecting a market valuation adjustment between the end of periods $t-1$ and $t$. When data on the discontinuities is not directly available, they are computed from the capital gains on the individual securities that comprise the foreign asset or liability category. In the final quarter of each year $D i s_{j, t}$ and $D i s_{i, t}$ are adjusted so that $F A_{j, t}$ and $F L_{i, t}$ map into the International Investment Position (IIP) data reported by the Bureau of Economic Analysis (BEA). Below I use time series of the U.S. aggregate foreign asset and liability positions, $F A_{t}=\sum_{j} F A_{j, t}$ and $F L_{t}=\sum_{i} F L_{i, t}$, as well as the four categories of assets and liabilities.

The returns on the asset and liability categories, $R_{j, t}^{\mathrm{FA}}$ and $R_{i, t}^{\mathrm{FL}}$, are computed from the portfolio weighted average of the returns on the individual assets that comprise each category. The portfolio shares for the underlying securities come from U.S.Treasury reports on U.S. holdings of foreign securities and foreign portfolio holdings of U.S. securities. These shares are also used to compute the capital gains on foreign asset and liability categories when needed. The returns on the aggregate foreign asset and liability positions are calculated as $R_{t}^{\mathrm{A}}=\sum_{j} \alpha_{j, t-1}^{\mathrm{A}} R_{j, t}^{\mathrm{FA}}$ and $R_{t}^{\mathrm{L}}=\sum_{i} \alpha_{i, t-1}^{\mathrm{L}} R_{i, t}^{\mathrm{FL}}$ where $\alpha_{j, t}^{\mathrm{A}}=F A_{j, t} / F A_{t}$ and $\alpha_{i, t}^{\mathrm{L}}=F L_{i, t} / F L_{t}$. All positions and returns are computed in constant U.S. dollars. ${ }^{7}$

\footnotetext{
${ }^{7}$ It is worth emphasizing that this method for computing returns differs from the one used by early papers in the
} 
In addition to the time series on positions and returns, I use data on U.S. exports and imports (in constant U.S. dollars) from the BEA to construct the variables in the VAR. I also make use of five additional variables: The U.S. real interest rate, $r_{t}$ (computed as the difference between the 3-month T-bill rate and realized inflation); the growth in real U.S. GDP, $\Delta y_{t}$; the growth in the U.S. debt-to-GDP ratio, $\Delta d_{t}$; the spread between the real yield on 10 year-U.S. government bonds and 3-month T-bills, $\nabla r_{t}$; and the quarterly real depreciation rate for the dollar against a trade-weighted index of foreign currencies, $\Delta \varepsilon_{t}$, as computed by the Federal Reserve Board.

\subsection{Adjusting Trade Flows}

In U.S. data the upward trend in gross foreign asset and liability positions is considerably higher than the trend in real exports and imports. This can be clearly seen in panel A of Figure 2 which plots the logs of foreign assets, liabilities, exports and imports. Over this sample period assets and liabilities grow at an average annual rate of $9.2 \%$ while exports and imports grow at just $4.4 \%$. Clearly, equations (13) and (14) would provide poor approximations to the dynamics of U.S. assets and liabilities if were to use the log exports and imports, $x_{t}$ and $m_{t}$, rather than their counterparts adjusted with a common trend, i.e. $x_{t}^{*}=\ln \left(X_{t}+\mathcal{T}_{t}\right)$ and $m_{t}^{*}=\ln \left(M_{t}+\mathcal{T}_{t}\right)$.

I adjust exports and imports by estimating $\mathcal{T}_{t}$ as a deterministic time-trend. Specifically, I estimate $\tau_{0}$ and $\tau_{1}$ from

$$
f a_{t \mid t-1}=\ln \left(M_{t}+\exp \left\{\tau_{0}+\tau_{1} t\right\}\right)+e_{t}^{\mathrm{FA}} \quad \text { and } \quad f l_{t \mid t-1}=\ln \left(X_{t}+\exp \left\{\tau_{0}+\tau_{1} t\right\}\right)+e_{t}^{\mathrm{FL}},
$$

by nonlinear least squares. Adjusted exports and imports are then computed as the fitted values: i.e., $m_{t}^{*}=\ln \left(X_{t}+\exp \left\{\hat{\tau}_{0}+\hat{\tau}_{1} t\right\}\right)$ and $x_{t}^{*}=\ln \left(X_{t}+\exp \left\{\hat{\tau}_{0}+\hat{\tau}_{1} t\right\}\right)$, where $\hat{\tau}_{i}$ are the estimated coefficients. Panel B of Figure 2 shows the effects of these adjustments. The solid lines plot the $\log$ ratios of unadjusted exports and imports to liabilities and assets, $m_{t}-f a_{t \mid t-1}$ and $x_{t}-f l_{t \mid t-1}$, computed from the series in panel $\mathrm{A}$, while the dashed lines plot the adjusted ratios, $m_{t}^{*}-f a_{t \mid t-1}$ and $x_{t}^{*}-f l_{t \mid t-1}$. Clearly, adjusting exports and imports in this manner makes the U.S. data much more conformable to the assumptions I made in approximating the consolidated budget constraint.

Figure 3 shows how these adjustments to exports and imports allows the approximation for the consolidated budget constraint in (17) to accurately track the dynamics of the U.S. external position. Here I plot $x p_{t}$ and the difference between the actual and implied values for $x p_{t}$ from (17): $\xi_{t}=$ $x p_{t}-r_{t}^{\mathrm{NFA}}-\Delta n x_{t}^{*}-\frac{1}{\rho} x p_{t-1}$. This error contains the approximation errors from (13) and (14) and measurement errors in the underlying data. Figure 3 plots $\xi_{t}$ using a value for $\rho$ of 0.989 (discussed below). The visual evidence in the plots clearly shows that there is little difference between the actual and implied values for $x p_{t}$. More precisely, the sample variance of $\xi_{t}$ is only 0.3 per cent of

literature (e.g., Lane and Milesi-Ferretti, 2005; Gourinchas and Rey, 2007a and Meissner and Taylor, 2006) based on the IIP data. Curcuru, Dvorak, and Warnock (2007) and Lane and Milesi-Ferretti (2009) argue that inaccuracies in these data lead to upwardly biased estimates of returns. 


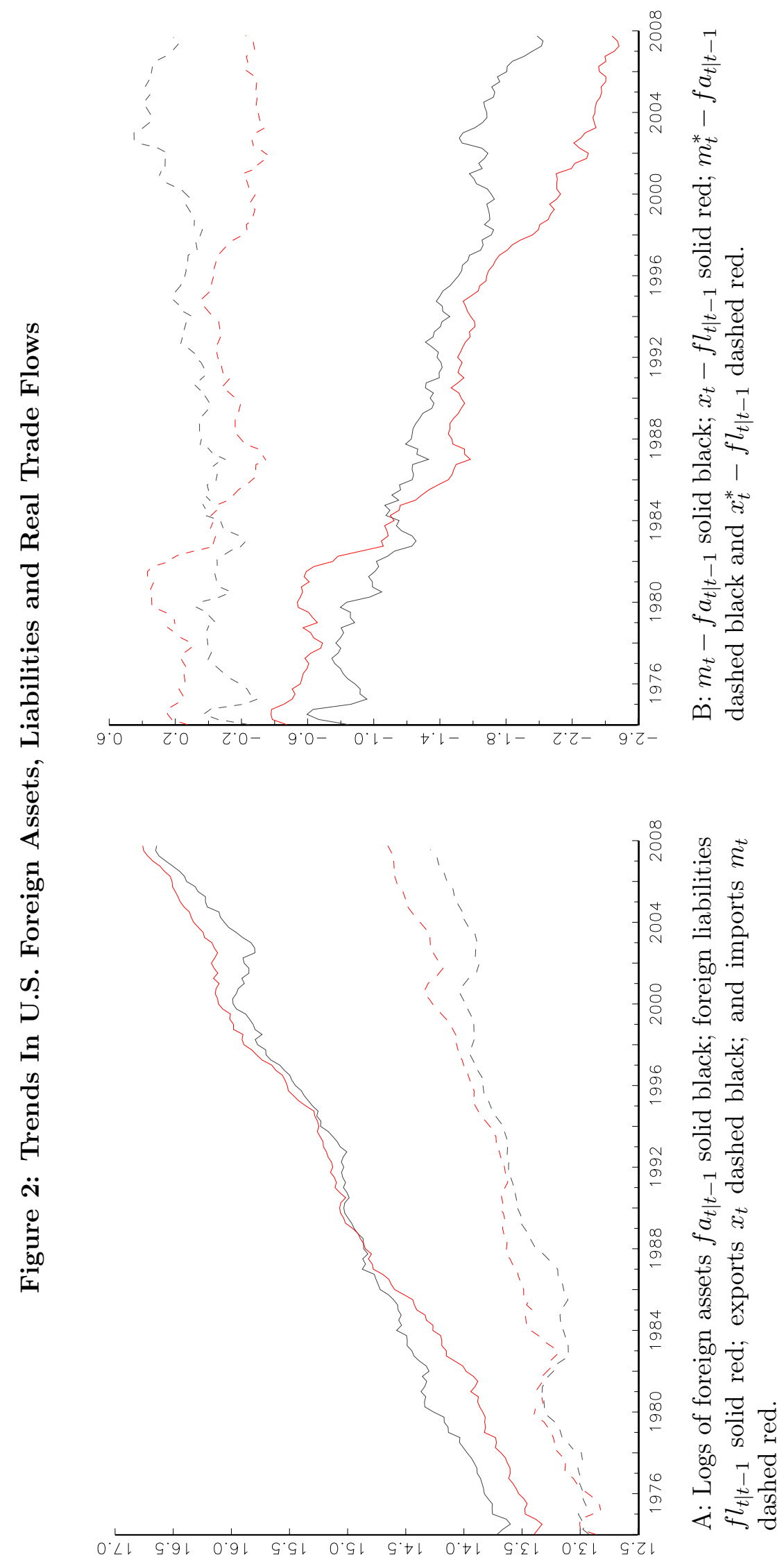


Figure 3: Approximation Accuracy

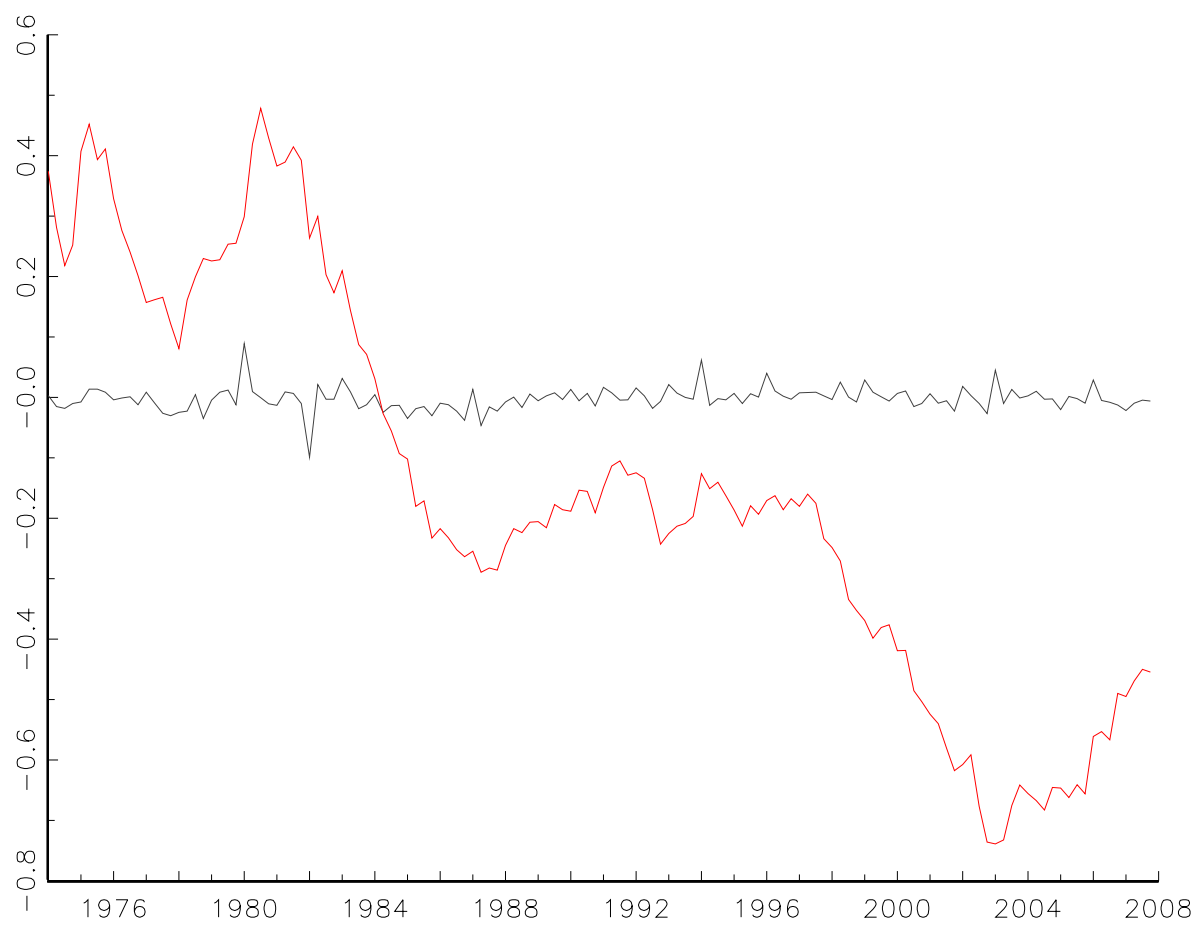

Key: U.S. External Position $x p_{t}$-red, and approximation error $\xi_{t}$-black.

the sample variance of the actual $x p_{t}$ series. By this metric, the approximate dynamics for the U.S. external position in (17) are highly accurate.

\subsection{Sample Statistics}

Table 1 presents summary statistics for the data used in my analysis. The sample runs for 1973:I to 2007:IV and all variables are computed at a quarterly frequency. The first six rows of the table report summary statistics for the variables included in the VAR. As one would expect, there is little serial correlation in the log real returns on assets and liabilities, $r_{t}^{\mathrm{FA}}$ and $r_{t}^{\mathrm{FL}}$, or in the growth or exports and imports, $\Delta x_{t}^{*}$ and $\Delta m_{t}^{*}$. In contrast, the sample autocorrelations for the log ratios of assets to imports and liabilities to exports, $\delta_{t}^{\mathrm{FA}}$ and $\delta_{t}^{\mathrm{FL}}$, decline quite slowly. Rows (vii) - (ix) report statistics for the three variables that appear in present value expression determining the U.S. external position (equation 18). Notice that the autocorrelations in my measure of the U.S. external position, $x p_{t}$, decline quite slowly, a finding consistent with the visual evidence in Figure 3. Nevertheless, I interpret these statistics to mean that $x p_{t}$ follows a covariance stationary process with a good deal of persistence. Both the return differential and the growth in net exports display little autocorrelation. The lower panel of Table 1 reports sample statistics for the ancillary variables I use to test robustness: the U.S. real interest rate, $r_{t}$; the growth in GDP, $\Delta y_{t}$; the real depreciation 
Table 1: Summary Statistics

\begin{tabular}{|c|c|c|c|c|c|c|c|}
\hline & \multirow[t]{2}{*}{ Variable } & \multirow[t]{2}{*}{ Mean } & \multirow{2}{*}{$\begin{array}{l}\text { Std. } \\
\text { Dev. }\end{array}$} & \multicolumn{4}{|c|}{ Autocorrelations at lags } \\
\hline & & & & 1 & 4 & 8 & 12 \\
\hline (i) & $r_{t}^{\mathrm{FA}}$ & 3.578 & 13.494 & 0.072 & 0.115 & 0.144 & -0.041 \\
\hline (ii) & $r_{t}^{\mathrm{FL}}$ & 3.259 & 11.101 & 0.155 & 0.135 & 0.122 & -0.011 \\
\hline (iii) & $\Delta x_{t}^{*}$ & 9.509 & 10.805 & 0.384 & 0.103 & -0.096 & -0.077 \\
\hline (iv) & $\Delta m_{t}^{*}$ & 10.423 & 13.230 & 0.355 & -0.192 & -0.042 & -0.049 \\
\hline$(\mathrm{v})$ & $\delta_{t}^{\mathrm{FA}}$ & -0.071 & 0.178 & 0.921 & 0.705 & 0.677 & 0.498 \\
\hline (vi) & $\delta_{t}^{\mathrm{FL}}$ & 0.071 & 0.201 & 0.979 & 0.867 & 0.718 & 0.561 \\
\hline (vii) & $x p_{t}$ & -0.142 & 0.333 & 0.980 & 0.906 & 0.801 & 0.655 \\
\hline (viii) & $r_{t}^{\mathrm{NFA}}$ & 0.318 & 8.485 & 0.205 & 0.115 & 0.115 & -0.139 \\
\hline (ix) & $\Delta n x_{t}^{*}$ & -0.913 & 12.942 & 0.170 & -0.018 & -0.020 & -0.005 \\
\hline$(\mathrm{x})$ & $r_{t}$ & 1.800 & 2.525 & 0.812 & 0.557 & 0.318 & 0.225 \\
\hline (xi) & $\Delta \varepsilon_{t}$ & -0.568 & 13.526 & 0.108 & 0.120 & -0.046 & -0.028 \\
\hline (xii) & $\Delta y_{t}$ & 0.007 & 0.008 & 0.287 & 0.047 & -0.209 & -0.253 \\
\hline (xiii) & $\Delta d_{t}$ & 0.004 & 0.011 & 0.885 & 0.540 & 0.210 & 0.175 \\
\hline (xiv) & $\nabla r_{t}$ & 0.396 & 0.329 & 0.872 & 0.430 & 0.020 & -0.320 \\
\hline
\end{tabular}

Notes: Rows (i) - (iv) report sample statistics for the log return on foreign assets, $r_{t}^{\mathrm{FA}}$; the $\log$ return on foreign liabilities, $r_{t}^{\mathrm{FL}}$; the growth in exports $\Delta x_{t}^{*}$, and the growth in imports $\Delta m_{t}^{*}$, all multiplied by 400 . Rows (v) and (vi) report statistics for the $\log$ ratios $\delta_{t}^{\mathrm{FA}}=f a_{t \mid t-1}-m_{t}^{*}$ and $\delta_{t}^{\mathrm{FL}}=f l_{t \mid t-1}-x_{t}^{*}$ where $f a_{t \mid t-1}$ and $f l_{t \mid t-1}$ are the log values of foreign asset and liability positions at the start of period $t$. The remaining rows of the table report statistics on: the net external position, $x p_{t}$; the return differential, $r_{t}^{\text {NFA }} \times 400$; the growth in net exports $\Delta n x_{t}^{*} \times 400$; the real interest rate $r_{t} \times 400$; the real dollar depreciation rate, $\Delta \varepsilon_{t} \times 400$; the growth in U.S. GDP, $\Delta y_{t}$; the growth in the U.S. government debt-to-GDP ratio, $\Delta d_{t} \times 400$, and the spread between the yield on 10-year U.S. government bonds and 3-month T-bills, $\nabla r_{t} \times 400$. All series are sampled at the quarterly frequency and span 1973:I to 2007:IV.

rate for the dollar, $\Delta \varepsilon_{t}$; the growth in the debt-to-GDP ratio, $\Delta d_{t}$; and the yield spread, $\nabla r_{t}$. All of these series appear covariance stationary.

Table 2 compares the the behavior of U.S. foreign asset returns, liability returns and their components across the whole sample period and two sub-samples. Panels A and B shows statistics for the log excess returns on assets and liabilities computed as $r_{t}^{\mathrm{FA}_{j}}-r_{t}$ and $r_{t}^{\mathrm{FL}_{i}}-r_{t}$, where $r_{t}^{\mathrm{FA}_{j}}$ and $r_{t}^{\mathrm{FL}_{i}}$ denote the $\log$ return on asset $j$ and liability $i$, respectively, and $r_{t}$ is the log U.S. real interest rate. Panels $\mathrm{C}$ and D report statistics for the return differential between assets and liabilities, $r_{t}^{\mathrm{FA}_{j}}-r_{t}^{\mathrm{FL}_{j}}$, and the log real interest rate. The table also reports the average share of each asset and liability category and the Sharpe ratio, computed as the sample average of gross excess returns, $R_{t}^{j}-R_{t}$, divided 


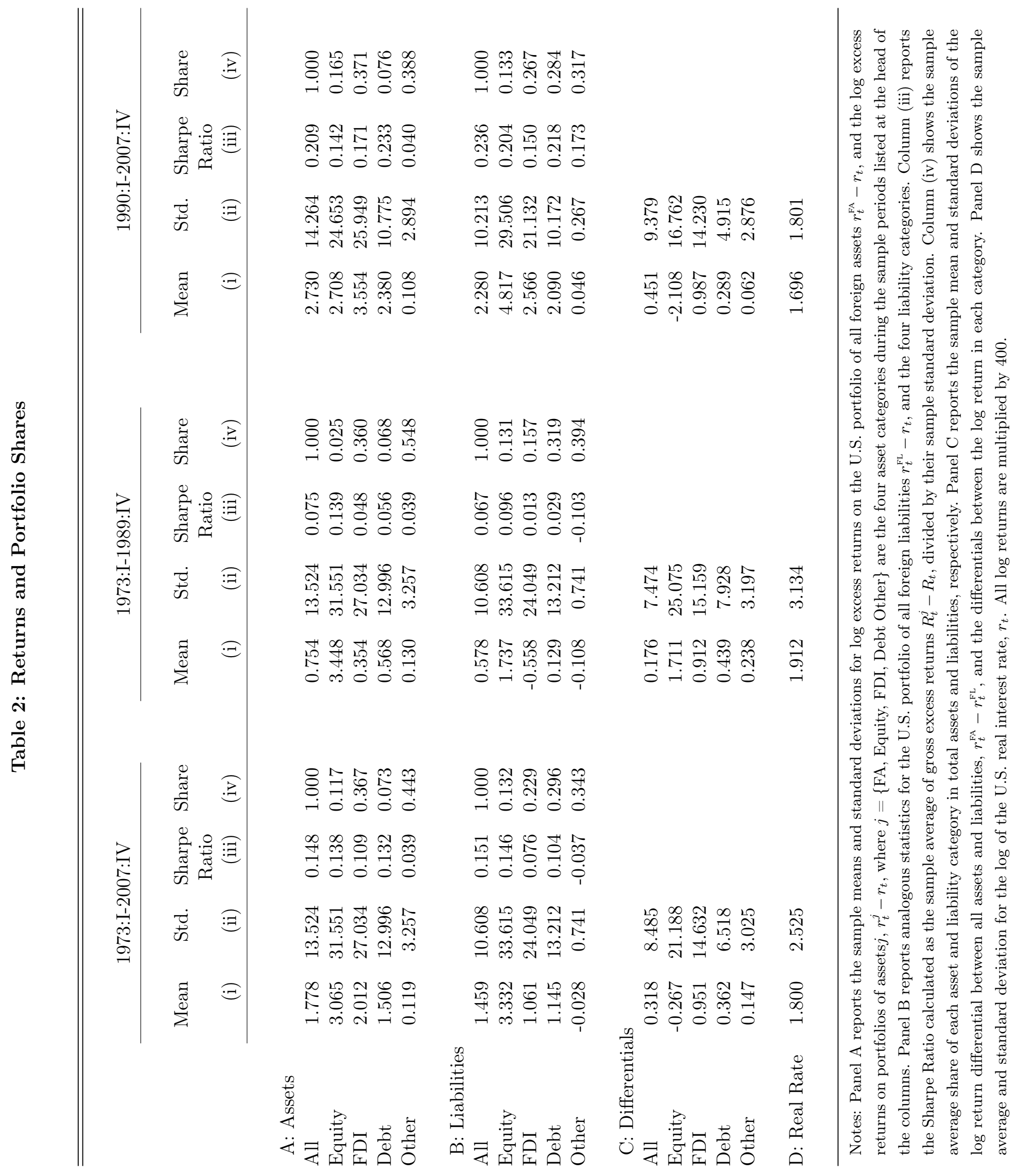


by their sample standard deviation.

Several features of Table 2 stand out. First, there are significant differences between the average excess returns on foreign assets and liabilities across different sample periods and across different categories. Average excess returns on assets were positive and rose between the first and second halves of the sample, except in the case of equity. These changes were reflected in higher Sharpe ratios. The excess returns on liabilities show a similar pattern. Second, Panel C shows that while the log return differential between assets and liabilities is on average just 32 basis points (on an annual basis), there are significant differences in the average differential through time and across categories. In particular, the average differential computed from the entire asset and liability portfolios more than doubled between the first and second sub-samples. Furthermore there is a large change in the differential for equities, moving from an average of $1.71 \%$ p.a. before 1990 to an average of $-2.11 \%$ p.a. thereafter. The third feature concerns the composition of the asset and liability portfolios. On average, FDI accounted for a larger share of assets than liabilities, while debt comprised a far smaller share of assets than liabilities. However, these differences masked sizable changes in the composition of the portfolios over the sample. Of particular note is the fact that equities grew as a share of assets while FDI grew as a share of liabilities.

Further evidence on the changing composition of the asset and liability portfolios is provided by Figure 4. Here I plot the difference between the asset share and liability share for each category (i.e., Equity, FDI, and Debt) over the sample period. Thus positive values for each plotted variable indicate that the category represents a larger share of assets than liabilities. Figure 4 shows that equity has moved from an underweighted to overweighted share in assets relative to liabilities over the sample period; the difference in shares moves from approximately -0.1 to 0.1 . At the same time, the relative shares of FDI and Debt have declined but still remain overweighted in assets relative to liabilities. Despite these changes, the plots generally substantiate the view that the U.S. has been transforming world savings into risky capital via the accumulation of debt liabilities and an increased holdings of equity and FDI assets.

The average return differential between U.S. foreign assets and liabilities of 0.32 percent per year in my data is far lower than the estimates first documented in the literature. For example, Lane and Milesi-Ferretti (2005) Gourinchas and Rey (2007a) and Meissner and Taylor (2006) report estimates of approximately 3 percent per year, an order of magnitude higher. Curcuru, Dvorak, and Warnock (2007) and Lane and Milesi-Ferretti (2009) argue that inaccuracies in the IIP data used to construct the returns in these studies induce an upward bias in the estimates. Curcuru, Dvorak, and Warnock (2007) compute returns on foreign asset and liability portfolios using market returns and portfolio positions from Bertaut and Tryon (2007). This approach is similar to the one I follow and their estimates of average returns on debt and equity correspond quite closely to the estimated averages in my data. Table $\mathrm{A}$ in the Appendix provides a direct comparison of average (nominal) returns over a common data period. As a further cross-check, I also compared the average returns for all assets and liabilities with the estimates in Forbes (2009) that use the Curcuru, Dvorak, and Warnock 
Figure 4: Changes in the Composition of Asset and Liability Portfolios

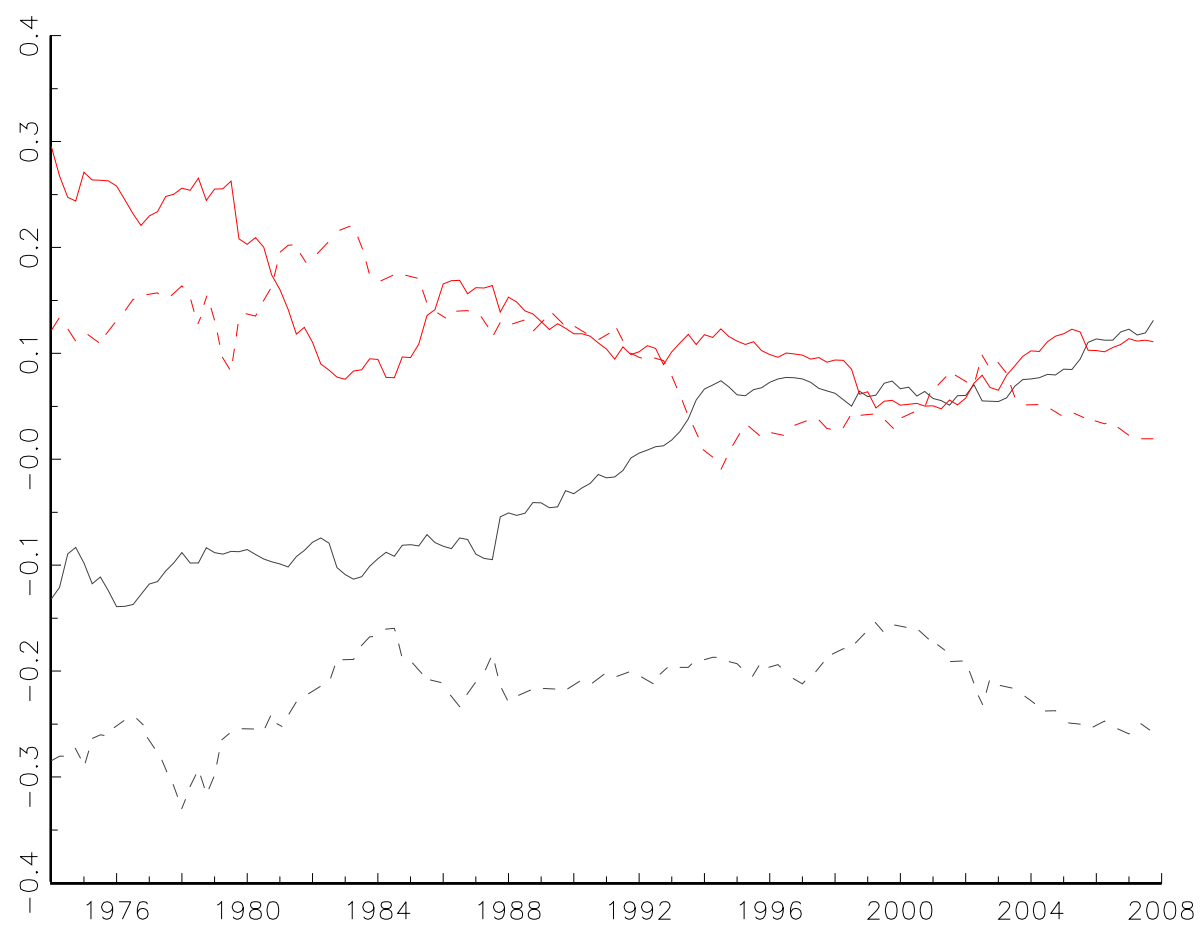

Key: Differences between the share in asset and liabilities portfolios for; (i) Equities - solid black; (ii) FDI - solid red; (iii) Debt - dashed black; and (iv) Other - dashed red.

(2007) methodology. Again, Table A shows that there is a close correspondence between the two sets of average returns.

\subsection{Estimation}

My baseline results are derived from estimates of a first-order VAR for six variables $\left\{r_{t}^{\mathrm{FA}}, r_{t}^{\mathrm{FL}}, \Delta x_{t}^{*}\right.$, $\left.\Delta m_{t}^{*}, \delta_{t}^{\mathrm{FA}}, \delta_{t}^{\mathrm{FL}}\right\}$. This specification minimizes both the AIK and BIC information criteria (verses higher-order specifications), and can be used to compute the expectations needed to identify the U.S. external positions and capital flows. The VAR is estimated without a constant to be consistent with the approximation of the consolidated budget constraint in (17) from which the equations for the external positions and capital flows are derived. This is important because I want to compare the level of the U.S. external position and capital flows with the present value of future returns and trade flows, not just changes in the positions, flows and the present value. Notice, also, that this specification includes more variables than are necessary to analyze the external position alone: Equation (18) implies that a VAR with three variables, $\left\{r_{t}^{\mathrm{NFA}}, \Delta n x_{t}^{*}, x p_{t}\right\}$, would suffice. I use the six-variable specification so that all the external position and capital flow measures are derived from a common set of VAR estimates, and check the robustness of my findings against those based on 
Table 3: Granger Causality Tests

\begin{tabular}{|c|c|c|c|c|c|c|}
\hline \multirow{2}{*}{$\begin{array}{l}\text { Forecast } \\
\text { Variable }\end{array}$} & \multicolumn{6}{|c|}{ Forecasting Variables } \\
\hline & $r_{t-i}^{\mathrm{FA}}$ & $r_{t-i}^{\mathrm{FL}}$ & $\Delta x_{t-i}^{*}$ & $\Delta m_{t-i}^{*}$ & $\delta_{t-i}^{\mathrm{FA}}$ & $\delta_{t-i}^{\mathrm{FL}}$ \\
\hline \multicolumn{7}{|l|}{ A: } \\
\hline$r_{t}^{\mathrm{FA}}$ & 0.378 & 0.010 & 0.025 & 0.594 & 0.522 & 0.027 \\
\hline$r_{t}^{\mathrm{FL}}$ & 0.050 & 0.000 & 0.037 & 0.936 & 0.129 & 0.001 \\
\hline$\Delta x_{t}^{*}$ & 0.783 & 0.913 & 0.000 & 0.050 & 0.790 & 0.086 \\
\hline$\Delta m_{t}^{*}$ & 0.933 & 0.716 & 0.000 & 0.000 & 0.003 & 0.469 \\
\hline \multicolumn{7}{|l|}{ B: } \\
\hline$r_{t}^{\mathrm{NFA}}$ & 0.044 & 0.085 & 0.765 & 0.725 & 0.031 & 0.956 \\
\hline$\Delta n x_{t}^{*}$ & 0.242 & 0.131 & 0.074 & 0.024 & 0.205 & 0.458 \\
\hline$\Delta m_{t}^{*}-r_{t}^{\mathrm{FA}}$ & 0.000 & 0.000 & 0.000 & 0.008 & 0.017 & 0.056 \\
\hline$\Delta x_{t}^{*}-r_{t}^{\mathrm{FL}}$ & 0.326 & 0.153 & 0.252 & 0.001 & 0.001 & 0.064 \\
\hline$r_{t}^{\mathrm{NFA}}+\Delta n x_{t}^{*}$ & 0.033 & 0.024 & 0.087 & 0.031 & 0.022 & 0.501 \\
\hline
\end{tabular}

Notes: The table reports asymptotic p-values for the null hypothesis that the variable listed at the head of each column does not Granger Cause the forecast variable in each row. The tests are calculated from a estimates of a first-order VAR for $z_{t}=\left[\begin{array}{llllll}r_{t}^{\mathrm{FA}} & r_{t}^{\mathrm{FL}} & \Delta x_{t}^{*} & \Delta m_{t}^{*} & \delta_{t}^{\mathrm{FA}} & \delta_{t}^{\mathrm{FL}}\end{array}\right]^{\prime}$, where $r_{t}^{\mathrm{FA}}$ and $r_{t}^{\mathrm{FL}}$; are the log returns on foreign assets and liabilities; $\Delta x_{t}^{*}$ and $\Delta m_{t}^{*}$ denote the growth in real exports and imports and the log ratios $\delta_{t}^{\mathrm{FA}}=f a_{t \mid t-1}-m_{t}^{*}$ and $\delta_{t}^{\mathrm{FL}}=f l_{t \mid t-1}-x_{t}^{*}$ where $f a_{t \mid t-1}$ and $f l_{t \mid t-1}$ are the log values of foreign assets and liabilities at the start of period $t$. Panel B reports Granger tests using the sums of coefficients from the VAR equations. Entries equal to 0.000 denote p-values $<0.001$.

alternative VAR specifications.

The results of Granger Causality tests for the variables in the VAR are presented in Table 3. Panel A reports the asymptotic p-values for the null hypothesis that the variable listed at the head of each column does not Granger Cause the Forecast Variable shown at the left-hand end of each row. These statistics indicate that at least one variable in the VAR has significant incremental forecasting power for future returns and trade flows, beyond the lagged variable itself. Panel B reports the pvalues from Granger Causality tests for variables that appear on the right-hand-side of the external position and capital flow equations. Here the p-values are computed from testing the null that the combination of coefficients for each forecasting variable from the appropriate equations equals zero. This is equivalent to testing for the joint statistical significance of the coefficients on the forecasting variables in an equation with $r_{t}^{\mathrm{NFA}}, \Delta n x_{t}^{*}, \Delta x_{t}^{*}-r_{t}^{\mathrm{FL}}, \Delta m_{t}^{*}-r_{t}^{\mathrm{FA}}$ or $r_{t}^{\mathrm{NFA}}+\Delta n x_{t}^{*}$ as the dependent variable. Again, the low p-values shown in the table indicate that every one of the variables in the VAR has significant incremental forecasting power for these variables. 


\section{Results}

In this section I first use the VAR estimates to study the historical evolution of U.S. foreign asset and liability positions. I then examine the factors driving net and gross capital flows.

\subsection{Net Position Dynamics}

Recall that the net external position is determined by

$$
x p_{t}=-\sum_{i=1}^{\infty} \rho^{i} \mathbb{E}\left[r_{t+i}^{\mathrm{NFA}}+\Delta n x_{t+i}^{*} \mid \Omega_{t}\right],
$$

so we need a value for $\rho \in(0,1)$ to compute the implications of the VAR forecasts for the return differential and net export growth. I choose the value for $\rho$ that minimizes the sample variance of the specification error $\hat{v}_{t}=x p_{t}-\widehat{x p}_{t}$, where $\widehat{x p}_{t}$ denotes the estimate of the present value term on the right-hand-side of (29) computed from the VAR. This produces a value for $\rho$ of 0.989 , which corresponds to an annual discount factor of 0.96. If this value is used in a (nonlinear) Wald test of the restrictions on the VAR coefficients in (26), the resulting statistic is not statistically significant at the 5 percent level (the p-value is 0.244 ). Of course precise inference in this situation is tricky. Standard practice is to conduct the Wald test using a pre-specified value for $\rho .^{8}$ My procedure for choosing $\rho$ means that the Wald statistic will be smaller. This does not mean that the restrictions in (26) are automatically satisfied because the minimized variance of the specification error may still be positive. However, it does mean that the true asymptotic distribution of Wald statistic under the null with $\rho \in(0,1)$ differs from the standard chi-squared. To account for this, the Appendix describes the bootstrap procedure I use to approximate the true p-value of the Wald statistic. This produces a p-value equal to 0.262. Based of these calculations, the restrictions on the VAR coefficients cannot be rejected at standard significance levels.

Figure 5 compares the historical behavior of the U.S. net external position with the implied position based on the VAR estimates, and its components. Here I plot the time series for $x p_{t}, \widehat{x p}_{t}$ and the estimated trade and valuation components:

$$
\begin{aligned}
\widehat{x p}_{t}^{\mathrm{TR}} & =-\sum_{i=1}^{\infty} \rho^{i} \mathbb{E}\left[\Delta n x_{t+i}^{*} \mid \Omega_{t}\right]=-\imath_{n x} \rho \hat{A}(I-\rho \hat{A}) Z_{t} \quad \text { and } \\
\widehat{x p}_{t}^{\mathrm{VAL}} & =-\sum_{i=1}^{\infty} \rho^{i} \mathbb{E}\left[r_{t+i}^{\mathrm{NFA}} \mid \Omega_{t}\right]=-\imath_{r} \rho \hat{A}(I-\rho \hat{A}) Z_{t} .
\end{aligned}
$$

\footnotetext{
${ }^{8}$ For example, Campbell and Shiller (1987) use a sample average to calibrate the value for $\rho$. I cannot follow their approach because the value of $\rho$ used in the approximation of the consolidated budget constrain depends on ratios involving adjusted exports and imports that incorporate a common trend that must be estimated.
} 
Figure 5: Historical Behavior of the U.S. Net External Position and its Components

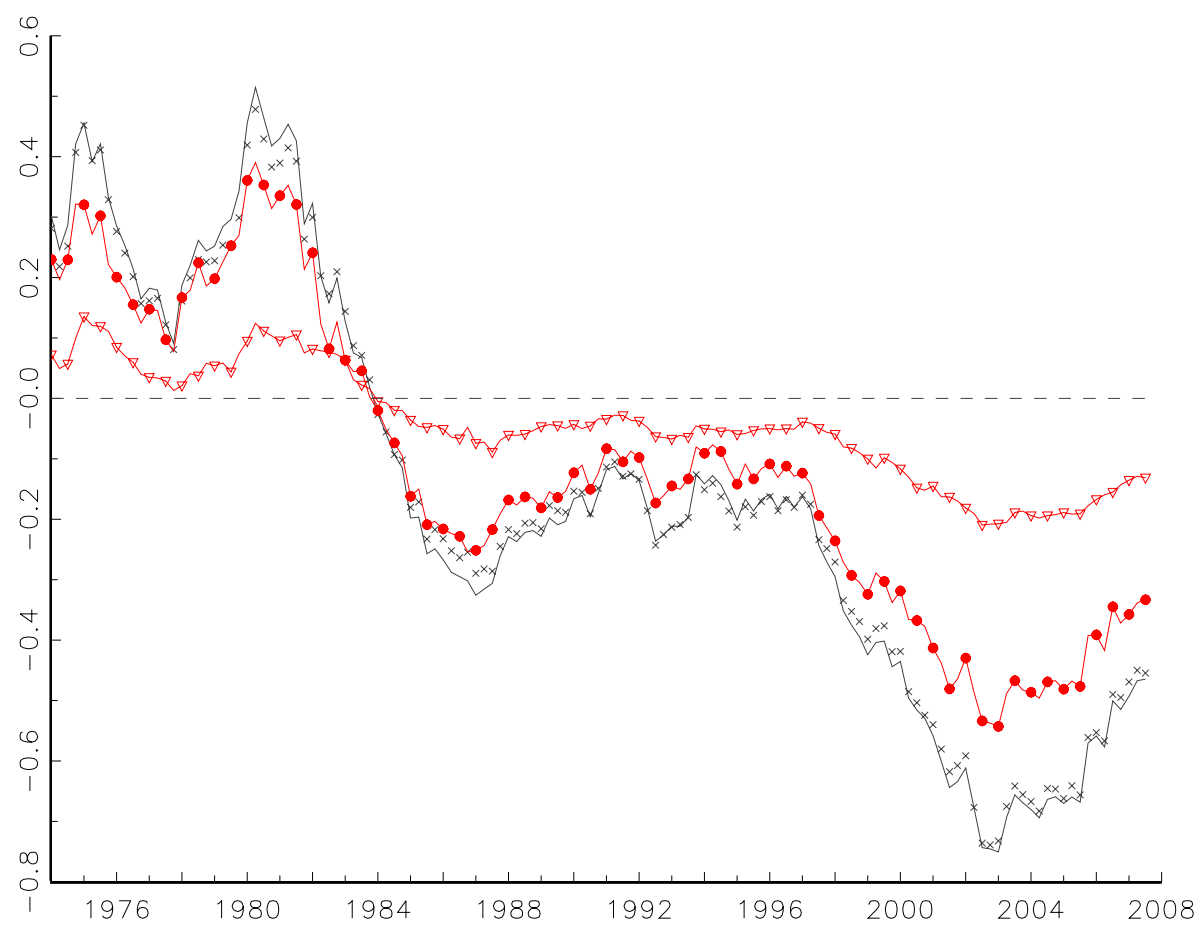

Key: Implied value for $\widehat{x p}_{t}$ - solid black; actual values for $x p_{t}$ - black crosses; valuation component $\widehat{x p}_{t}^{\mathrm{VAL}}$ - red with dots; and trade component $\widehat{x p}_{t}^{\mathrm{TR}}$ - red with triangles.

Clearly, the estimated present value $\widehat{x p}_{t}$ captures almost all of the historical variations in the U.S. external position. (The specification errors $\hat{v}_{t}$ account for approximated 3 percent of the sample variance in $x p_{t}$ and are economically insignificant.) Figure 5 also shows how the estimated trade and valuation components contributed to the secular deterioration of the U.S. external position over the past three decades. In particular, it is clear that variations in the valuation component are have been a major contributor to the changes in $x p_{t}$.

We can examine the contributions of the valuation and trade components more formally. By definition, $x p_{t}=\widehat{x p}_{t}^{\mathrm{VAL}}+\widehat{x p}_{t}^{\mathrm{TR}}+\hat{v}_{t}$, so the variance of the external position can be decomposed as

$$
\mathbb{V}\left(x p_{t}\right)=\mathbb{C V}\left(\widehat{x p}_{t}^{\mathrm{VAL}}, x p_{t}\right)+\mathbb{C V}\left(\widehat{x p}_{t}^{\mathrm{TR}}, x p_{t}\right)+\mathbb{C V}\left(\hat{v}_{t}, x p_{t}\right)
$$

where $\mathbb{V}($.$) and \mathbb{C}(.,$.$) denote the variance and covariance operators, respectively. The first term$ on the right-hand-side identifies the contribution of variations in the estimated valuation component to the variance of $x p_{t}$. The second term identifies the variance contribution of the estimates trade component. I estimate these contributions as the slope coefficient from the OLS regression of the estimated component on $x p_{t}$ :

$$
\widehat{x p}_{t}^{\mathrm{VAL}}=\beta_{x p}^{\mathrm{VAL}} x p_{t}+\zeta_{t}^{\mathrm{Val}} \quad \text { and } \quad \widehat{x p}_{t}^{\mathrm{TR}}=\beta_{x p}^{\mathrm{TR}} x p_{t}+\zeta_{t}^{\mathrm{TR}}
$$


By least squares, $\beta_{x p}^{\mathrm{VAL}}=\mathbb{C V}\left(\widehat{x p}_{t}^{\mathrm{Val}}, x p_{t}\right) / \mathbb{V}\left(x p_{t}\right)$ and $\beta_{x p}^{\mathrm{TR}}=\mathbb{C V}\left(\widehat{x p}_{t}^{\mathrm{TR}}, x p_{t}\right) / \mathbb{V}\left(x p_{t}\right)$ so the regression coefficients provide estimates of the variance contributions. I also compute confidence bands for these estimates using White (1980) heteroskedastic consistent standard errors.

The first row of Table 4 reports the estimates of $\beta^{\mathrm{TR}}$ and $\beta^{\mathrm{VAL}}$ computed using the forecasts from the baseline VAR specification, together with 95 percent confidence bands. The remaining rows of the table report statistics computed from VAR specifications that add the real depreciation rate, growth in GDP, growth in the debt-to-GDP ratio and the long-term U.S. bond spread as a seventh variable. These statistics show the the robustness of the variance decomposition between the trade and valuation components as we change the conditioning information set used to compute the forecasts of future trade and return differentials. ${ }^{9}$

Table 4: Variance Decompositions of $x p_{t}$

\begin{tabular}{|c|c|c|c|c|c|c|}
\hline \multirow[b]{2}{*}{ VAR Specifications } & \multicolumn{3}{|c|}{ Trade: $\hat{\beta}_{x p}^{\mathrm{TR}}$} & \multicolumn{3}{|c|}{ Valuation: $\hat{\beta}_{x p}^{\mathrm{VAL}}$} \\
\hline & $\begin{array}{c}\text { lower } \\
\text { bound } \\
(\mathrm{i})\end{array}$ & $\begin{array}{c}\text { estimate } \\
\text { (ii) }\end{array}$ & $\begin{array}{l}\text { upper } \\
\text { bound } \\
\text { (iii) }\end{array}$ & $\begin{array}{c}\text { lower } \\
\text { bound } \\
\text { (i) }\end{array}$ & $\begin{array}{c}\text { estimate } \\
\text { (ii) }\end{array}$ & $\begin{array}{c}\text { upper } \\
\text { bound } \\
\text { (ii) }\end{array}$ \\
\hline Baseline & 0.276 & 0.280 & 0.285 & 0.744 & 0.754 & 0.764 \\
\hline A1: $\Delta \varepsilon$ & 0.289 & 0.294 & 0.299 & 0.744 & 0.754 & 0.764 \\
\hline $\mathrm{A} 2: \Delta y$ & 0.338 & 0.345 & 0.352 & 0.664 & 0.674 & 0.684 \\
\hline $\mathrm{A} 3: \Delta d$ & 0.364 & 0.373 & 0.383 & 0.582 & 0.597 & 0.611 \\
\hline $\mathrm{A} 4: \nabla r$ & 0.367 & 0.379 & 0.391 & 0.512 & 0.537 & 0.563 \\
\hline \multicolumn{7}{|c|}{$\begin{array}{l}\text { Notes: Column (ii) in each panel reports the OLS estimate of the slope coefficient from (30) using } \\
\text { forecast of net exports and the return differential from the VARs. Columns (i) and (iii) report the } \\
\text { lower and upper } 95 \text { percent bounds associated with the slope estimates computed as } \hat{\beta} \pm 1.96 \hat{\sigma}^{2} \text {, } \\
\text { where } \hat{\sigma} \text { is the coefficient standard error computed from the White (1980) procedure. The statistics } \\
\text { in rows A1 - A4 are computed using a VAR that adds the real depreciation rate } \Delta \varepsilon \text {, real GDP } \\
\text { growth } \Delta y, \text { the growth in the debt-to-gdp ratio, } \Delta d \text {, and the spread between } 10 \text { year and } 3 \text { month } \\
\text { U.S. bonds, } \nabla r \text {. }\end{array}$} \\
\hline
\end{tabular}

\footnotetext{
${ }^{9}$ While I cannot reject the restrictions implied by the present value relation for $x p_{t}$ in (26), this does not mean that the estimated trade and valuation components won't be sensitive to the choice of variables in the VAR. As I note above, since data on $x p^{\mathrm{VAL}}$ and $x p_{t}^{\mathrm{TR}}$ is unavailable, I cannot use the history of these variables to capture information in agents' separate forecasts for the return differential and net export growth that was not contained in the history of $\left\{r_{t}^{\mathrm{FA}}, r_{t}^{\mathrm{FL}}, \Delta x_{t}^{*}, \Delta m_{t}^{*}, \delta_{t}^{\mathrm{FA}}, \delta_{t}^{\mathrm{FL}}\right\}$.
} 
The results in Table 4 deliver a simple message: Most of the variations in the U.S. external position are attributable to changing expectations concerning future return differentials rather than future trade flows. In the baseline specification, approximately 75 percent of the variation in $x p_{t}$ comes from the valuation component, while 28 percent is attributable to the trade component. ${ }^{10}$ This basic finding appears robust across alternative specifications for the VAR. If we include GDP growth, the growth in debt-to-GDP or the yield spread in the VAR, the variance contribution of the trade component is a little higher, but in every case, its estimated contribution is well below that of the valuation component. Indeed, the confidence bands indicate that 40 percent represents a reasonable upper bound on the variance contribution of the trade component.

It is also worth stressing that this role for the valuation component reflects the effects of predictable variations in return differentials rather than a large average differential between U.S. foreign assets and liabilities. Recall that the sample average value for $r_{t}^{\mathrm{NFA}}$ is just 0.32 percent per year. If agents had used this average as their forecast for future differentials, the valuation component would have been constant equal to $-0.072\left(=-\frac{0.989}{1-0.989} \frac{0.32}{400}\right)$. Under these circumstances, the plots in Figure 5 suggest that the U.S. external position could not have deteriorated beyond the level it reached in the early 1980s without running into the solvency constraint. As things turned out, expected future return differentials rose significantly in the early 1980's and late 1990's allowing the U.S. external position to deteriorate without risking insolvency. ${ }^{11}$

The findings in Figure 5 and Table 4 contrast with the results reported by Gourinchas and Rey (2007b). They estimate the variance contribution of the trade component to cyclical changes in the U.S. external position was between 60 and 70 percent between 1952:I and 2004:I, almost twice the size I estimate. Much of this difference reflects the effects of de-trending. As Figure 5 shows, the low frequency swings in the net external position are more closely tracked by the valuation than trade components, so de-trending the data will change their relative contributions.

My results also represent a theoretical challenge. In open-economy models where all international borrowing takes place via a single bond, the return on foreign assets and liabilities are the same. This means that the valuation component equals zero, so variations in the country's external position are entirely driven by changing expectations concerning future real trade flows. Variations in the valuation component are permitted in some recent models that allow for international borrowing and lending in multiple securities. For example, Devereux and Sutherland (2010) study a model with international trade in two bonds that produces changes in expected return differentials when the economy is hit by endowment shocks, but the effects are too small to make variations in the valuation component economically important. In a similar vein, Tille and Wincoop (2010) are unable

\footnotetext{
${ }^{10}$ The estimates of $\beta_{\text {Trade }}$ and $\beta_{\mathrm{VAL}}$ do not sum to one because $\mathbb{C V}\left(\hat{v}_{t}, x p_{t}\right) \neq 0$ in the sample. Of course the p-value for the Wald statistic on the restriction in (26) implies that we cannot reject the null that $\mathbb{C V}\left(\hat{v}_{t}, x p_{t}\right)=0$ at standard significance levels.

${ }^{11}$ It is tempting to interpret the model estimates as indicating that the deterioration in the U.S. external position caused the rise in expected future return differentials, but this is speculation. In fact the model is silent on the ultimate source of the change in expected returns. It simply uses the variables in the VAR to capture the real-time information embedded in expected returns (and net export growth) without identifying its ultimate source.
} 
to generate large predictable return differentials in a model with international trade in two equities, so again countries' external positions are almost entirely driven by the trade component. As Tille and Wincoop note, the heart of the problem is that the first-order component of expected return differentials are zero. Consequently, producing large predictable return differentials is a challenge without financial frictions that limit the international arbitrage opportunities between securities. ${ }^{12}$

\subsection{Gross Position Dynamics}

Recall that the log ratios of foreign assets to imports and liabilities to exports satisfy

$$
\begin{aligned}
\delta_{t}^{\mathrm{FA}} & =\mathbb{E}_{t} \sum_{i=1}^{\infty} \rho^{i}\left[\Delta m_{t+i}^{*}-r_{t+i}^{\mathrm{FA}}\right]+(1-\rho) \mathbb{E}_{t} \sum_{i=0}^{\infty} \rho^{i}\left[y_{t+i}^{\mathrm{FL}}-x_{t+i}^{*}\right]-\frac{\rho}{1-\rho} k \quad \text { and } \\
\delta_{t}^{\mathrm{FL}} & =\mathbb{E}_{t} \sum_{i=1}^{\infty} \rho^{i}\left[\Delta x_{t+i}^{*}-r_{t+i}^{\mathrm{FL}}\right]+(1-\rho) \mathbb{E}_{t} \sum_{i=0}^{\infty} \rho^{i}\left[y_{t+i}^{\mathrm{FA}}-m_{t+i}^{*}\right]-\frac{\rho}{1-\rho} k,
\end{aligned}
$$

where $y_{t}^{\mathrm{FA}}$ and $y_{t}^{\mathrm{FL}}$ denote the log income from assets and liabilities net of asset purchases and liabilities sales. Figure 6 plots the historical behavior of $\delta_{t}^{\mathrm{FA}}$ and $\delta_{t}^{\mathrm{FL}}$ together with the VAR estimates of the components on the right-hand-side of each equation. These plots display several noteworthy features. First, there is more variation in $\delta_{t}^{\mathrm{FL}}$ than in $\delta_{t}^{\mathrm{FA}}$ over the sample period: the sample standard deviations are 0.20 and 0.18 , respectively. Second, expectations concerning future "dividend" growth and returns play different roles in driving the variations in $\delta_{t}^{\mathrm{FA}}$ and $\delta_{t}^{\mathrm{FL}}$. In particular, the plots in panel A shows that the present value term $\mathbb{E}_{t} \sum_{i=1}^{\infty} \rho^{i}\left[\Delta m_{t+i}^{*}-r_{t+i}^{\mathrm{FA}}\right]$ is less volatile and negatively correlated with $\delta_{t}^{\mathrm{FA}}$, while the plots in panel B show that the present value term $\mathbb{E}_{t} \sum_{i=1}^{\infty} \rho^{i}\left[\Delta x_{t+i}^{*}-\right.$ $\left.r_{t+i}^{\mathrm{FL}}\right]$ is positively correlated with $\delta_{t}^{\mathrm{FL}}$ and more volatile. Notice also that the plots for both $(1-$ $\rho) \mathbb{E}_{t} \sum_{i=0}^{\infty} \rho^{i}\left[y_{t+i}^{\mathrm{FL}}-x_{t+i}^{*}\right]$ and $(1-\rho) \mathbb{E}_{t} \sum_{i=0}^{\infty} \rho^{i}\left[y_{t+i}^{\mathrm{FA}}-m_{t+i}^{*}\right]$ trend downward. ${ }^{13}$ Throughout the sample period the evolution of the U.S. gross asset and liabilities positions reflected expectations that net income paid to the holders of U.S. liabilities would fall relative to exports, or equivalently, that net income from U.S. assets would fall relative to imports.

\footnotetext{
${ }^{12}$ This problem is also present in the multi-asset models of Evans and Hnatkovska (2005 \& 2007), Hnatkovska (2010) and Coeurdacier, Kollmann, and Martin (2010). Evans (2012) presents a model with financial frictions that produces persistent variations in expected return differentials on bonds, but not the return differentials on the asset and liability portfolios containing bonds, equity and FDI that drive the U.S. valuational component.

${ }^{13}$ Recall that the net income on foreign liabilities and assets are linked by $y_{t}^{\mathrm{FL}}=y_{t}^{\mathrm{FA}}+x_{t}^{*}-m_{t}^{*}$ to insure that $x p_{t}=\delta_{t}^{\mathrm{FA}}-\delta_{t}^{\mathrm{FL}}$ satisfies the international solvency condition in $(18)$, so the plots for $(1-\rho) \mathbb{E}_{t} \sum_{i=0}^{\infty} \rho^{i}\left[y_{t+i}^{\mathrm{FL}}-x_{t+i}^{*}\right]$ and $(1-\rho) \mathbb{E}_{t} \sum_{i=0}^{\infty} \rho^{i}\left[y_{t+i}^{\mathrm{FA}}-m_{t+i}^{*}\right]$ are identical.
} 


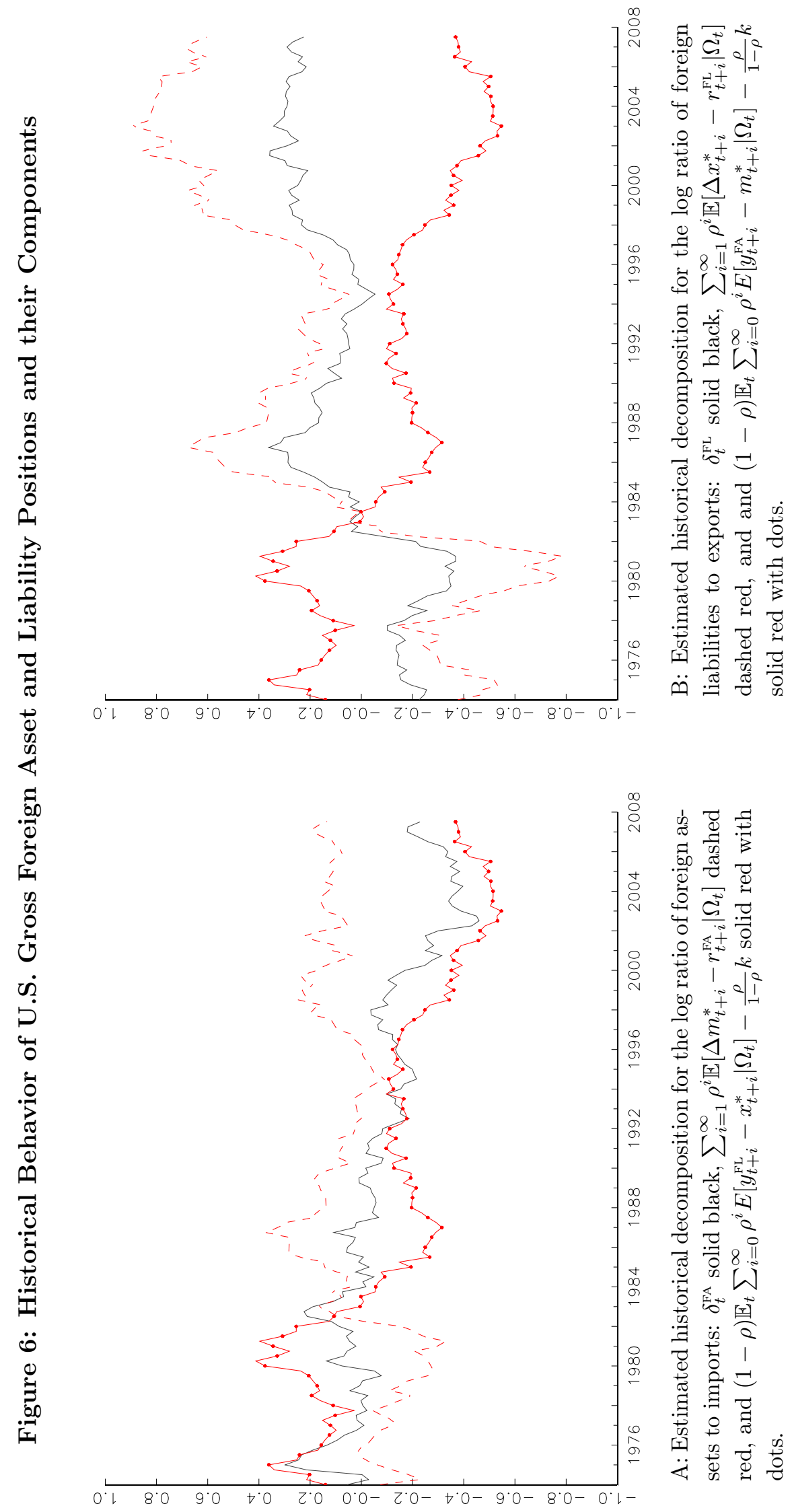


Table 5: Variance Decompositions for $\delta_{t}^{\mathrm{FA}}$ and $\delta_{t}^{\mathrm{FL}}$

\begin{tabular}{lccc}
\hline \hline & lower & estimate & upper \\
Component & bound & bound \\
(i) & (ii) & (iii) & (iv) \\
\hline
\end{tabular}

A: Gross Assets: $\delta_{t}^{\mathrm{FA}}$

$\begin{array}{lccc}\sum_{i=1}^{\infty} \rho^{i} \mathbb{E}\left[\Delta m_{t+i}^{*}-r_{t+i}^{\mathrm{FA}} \mid \Omega_{t}\right] & -0.250 & -0.114 & 0.023 \\ \sum_{i=1}^{\infty} \rho^{i} \mathbb{E}\left[\Delta m_{t+i}^{*} \mid \Omega_{t}\right] & -2.681 & -2.297 & -1.912 \\ \sum_{i=1}^{\infty} \rho^{i} \mathbb{E}\left[r_{t+i}^{\mathrm{FA}} \mid \Omega_{t}\right] & 1.934 & 2.183 & 2.433 \\ (1-\rho) \sum_{i=0}^{\infty} \rho^{i} \mathbb{E}\left[y_{t+i}^{\mathrm{FL}}-x_{t+i}^{*} \mid \Omega_{t}\right] & 0.977 & 1.114 & 1.250\end{array}$

B: Gross Liabilities: $\delta_{t}^{\mathrm{FL}}$

$\begin{array}{lccc}\sum_{i=1}^{\infty} \rho^{i} \mathbb{E}\left[\Delta x_{t+i}^{*}-r_{t+i}^{\mathrm{FL}} \mid \Omega_{t}\right] & 2.159 & 2.225 & 2.291 \\ \sum_{i=1}^{\infty} \rho^{i} \mathbb{E}\left[\Delta x_{t+i}^{*} \mid \Omega_{t}\right] & 3.172 & 3.294 & 3.416 \\ \sum_{i=1}^{\infty} \rho^{i} \mathbb{E}\left[r_{t+i}^{\mathrm{FL}} \mid \Omega_{t}\right] & -1.128 & -1.069 & -1.010 \\ (1-\rho) \sum_{i=0}^{\infty} \rho^{i} \mathbb{E}\left[y_{t+i}^{\mathrm{FA}}-m_{t+i}^{*} \mid \Omega_{t}\right] & -1.291 & -1.225 & -1.159\end{array}$

Notes: Column (iii) reports the OLS estimate of the slope coefficient from a regression of the component listed in column (i) on either $\delta_{t}^{\mathrm{FA}}$ (panel A) or $\delta_{t}^{\mathrm{FL}}$ (panel B). Columns (ii) and (iv) report the lower and upper 95 percent bounds associated with the slope estimates computed as $\hat{\beta} \pm 1.96 \hat{\sigma}^{2}$, where $\hat{\sigma}$ is the coefficient standard error computed from the White (1980) procedure. All the components are computed from the baseline VAR.

Table 5 compliments the visual evidence in Figure 6 by reporting the variance contributions of the components driving $\delta_{t}^{\mathrm{FA}}$ and $\delta_{t}^{\mathrm{FL}}$. As above, the contributions are computed from the slope coefficient of the component computed from the baseline VAR on either $\delta_{t}^{\mathrm{FA}}$ or $\delta_{t}^{\mathrm{FL}} .{ }^{14}$ The statistics in panel A show that changing expectations concerning future imports and returns had offsetting effects on the U.S. gross asset-to-import position, with a net contribution of -0.114. Notice, however, that zero lies within the 95 percent confidence band, so the net contribution is not statistically significant at conventional levels. This means that expectations concerning $y_{t+i}^{\mathrm{FL}}-x_{t+i}^{*}$ are the dominant

\footnotetext{
${ }^{14}$ The results are robust to the use of alternative VAR specifications; i.e., specifications that include a seventh variable as in Table 4.
} 
driver of the gross asset position. Indeed, as the last row in panel A shows, we cannot reject the hypothesis that these expectations are the only driver of the U.S. gross asset-to-import position. The statistics in Panel B tell a different story. Here changing expectations concerning future export growth and returns make a significant contribution to the volatility of the gross liability-to-export position, but the variations are far larger than the fluctuations in $\delta_{t}^{\mathrm{FL}}$. In particular, the estimated variance contribution of 2.225 means that $\delta_{t}^{\mathrm{FL}}$ under-reacts to changing expectations concerning

$\Delta x_{t+i}^{*}-r_{t+i}^{\mathrm{FL}}$. This under-reaction reflects the effects of changing expectations concerning future asset income relative to imports. As the last line in panel B shows, changes in these expectations contribute significantly to the volatility of $\delta_{t}^{\mathrm{FL}}$.

Table 5 also reveals that changing expectations concerning future trade flows and returns have have asymmetric affects on gross asset and liability positions. The statistics in panel B show that an increase in the present value of future export growth and a fall in the present value of future liability returns both induce a rise in $\delta_{t}^{\mathrm{FL}}$, consistent with the idea that exports can be viewed as the dividends paid to U.S. creditors. In fact, variations in expected future export growth appear as the single most important driver of changes in the gross liability-to-export ratio. Changing expectations concerning future import growth and asset returns have the opposite effect on the gross asset-to-import ratio: An increase in the present value of future import growth and a fall in the present value of future asset returns both induce a fall in $\delta_{t}^{\mathrm{FA}}$. These results contradict the idea that the U.S. accumulated foreign assets to pay for future imports, or that imports can be viewed as the dividend on foreign asset holdings.

Overall, the results in Figure 6 and Table 5 show that two sets of factors have been the dominant drivers of the U.S. gross asset and liability positions. On the asset side, expectations concerning future export earnings relative to payments on outstanding liabilities were the main driver of changes in the asset-to-import ratio. These expectations also affected gross liabilities, but the dominant drivers of the liability-to-asset ratio were changes in expectations concerning future export growth and returns on liabilities.

\subsection{Net Capital Flows}

I now use the VAR estimates to study the drivers of U.S. net capital flows over different horizons. For this purpose, I define the $k$-period net flow as the cumulant of the period-by-period flows: $f l w_{t+k, k}=\sum_{i=1}^{k} f l w_{t+i}$. Recall that the approximation of the consolidated budget constraint in (15) implies that $f l w_{t}=\left(\frac{1-\rho}{\rho}\right) x p_{t}$, so the $k$-period flows can be written as

$$
f l w_{t+k, k}=\frac{1-\rho}{\rho} \sum_{i=1}^{k} x p_{t+i}^{\mathrm{TR}}+\frac{1-\rho}{\rho} \sum_{i=1}^{k} x p_{t+i}^{\mathrm{VAL}}
$$


where $x p_{t}^{\mathrm{TR}}$ and $x p_{t}^{\mathrm{VAL}}$ are the trade and valuation components identified in (18). If we take expectations on both sides of (31) conditioned on period- $t$ information, and combine the result with the original equation, we find that

$$
\begin{aligned}
f l w_{t+k, k}=\frac{1-\rho}{\rho} \mathbb{E}_{t} \sum_{i=1}^{k} x p_{t+i}^{\mathrm{TR}} & +\frac{1-\rho}{\rho} \mathbb{E}_{t} \sum_{i=1}^{k} x p_{t+i}^{\mathrm{VAL}} \\
& +\frac{1-\rho}{\rho}\left(1-\mathbb{E}_{t}\right) \sum_{i=1}^{k} x p_{t+i}^{\mathrm{TR}}+\left(\frac{1-\rho}{\rho}\right)\left(1-\mathbb{E}_{t}\right) \sum_{i=1}^{k} x p_{t+i}^{\mathrm{VAL}} .
\end{aligned}
$$

The first two terms on the right-hand-side identify the effects of ex ante expectations that drive predictable net capital flows. The flows of news concerning future trade flows and returns between $t+1$ to $t+k$ that drive unpredictable net capital flows are identified by the third and forth terms, respectively. The variance contributions of these terms can be computed as

$$
\begin{aligned}
\beta_{f l w}^{\mathrm{TR}}(k) & =\frac{1-\rho}{\rho} \sum_{i=1}^{k} \mathbb{C V}\left(\mathbb{E}\left[x p_{t+i}^{\mathrm{TR}} \mid \Omega_{t}\right], f l w_{t+k, k}\right) / \mathbb{V}\left(f l w_{t+k, k}\right) \\
\beta_{f l w}^{\mathrm{VAL}}(k) & =\frac{1-\rho}{\rho} \sum_{i=1}^{k} \mathbb{C V}\left(\mathbb{E}\left[x p_{t+i}^{\mathrm{VAL}} \mid \Omega_{t}\right], f l w_{t+k, k}\right) / \mathbb{V}\left(f l w_{t+k, k}\right), \\
\beta_{f l w}^{\mathrm{T}-\mathrm{NEWS}}(k) & =\frac{1-\rho}{\rho} \sum_{i=1}^{k} \mathbb{C V}\left(\mathbb{E}\left[x p_{t+i}^{\mathrm{TR}} \mid \Omega_{t+i}\right]-\mathbb{E}\left[x p_{t+i}^{\mathrm{TR}} \mid \Omega_{t}\right], f l w_{t+k, k}\right) / \mathbb{V}\left(f l w_{t+k, k}\right) \quad \text { and } \\
\beta_{f l w}^{\mathrm{V}-\mathrm{NEWS}}(k) & =\frac{1-\rho}{\rho} \sum_{i=1}^{k} \mathbb{C V}\left(\mathbb{E}\left[x p_{t+i}^{\mathrm{VAL}} \mid \Omega_{t+i}\right]-\mathbb{E}\left[x p_{t+i}^{\mathrm{VAL}} \mid \Omega_{t}\right], f l w_{t+k, k}\right) / \mathbb{V}\left(f l w_{t+k, k}\right),
\end{aligned}
$$

where $\mathbb{E}\left[n p_{t+i}^{\mathrm{TR}} \mid \Omega_{t}\right]$ and $\mathbb{E}\left[n p_{t+i}^{\mathrm{VAL}} \mid \Omega_{t}\right]$ are computed from the baseline VAR.

Figure 7 shows how ex ante expectations and news contributes to the variations in U.S. net capital flows. The figure plots estimates of the betas, $\beta_{f l w}^{i}(k)$ for $i=\{\mathrm{TR}, \mathrm{VAL}, \mathrm{T}-\mathrm{NEWS}, \mathrm{V}-\mathrm{NEWS}\}$ and their associated 95 percent confidence bands for horizons ranging from one quarter to ten years (i.e., $k=1, \ldots ., 40)$. Panel A provides information on the drives of anticipated net capital flows. One-period flows are entirely driven by the ex ante expectations of future trade flows and returns that determine the current external position, so $\beta_{f l w}^{\mathrm{TR}}(1)+\beta_{f l w}^{\mathrm{VAL}}(1)=1$. As the horizon lengthens, predictability gradually declines, with ex ante expectations accounting for approximately 60 percent of the variance in net capital flows at the ten year horizon. The plots for $\beta_{f l w}^{\mathrm{TR}}(k)$ and $\beta_{f l w}^{\mathrm{VAL}}(k)$ in panel A also show that ex ante variations in the expectations concerning future return differentials are much more important than those concerning the future growth in net exports. The variance contributions of news to U.S. net capital flows are shown by the plots for $\beta_{f l w}^{\text {T-NEWS }}(k)$ and $\beta_{f l w}^{\mathrm{V} \text {-NEWS }}(k)$ in Panel B. Here we see that news concerning future return differentials as measured by $\beta_{f l w}^{\mathrm{V} \text {-NEws }}(k)$ is the most importance driver of unanticipated variations in net capital flows at long horizons. Overall, U.S. net capital flows do reflect information about future trade flows, but not nearly as 
Figure 7: Variance Contributions of Trade and Returns to U.S. Net Capital Flows

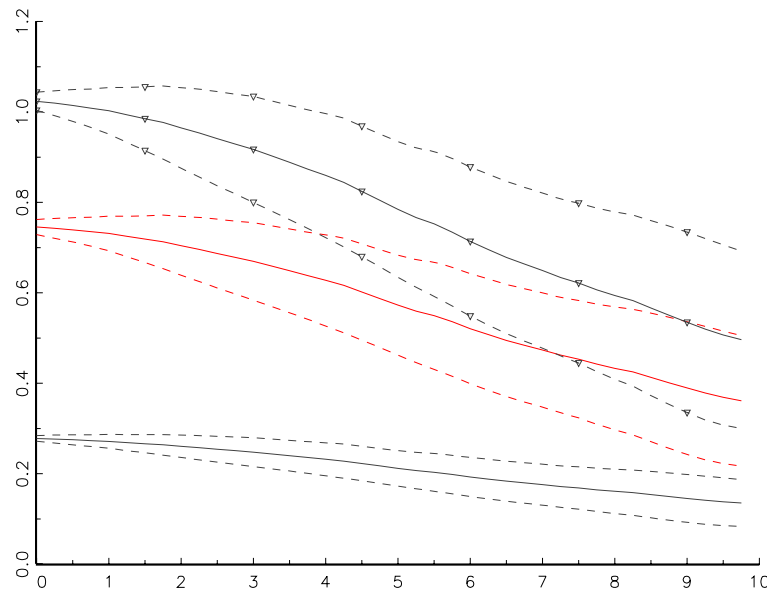

A: Variance contributions of ex ante trade expectations $\beta_{f l w}^{\mathrm{TR}}(k)$ solid black; ex ante return expectations $\beta_{\text {flw }}^{\mathrm{VAL}}(k)$ solid red, and ex ante total expectations $\beta_{f l w}^{\mathrm{TR}}(k)+\beta_{f l w}^{\mathrm{VAL}}(k)$ solid black with triangles. 95 percent confidence bands marked by corresponding dashed lines.

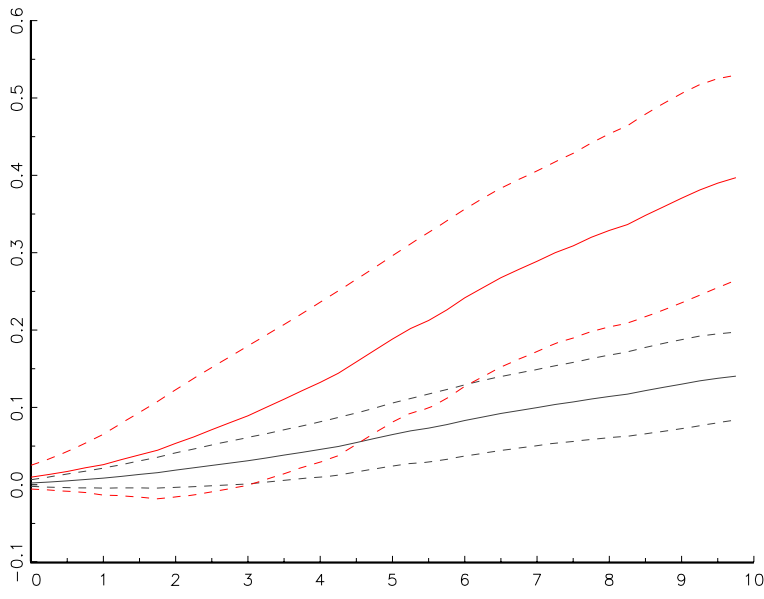

B: Variance contributions of trade news $\beta_{f l w}^{\text {T-NEWS }}(k)$ solid black; and return news $\beta_{f l w}^{\mathrm{v}-\mathrm{NEWS}}(k)$ solid red. 95 percent confidence bands marked by corresponding dashed lines.

much as they reflect information about future return differentials.

For perspective on these findings, consider how capital flows contribute to changes in the U.S. net asset and external positions. By definition, the $k$-period change in the net foreign asset position can be expressed as $\Delta^{k} n f a_{t+k}=\sum_{i=1}^{k} r_{t+i}^{\text {NFA }}+f l w_{t+k, k}$. Thus, capital flows contribute to changes in the net foreign asset position, but their impact may be overshadowed by the cumulated effects of the return differentials. I quantify the contributions of expected differentials and news concerning the differentials by computing

$$
\begin{aligned}
\beta_{n f a}^{\mathrm{VAL}}(k) & =\mathbb{C} \mathbb{V}\left(\sum_{i=1}^{k} \mathbb{E}\left[r_{t+i}^{\mathrm{NFA}} \mid \Omega_{t}\right], \Delta^{k} n f a_{t+k}\right) / \mathbb{V}\left(\Delta^{k} n f a_{t+k}\right), \quad \text { and } \\
\beta_{n f a}^{\mathrm{V}-\mathrm{NEWS}}(k) & =\mathbb{C} \mathbb{V}\left(\sum_{i=1}^{k}\left(r_{t+i}^{\mathrm{NFA}}-\mathbb{E}\left[r_{t+i}^{\mathrm{NFA}} \mid \Omega_{t}\right]\right), \Delta^{k} n f a_{t+k}\right) / \mathbb{V}\left(\Delta^{k} n f a_{t+k}\right) .
\end{aligned}
$$

Capital flows also contribute to changes in the net external position. The approximation in (15) implies that $x p_{t}=\rho n f a_{t}+\rho n x_{t}^{*}$, so the $k$-period change in the external position can be written as

$$
\Delta^{k} x p_{t+k}=\rho \Delta^{k} n f a_{t+k}+\rho \Delta^{k} n x_{t+k}^{*}=\rho f l w_{t+k, k}+\rho \sum_{i=1}^{k}\left(r_{t+i}^{\mathrm{NFA}}+\Delta n x_{t+i}^{*}\right) .
$$




\section{Figure 8: Variance Contributions of Net Capital Flows}

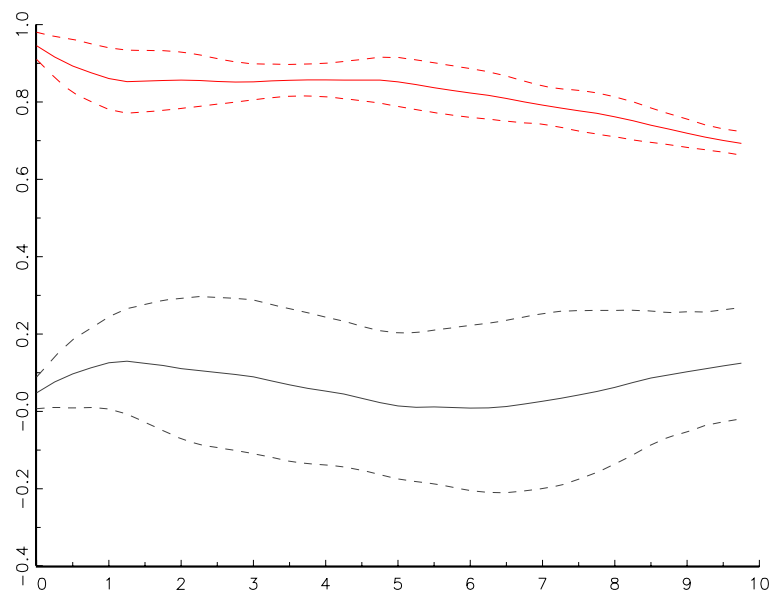

A: Contributions to the variance of $k$-period changes in the U.S. net foreign asset position, from expected differentials, $\beta_{n f a}^{\mathrm{VAL}}(k)$ solid black; news about differentials, $\beta_{n f a}^{\mathrm{V} \text {-NEws }}(k)$ solid red. 95 percent confidence bands marked by corresponding dashed lines.

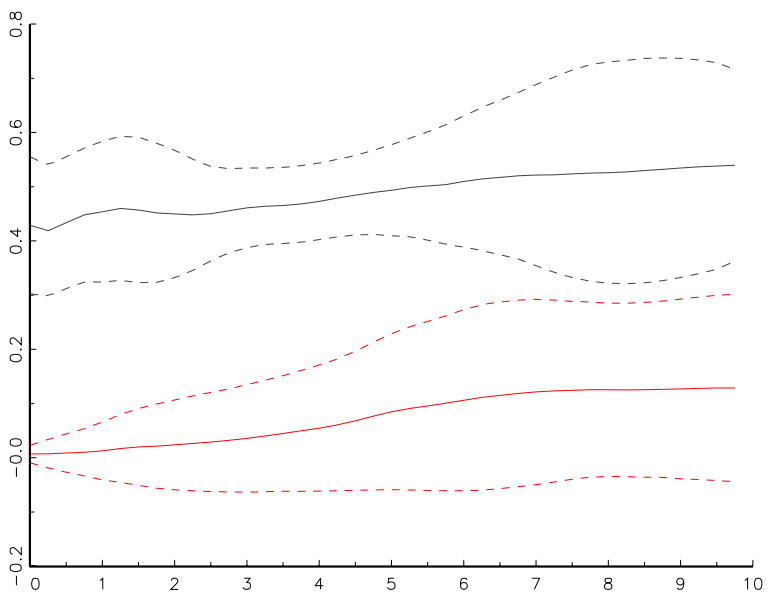

B: Contributions to the variance of $k$-period changes in the U.S. net external position, from changes in the net foreign asset position, $\beta_{x p}^{\mathrm{NFA}}(k)$ solid black; and from net capital flows $\beta_{x p}^{\mathrm{FLW}}(k) .95$ percent confidence bands marked by corresponding dashed lines.

The variance contributions of changing net asset positions and net capital flows are therefore given by

$$
\begin{aligned}
& \beta_{x p}^{\mathrm{NFA}}(k)=\rho \mathbb{C V}\left(\Delta^{k} n f a_{t+k}, \Delta^{k} x p_{t+k}\right) / \mathbb{V}\left(\Delta^{k} x p_{t+k}\right) \quad \text { and } \\
& \beta_{x p}^{\mathrm{FLW}}(k)=\rho \mathbb{C V}\left(f l w_{t+k, k}^{\mathrm{NFA}}, \Delta^{k} x p_{t+k}\right) / \mathbb{V}\left(\Delta^{k} x p_{t+k}\right) .
\end{aligned}
$$

Figure 8 plots the variance contributions $\beta_{n f a}^{\mathrm{VAL}}(k), \beta_{n f a}^{\mathrm{V}-\mathrm{NEWS}}(k), \beta_{x p}^{\mathrm{NFA}}(k)$ and $\beta_{x p}^{\mathrm{FLW}}(k)$ and their associated 95 percent confidence bands for horizons ranging from one quarter to ten years. Panel A shows that news about future returns is the dominant driver of changes in the U.S. net foreign asset position. The combined contribution of the expected and unexpected differentials, $\beta_{n f a}^{\mathrm{VAL}}(k)+\beta_{n f a}^{\mathrm{V}-\mathrm{NEWS}}(k)$, ranges from 0.99 at one quarter to 0.82 at ten years. From this perspective, net capital flows appear to be a rather minor driver of changes in the U.S. net asset position over short- and medium-term horizons. ${ }^{15}$ The plots in panel B show that net capital flows make a small but slowly rising contribution to changes in the net external position as the horizon increases, rising to approximately 10 per cent at ten years. This minor role for capital flows reflects the fact that they contribution little

\footnotetext{
${ }^{15}$ Of course the financial transactions embedded in net capital flows also change the composition of the foreign asset and liability portfolios, so the flows may indirectly contribute to changes in the net foreign asset position via the return differential. I will return to this point when examining how the changes in the composition of asset and liability portfolios affect returns in Section 6.1.
} 
to changes in the U.S. net foreign asset position, which in turn contribute roughly 50 percent of the variance in $\Delta^{k} x p_{t+k}$.

To summarize, the results above show that changes in expected future return differentials between foreign asset and liability portfolio are an empirically important driver of U.S. net capital flows; indeed they are a good deal more important than changes in expected future trade flows. At the same time, net capital flows have played a rather minor role as the driver of changes in the U.S. external position.

\subsection{Gross Capital Flows}

Recall that the period- $t$ flows of foreign assets and liabilities are related to existing gross holdings, exports, imports and net income flows by

$$
f l w_{t}^{\mathrm{FA}}=\frac{1-\rho}{\rho} \delta_{t}^{\mathrm{FA}}+\frac{1-\rho}{\rho}\left(x_{t}^{*}-y_{t}^{\mathrm{FL}}\right)+k \quad \text { and } \quad f l w_{t}^{\mathrm{FL}}=\frac{1-\rho}{\rho} \delta_{t}^{\mathrm{FL}}+\frac{1-\rho}{\rho}\left(m_{t}^{*}-y_{t}^{\mathrm{FA}}\right)+k .
$$

If we substitute for $\delta_{t}^{\mathrm{FA}}$ and $\delta_{t}^{\mathrm{FL}}$ from $(21)$ and (23a), we can rewrite these expressions as

$$
f l w_{t}^{\mathrm{FA}}=f l w_{t}^{\mathrm{COM}}+\frac{1}{2} f l w_{t} \quad \text { and } \quad f l w_{t}^{\mathrm{FL}}=f l w_{t}^{\mathrm{COM}}-\frac{1}{2} f l w_{t}
$$

where

$$
f l w_{t}^{\mathrm{COM}}=\frac{1-\rho}{2 \rho} \quad \mathbb{E}_{t} \sum_{i=1}^{\infty} \rho^{i}\left(\Delta y_{t+i}^{\mathrm{FA}}+\Delta y_{t+i}^{\mathrm{FL}}-r_{t+i}^{\mathrm{FA}}-r_{t+i}^{\mathrm{FL}}\right) .
$$

Equation (33) decomposes gross capital flows into a common component, $f l w_{t}^{\mathrm{CoM}}$, and one half times the net capital flow, $f l w_{t}$, identified in (19). The common component is the average of $f l w_{t}^{\mathrm{FA}}$ and $f l w_{t}^{\mathrm{FL}}$ when exports equal the net income on liabilities, and imports equal the net income on assets (i.e., $x_{t}^{*}=y_{t}^{\mathrm{FL}}$ and $m_{t}^{*}=y_{t}^{\mathrm{FA}}$ ).

Figure 9 plots the gross asset and liability flows, flw $w_{t}^{\mathrm{FA}}$ and $f l w_{t}^{\mathrm{FL}}$, together with estimates of the common component, $f l w_{t}^{\mathrm{COM}}$, over the sample period. I plot 4-quarter moving averages of each series for the sake of clarity. Panel A shows that the gross flows follow similar paths during some episodes and divergent paths during others. For example, asset and liability flows followed wildly divergent paths in the mid-1980s but very a similar path in the early 1990's. Panel B shows the path of the common component of gross flows, $f l w_{t}^{\mathrm{COM}}$. Here we see that the variations in $f l w_{t}^{\mathrm{COM}}$ are almost as large as those in the gross flows, and are mainly driven by changing expectations about future net income growth from assets and liabilities.

As above, we can compute the variance contributions of the gross flow components for different horizons. I define the $k$ - period gross flows as $f l w_{t+k, k}^{j}=\sum_{i=1}^{k} f l w_{t+i}^{j}$ for $j=\{\mathrm{FA}$, FL $\}$ and identify the variance contributions of the common, trade and valuation components for gross flow $j$ 


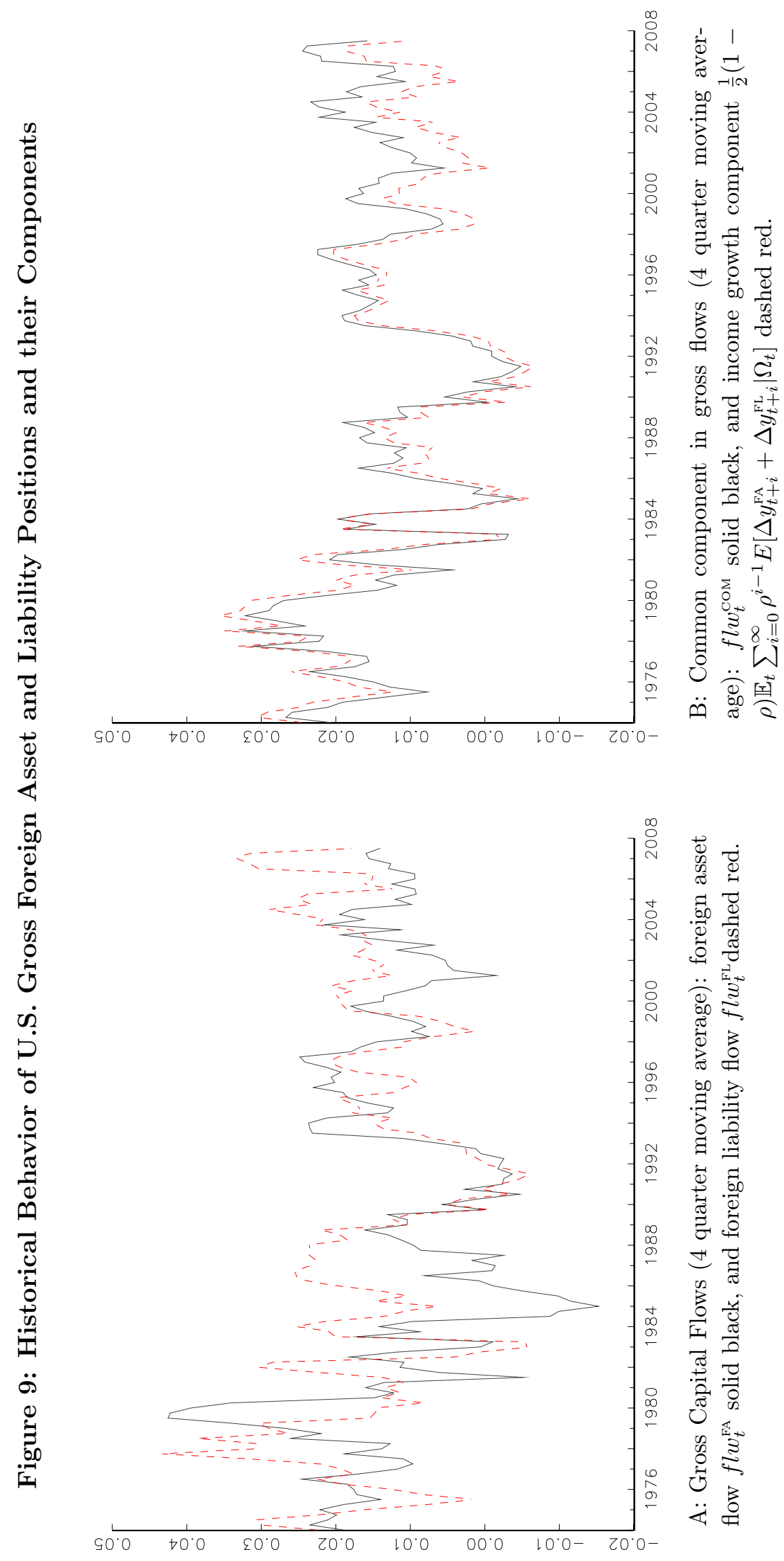


by

$$
\begin{aligned}
& \beta_{f l w^{j}}^{\mathrm{COM}}(k)=\mathbb{C V}\left(\sum_{i=1}^{k} f l w_{t+i}^{\mathrm{COM}}, f l w_{t+k, k}^{i}\right) / \mathbb{V}\left(f l w_{t+k, k}^{i}\right), \\
& \beta_{f l w^{j}}^{\mathrm{TR}}(k)=\frac{1-\rho}{2 \rho} \mathbb{C} \mathbb{V}\left(\sum_{i=1}^{k} x p_{t+i}^{\mathrm{TR}}, f l w_{t+k, k}^{i}\right) / \mathbb{V}\left(f l w_{t+k, k}^{i}\right) \quad \text { and } \\
& \beta_{f l w^{j}}^{\mathrm{VAL}}(k)=\frac{1-\rho}{2 \rho} \mathbb{C} \mathbb{V}\left(\sum_{i=1}^{k} x p_{t+i}^{\mathrm{VAL}}, f l w_{t+k, k}^{i}\right) / \mathbb{V}\left(f l w_{t+k, k}^{i}\right) .
\end{aligned}
$$

These decompositions use the fact that $f l w_{t}=\frac{1-\rho}{\rho}\left(x p_{t}^{\mathrm{TR}}+x p_{t}^{\mathrm{VAL}}\right)$ so $\beta_{f l w^{j}}^{\mathrm{TR}}(k)$ and $\beta_{f l w^{j}}^{\mathrm{VAL}}(k)$ measure the variance contributions of future trade flows and returns to gross capital flows.

\section{Figure 10: Variance Contributions to Gross Capital Flows}

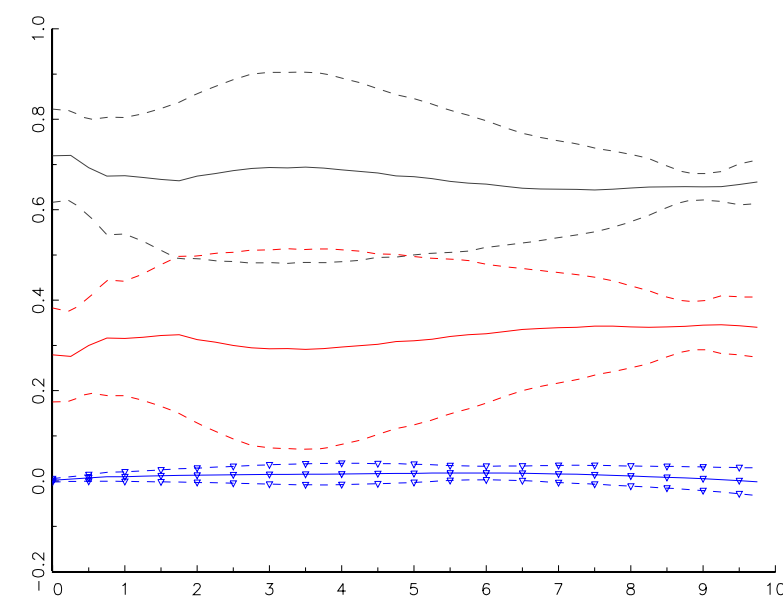

A: Contributions to the variance of $k$-period gross foreign asset flows from the common component, $\beta_{f l w^{\mathrm{FA}}}^{\mathrm{COM}}(k)$ solid black; valuation component $\beta_{f l w^{\mathrm{FA}}}^{\mathrm{VAL}}(k)$ solid red, and trade component $\beta_{f l w^{\mathrm{FA}}}^{\mathrm{TR}}(k)$ solid blue with triangles. 95 percent confidence bands marked by corresponding dashed lines.

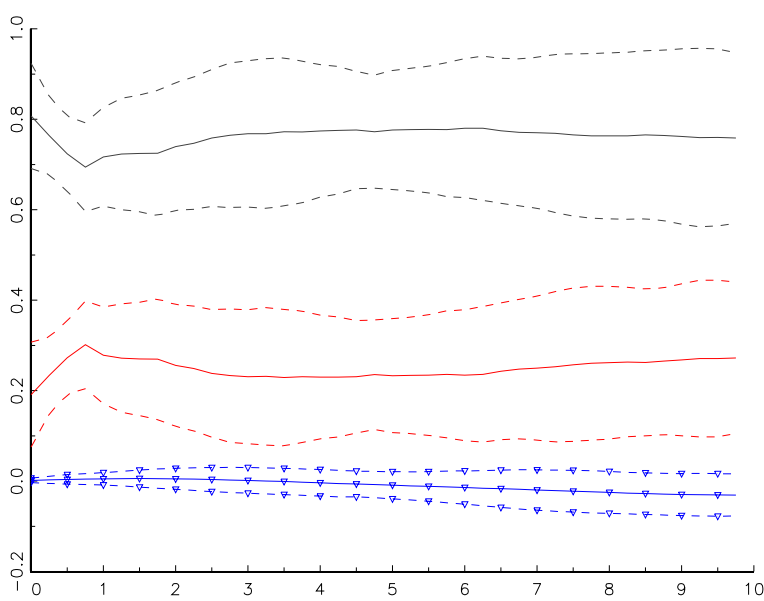

B: Contributions to the variance of $k$-period gross foreign liability flows from the common component, $\beta_{f l w^{\mathrm{FAL}}}^{\mathrm{COM}}(k)$ solid black; valuation component $\beta_{f l w^{\mathrm{LL}}}^{\mathrm{VAL}}(k)$ solid red, and trade component $\beta_{f l w^{\mathrm{FL}}}^{\mathrm{TR}}(k)$ solid blue with triangles. 95 percent confidence bands marked by corresponding dashed lines.

Figure 10 plots the variance contributions for the gross asset and liabilities flows computed from the baseline VAR for horizons ranging from one quarter to ten years. Here we see that there is very little variation in the contributions across different horizons. Changes in the common component account for approximately 70 percent of the variation in both asset and liability flows, while changes in the valuation component (expected return differentials) account for approximately 30 percent. Changing expectations concerning the future growth in net exports, make a negligible contribution to the gross flows at all horizons, a finding consistent with their small contribution to the variance 
of net capital flows shown in Figure 8a.

Information on the contribution of gross flows to the changes in asset and liability holdings is provided in Figure 11. Here I plot the variance contributions of expected and unexpected returns based on the decompositions of the $k$-period changes in asset and liability positions:

$$
\Delta^{k} f a_{t+k}=\sum_{i=1}^{k} r_{t+i}^{\mathrm{FA}}+f l w_{t+k, k}^{\mathrm{FA}} \quad \text { and } \quad \Delta^{k} f l_{t+k}=\sum_{i=1}^{k} r_{t+i}^{\mathrm{FL}}+f l w_{t+k, k}^{\mathrm{FL}} .
$$

The variance contributions of expected and unexpected returns to the change in foreign asset positions are computed from the baseline VAR as

$$
\begin{aligned}
& \beta_{f a}^{\mathrm{ERET}}(k)=\mathbb{C} \mathbb{V}\left(\sum_{i=1}^{k} \mathbb{E}\left[r_{t+i}^{\mathrm{FA}} \mid \Omega_{t}\right], \Delta^{k} f a_{t+k}\right) / \mathbb{V}\left(\Delta^{k} f a_{t+k}\right), \quad \text { and } \\
& \beta_{f a}^{\mathrm{URET}}(k)=\mathbb{C} \mathbb{V}\left(\sum_{i=1}^{k}\left(r_{t+i}^{\mathrm{FA}}-\mathbb{E}\left[r_{t+i}^{\mathrm{FA}} \mid \Omega_{t}\right]\right), \Delta^{k} f a_{t+k}\right) / \mathbb{V}\left(\Delta^{k} f a_{t+k}\right),
\end{aligned}
$$

with analogous decompositions for foreign liabilities. Note that the variance contribution of capital flows to changes in assets and liabilities over horizon $k$ are $1-\beta_{f a}^{\mathrm{ERET}}(k)-\beta_{f a}^{\mathrm{URET}}(k)$ and $1-\beta_{f l}^{\mathrm{ERET}}(k)-$ $\beta_{f l}^{\mathrm{URET}}(k)$, respectively.

\section{Figure 11: Variance Contributions of Gross Capital Flows}

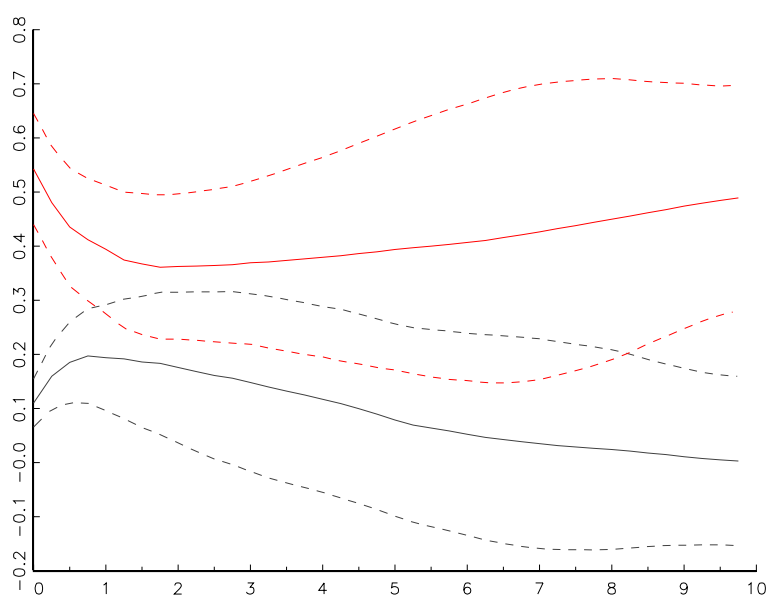

A: Contributions to the variance of $k$-period changes in the U.S. gross asset position, from expected returns $\beta_{f a}^{\mathrm{RET}}(k)$ solid black; and news about returns $\beta_{f a}^{\mathrm{R}-\mathrm{NEWs}}(k)$ solid red. 95 percent confidence bands marked by corresponding dashed lines.

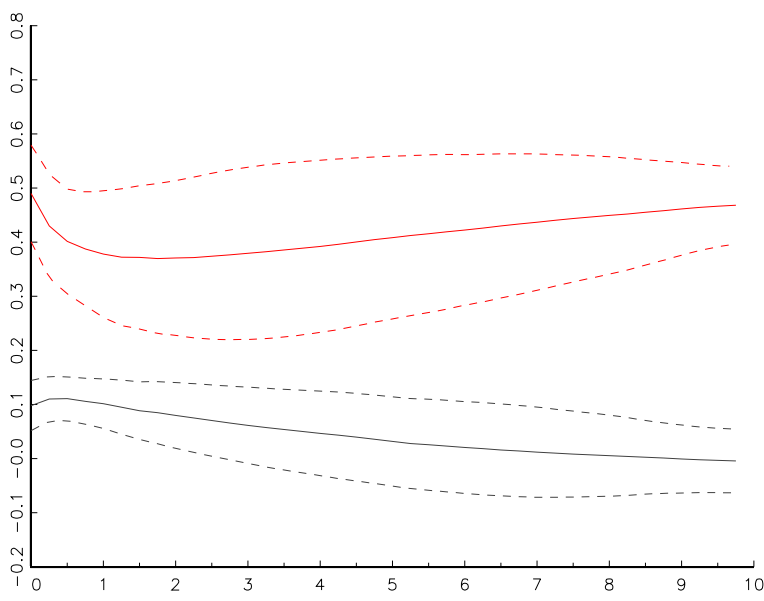

B: Contributions to the variance of $k$-period changes in the U.S. gross liability position, from expected returns $\beta_{f l}^{\mathrm{RET}}(k)$ solid black; and news about returns $\beta_{f l}^{\text {R-NEws }}(k)$ solid red. 95 percent confidence bands marked by corresponding dashed lines. 
Figure 11 shows that returns and capital flows make roughly similar contributions to changes in asset and liability positions across horizons ranging from one quarter to 10 years. Unexpected returns contribute between 40 and 50 percent across all horizons while variations in expected returns are smaller ranging between 20 percent and zero. The estimated contribution of expected returns to the changes in assets are somewhat larger than their contribution to changes in liabilities, but the difference is small compared to the confidence bands. The plots in Figure 11 also imply that gross capital flows contribute between 40 and 50 percent to the variance of position changes as the horizon rises from one quarter to 10 years. This finding contrasts with the results concerning the role of net capital flows. Recall from Figure 8 that net capital flows are a rather minor driver of the changes in the U.S. net financial position (i.e., $\Delta^{k} n f a_{t+k}$ ). The larger contribution of gross flows to changes in the U.S. asset and liability positions, $\Delta^{k} f a_{t+k}$ and $\Delta^{k} f l_{t+k}$, reflects the importance of the common flow component, flw $w_{t}^{\mathrm{COM}}$.

\section{U.S. Returns and The Exorbitant Privilege}

The results above show that predicable variations in the returns on U.S. foreign asset and liability portfolios have played an historically significant role in the evolution of the U.S. external position, and as a driver of both net and gross capital flows. In this final section I investigate the factors affecting the portfolio returns. Specifically, I address two questions: First, how do differences in the composition of the asset and liability portfolios contribute to the effects of expected future return differentials on the U.S. external position? Second, to what extent are the return differentials between U.S. asset and liability portfolios a reflection of variations in the international value of the dollar? These questions go the heart of whether the U.S. has enjoyed the so-called "exorbitantprivilege" of issuing a reserve currency and transforming savings from the rest of the world into risky capital.

\subsection{Portfolio Composition}

Section 5.1 showed that variations in the present value of the future portfolio return differentials were the major contributor to the evolution of the U.S. net external position, accounting for 75 percent of the sample variation. In principle, these predictable variations in the differentials can come from two sources. First, they may reflect predictability in the differentials within each securityclass (e.g., Equity, FDI, Debt, or Other). Second, predictability may reflect differences between the composition of the asset and liability portfolios. Recall that on average equity and FDI comprise a larger share of assets than liabilities (Table 2), and the relative shares have changed over the sample (Figure 4).

To quantify the importance of within-class return differentials and composition effects, I compute the $\log$ returns on two synthetic portfolios of assets and liabilities. The asset and liability returns 
are constructed as

$$
r_{t}^{\mathrm{FA}}\left(\alpha_{j, t}^{\mathrm{Z}}\right)=\ln \left(\sum_{j} \alpha_{j, t-1}^{\mathrm{Z}} R_{j, t}^{\mathrm{FA}}\right) \quad \text { and } \quad r_{t}^{\mathrm{FL}}\left(\alpha_{j, t}^{\mathrm{Z}}\right)=\ln \left(\sum_{j} \alpha_{j, t-1}^{\mathrm{Z}} R_{j, t}^{\mathrm{FL}}\right)
$$

where $R_{j, t}^{\mathrm{FA}}$ and $R_{j, t}^{\mathrm{FL}}$ are the gross returns on class $j$ asset and liability, respectively. The first pair of synthetic portfolios use the average share for each asset and liability class, giving log returns of $r_{t}^{\mathrm{FA}}\left(\overline{\alpha_{j}^{\mathrm{FA}}}\right)$ and $r_{t}^{\mathrm{FL}}\left(\overline{\alpha_{j}^{\mathrm{FL}}}\right)$ where $\alpha_{j, t-1}^{\mathrm{Z}}=\overline{\alpha_{j}^{\mathrm{Z}}}$ for all $j$. Comparing $r_{t}^{\mathrm{FA}}\left(\overline{\alpha_{j}^{\mathrm{FA}}}\right)$ and $r_{t}^{\mathrm{FL}}\left(\overline{\alpha_{j}^{\mathrm{FL}}}\right)$ with the actual returns, $r_{t}^{\mathrm{FA}}$ and $r_{t}^{\mathrm{FL}}$, provides information on how time-varying changes in the composition of asset and liability portfolios contributes to returns. The second pair of synthetic portfolios use the average of the asset and liability share for each class of assets. This gives log returns of $r_{t}^{\mathrm{FA}}\left(\alpha_{j, t}^{\mathrm{AV}}\right)$ and $r_{t}^{\mathrm{FL}}\left(\alpha_{j, t}^{\mathrm{AV}}\right)$ where $\alpha_{j, t}^{\mathrm{av}}=\frac{1}{2} \alpha_{j, t}^{\mathrm{FA}}+\frac{1}{2} \alpha_{j, t}^{\mathrm{FL}}$ for all $j$. Here any difference between $r_{t}^{\mathrm{FA}}\left(\alpha_{j, t}^{\mathrm{AV}}\right)$ and $r_{t}^{\mathrm{FL}}\left(\alpha_{j, t}^{\mathrm{AV}}\right)$ must original from differences between the returns within each class because the the asset and liability portfolios contain the same (time-varying) shares.

Table 6 compares the behavior of log excess returns on actual asset and liability portfolios with the returns computed from synthetic portfolios over the whole sample period. Panels A and B show that average excess returns on the synthetic portfolios are lower than on the actual portfolios, while their sample standard deviations are generally higher. These differences combine to produce lower Sharpe ratios for the synthetic portfolios than their actual counterparts. This is particularly noticeable in the case of liability portfolio using average shares, $\alpha_{j, t}^{\mathrm{AV}}$, where the Sharpe ratio is 30 percent smaller. Panel $\mathrm{C}$ compares the log return differentials from the actual and synthetic portfolios. Here, in contrast to the statistics in Panels $\mathrm{A}$ and $\mathrm{B}$, the differential using average portfolio shares has a higher average and lower standard deviation over the sample than the actual differential. According to this metric, the U.S. does not appear to have benefited from composition effects. On the contrary, they appear to have reduce average excess returns. This finding is consistent with the results in Habib (2010) based on returns from 1986 and 2007. However, Gourinchas and Rey (2007a) estimate that composition effects added to average excess returns in other sample periods. They also argue that the effects have become increasingly important over time. I shall return to this point below.

The right-hand columns of Table 6 show how time-variation and differences in the composition of asset and liability portfolios contribute to the log excess returns and return differentials. The statistics in Panels A and B show that the log excess returns on the synthetic portfolios account for almost all the variation in actual log excess returns for both assets and liabilities. This means that most of the volatility in excess returns originates from the volatility of the underlying returns within each security class. For example, the estimated contribution of 1.011 from $r_{t}^{\mathrm{FL}}\left(\overline{\alpha^{\mathrm{FL}}}\right)-r_{t}$ to the volatility in $r_{t}^{\mathrm{FL}}-r_{t}$ implies that time-varying liability shares contribute only one percent to the overall volatility in excess liability returns over the sample - an economically insignificant amount. Composition effects are more important in return differentials. The estimated contribution of 0.805 by $r_{t}^{\mathrm{FA}}\left(\alpha_{t}^{\mathrm{AV}}\right)-r_{t}^{\mathrm{FL}}\left(\alpha_{t}^{\mathrm{AV}}\right)$ to the volatility of $r_{t}^{\mathrm{NFA}}$ implies that differences between the composition of asset and liability portfolios account for approximately 20 percent of the volatility in actual return differentials. 


\title{
Table 6: Portfolio Returns and Their Components
}

\begin{tabular}{|c|c|c|c|c|c|c|}
\hline \multirow{2}{*}{$\begin{array}{l}\text { Return } \\
\text { (i) }\end{array}$} & \multirow{2}{*}{$\begin{array}{c}\text { Mean } \\
\text { (ii) }\end{array}$} & \multirow{2}{*}{$\begin{array}{l}\text { Std. } \\
\text { (iii) }\end{array}$} & \multirow{2}{*}{$\begin{array}{c}\text { Sharpe } \\
\text { Ratio } \\
\text { (iv) }\end{array}$} & \multicolumn{3}{|c|}{ Variance Contributions } \\
\hline & & & & $\begin{array}{l}\text { lower } \\
(\mathrm{v})\end{array}$ & $\begin{array}{l}\text { estimate } \\
\text { (vi) }\end{array}$ & $\begin{array}{l}\text { upper } \\
\text { (vii) }\end{array}$ \\
\hline \multicolumn{7}{|l|}{ A: Assets } \\
\hline$r_{t}^{\mathrm{FA}}-r_{t}$ & 1.778 & 13.524 & 0.148 & & & \\
\hline$r_{t}^{\mathrm{FA}}\left(\overline{\alpha^{\mathrm{FA}}}\right)-r_{t}$ & 1.504 & 14.219 & 0.123 & 0.968 & 1.029 & 1.090 \\
\hline$r_{t}^{\mathrm{FA}}\left(\alpha_{t}^{\mathrm{AV}}\right)-r_{t}$ & 1.339 & 12.923 & 0.119 & 0.926 & 0.950 & 0.974 \\
\hline \multicolumn{7}{|l|}{ B: Liabilities } \\
\hline$r_{t}^{\mathrm{FL}}-r_{t}$ & 1.459 & 10.608 & 0.151 & & & \\
\hline$r_{t}^{\mathrm{FL}}\left(\overline{\alpha^{\mathrm{FL}}}\right)-r_{t}$ & 1.272 & 10.924 & 0.131 & 0.945 & 1.011 & 1.078 \\
\hline$r_{t}^{\mathrm{FL}}\left(\alpha_{t}^{\mathrm{AV}}\right)-r_{t}$ & 0.936 & 11.603 & 0.096 & 1.006 & 1.066 & 1.127 \\
\hline \multicolumn{7}{|l|}{ C: Net Assets } \\
\hline$r_{t}^{\mathrm{NFA}}=r_{t}^{\mathrm{FA}}-r_{t}^{\mathrm{FL}}$ & 0.318 & 8.485 & & & & \\
\hline$r_{t}^{\mathrm{FA}}\left(\overline{\alpha^{\mathrm{FA}}}\right)-r_{t}^{\mathrm{FL}}\left(\overline{\alpha^{\mathrm{FL}}}\right)$ & 0.232 & 8.557 & & 0.926 & 0.978 & 1.030 \\
\hline$r_{t}^{\mathrm{FA}}\left(\alpha_{t}^{\mathrm{AV}}\right)-r_{t}^{\mathrm{FL}}\left(\alpha_{t}^{\mathrm{AV}}\right)$ & 0.403 & 7.709 & & 0.716 & 0.805 & 0.893 \\
\hline
\end{tabular}

\begin{abstract}
Notes: All statistics are computed for the entire sample period: 1973:I-2007:IV. Columns (ii) and (iii) report the sample means and standard deviations for the log returns listed in column (i). $r_{t}^{\mathrm{Z}}\left(\overline{\alpha^{\mathrm{z}}}\right)$ denotes the $\log$ return on a portfolio of foreign assets $(\mathrm{z}=\mathrm{FA})$ and liabilities $(\mathrm{z}=\mathrm{FL})$ with constant portfolio shares equal to the average share in the sample. $r_{t}^{\mathrm{Z}}\left(\alpha_{t}^{\mathrm{AV}}\right)$ denotes the log return on a portfolio of foreign assets $(\mathrm{z}=\mathrm{FA})$ and liabilities $(\mathrm{z}=\mathrm{FL})$ with time-varying shares equal to the average of the shares for each asset and liability class. All log returns are multiplied by 400 . Column (iii) reports the Sharpe ratio calculated as the sample average of gross excess returns $R_{t}^{j}-R_{t}$, divided by their sample standard deviation. Column (vi) reports the OLS estimate of the slope coefficient from a regression of the component listed in column (i) on $r_{t}^{\mathrm{FA}}-r_{t}$ in panel $\mathrm{A}$, $r_{t}^{\mathrm{FL}}-r_{t}$ in panel $\mathrm{B}$, and on $r_{t}^{\mathrm{FA}}-r_{t}^{\mathrm{FL}}$ in panel C. Columns (v) and (vii) report the lower and upper 95 percent bounds associated with the slope estimates computed as $\hat{\beta} \pm 1.96 \hat{\sigma}^{2}$, where $\hat{\sigma}$ is the coefficient standard error computed from the White (1980) procedure.
\end{abstract}

The results in Table 6 show that differences in the composition of the asset and liability portfolios have some measurable effects on return differentials, but they do not establish whether these differences contribute significantly to the historical evolution of the U.S. external position. To address this issue, I added the synthetic differential $r_{t}^{\mathrm{SYN}}=r_{t}^{\mathrm{FA}}\left(\alpha_{t}^{\mathrm{AV}}\right)-r_{t}^{\mathrm{FL}}\left(\alpha_{t}^{\mathrm{AV}}\right)$ as a variable to the baseline VAR and used the estimates to compute an alternative measure of the valuation component: $\widehat{x p}_{t}^{\text {SYN }}=-\sum_{i=1}^{\infty} \rho^{i} \mathbb{E}\left[r_{t+i}^{\text {SYN }} \mid \Omega_{t}\right]$. Figure 12 a plots $\widehat{x p}_{t}^{\text {SYN }}$ together with the external position, $x p_{t}$, and estimates of the valuation component: $\widehat{x p}_{t}^{\mathrm{VAL}}=-\sum_{i=1}^{\infty} \rho^{i} \mathbb{E}\left[r_{t+i}^{\mathrm{NFA}} \mid \Omega_{t}\right]$. Overall, the plots show that there is little difference between $\widehat{x p}_{t}^{\mathrm{VAL}}$ and $\widehat{x p}_{t}^{\text {SYN }}$, although the values for $\widehat{x p}_{t}^{\mathrm{VAL}}$ are slightly lower in the last decade of the sample. In this period the U.S. did benefit from portfolio composition effects 


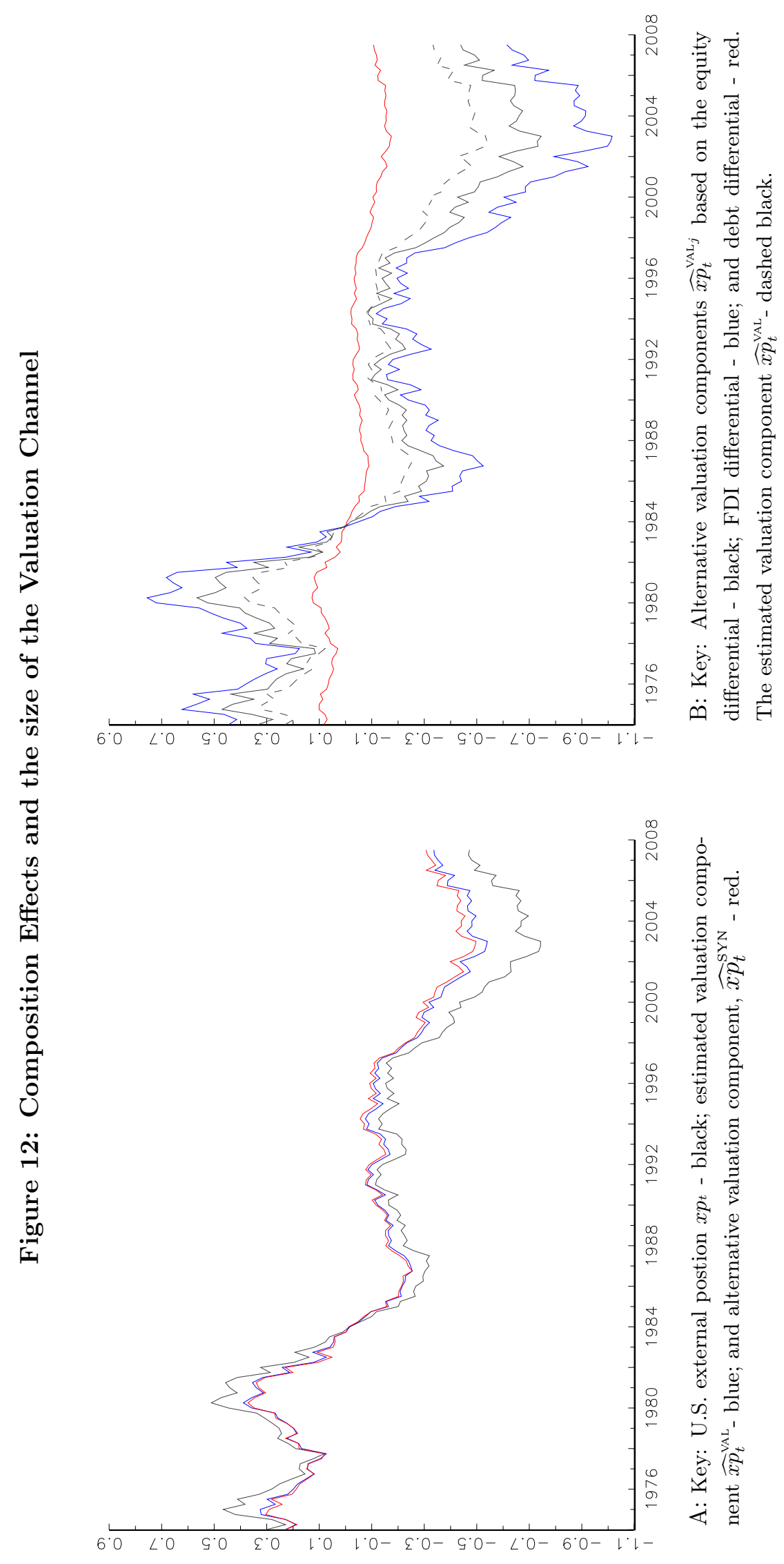


in the sense that it was able to carry roughly a 3 percent larger foreign liability-to-asset ratio without threatening its international solvency. In this respect my findings are consistent with the view that composition effects have become increasingly important (Gourinchas and Rey, 2007a), but it is hard to argue that the U.S. enjoyed a significant economic benefit in its capacity of transforming world savings into risky capital.

These findings contrast with the view that the U.S. has benefited significantly from the concentration of its asset holdings in equity and FDI and its liabilities in debt. While Table 6 shows that there are measurable composition effects in average return differentials and their volatility, they have no significant influence on (estimated) expected future return differentials that determine the size of the valuation component. This means that the valuation component's contribution to the evolution of the U.S. external position must originate in the expected return differentials within classes of securities (e.g., Equity, FDI, Debt, Other). Figure 12b provides evidence confirming this conjecture. Here I plot alternative estimates of the valuation component based on the equity, FDI and debt differentials: i.e., $\widehat{x p}_{t}^{\mathrm{VAL}_{j}}=-\sum_{i=1}^{\infty} \rho^{i} \mathbb{E}\left[r_{t+i}^{\mathrm{NFA}_{j}} \mid \Omega_{t}\right]$, where $r_{t}^{\mathrm{NFA}_{j}}$ is the difference between the log returns on assets and liabilities in class $j=\{$ Equity, FDI, Debt $\}$, using VARs with $r_{t}^{\mathrm{NFA}_{j}}$ as an additional variable. These plots show that variations in the present values of the equity and FDI return differentials are much larger than the variations in the valuation component, while variations in the present value of the debt differential are a good deal smaller. Clearly, variations in expected future return differentials on equity and FDI that are the main drivers of the U.S. valuation component. While there is a well-established literature documenting the differences between the returns on FDI assets and liabilities, my results suggest that the U.S. enjoyed a substantial economic benefit from persistent predictable variations in FDI return differentials. ${ }^{16}$

\subsection{The Role of the Dollar}

If variations in the U.S. valuation component primarily reflect changes in the expect return differentials within security classes, to what extent are these changes related to movements in the international value of the dollar? To address this question, I first examine the exposure of returns to variations in the dollar's international value. Specifically, Table 7 shows regression estimates of log real returns on a constant and the quarterly real depreciation of the dollar against a broad, trade-weighted basket of foreign currencies: $r_{t}^{j}=\gamma_{0}+\gamma \Delta \varepsilon_{t}+\eta_{t}$. Panels A and B report estimates from regressions using log returns on assets and liabilities, while those in Panel $\mathrm{C}$ show the estimates from regressions that use return differentials between asset and liabilities.

\footnotetext{
${ }^{16}$ A partial list of papers studying FDI returns includes: Raymond Jr (2000); Hung and Mascaro (2004); Higgins, Klitgaard, and Tille (2005); ECB (2006); Gros (2006) and Bosworth, Collins, and Chodorow-Reich (2007).
} 
Table 7: Returns and the Dollar Depreciation Rates

\begin{tabular}{|c|c|c|c|c|}
\hline & \multicolumn{4}{|c|}{$r_{t}^{j}=\gamma_{0}+\gamma \Delta \varepsilon_{t}+\eta_{t}$} \\
\hline & $\hat{\gamma}$ & Std. & t-stat. & $R^{2}$ \\
\hline \multicolumn{5}{|l|}{ A: Assets } \\
\hline All & 0.385 & $(0.085)$ & 4.545 & 0.149 \\
\hline Equity & 0.841 & $(0.232)$ & 3.621 & 0.130 \\
\hline FDI & 0.586 & $(0.191)$ & 3.071 & 0.087 \\
\hline Debt & 0.559 & $(0.067)$ & 8.338 & 0.329 \\
\hline \multicolumn{5}{|l|}{ B: Liabilities } \\
\hline All & 0.112 & $(0.080)$ & 1.406 & 0.019 \\
\hline Equity & 0.224 & $(0.265)$ & 0.845 & 0.008 \\
\hline FDI & 0.173 & $(0.189)$ & 0.912 & 0.009 \\
\hline Debt & 0.231 & $(0.082)$ & 2.812 & 0.052 \\
\hline \multicolumn{5}{|l|}{ C: Differentials } \\
\hline All & 0.273 & $(0.045)$ & 6.025 & 0.189 \\
\hline Equity & 0.617 & $(0.115)$ & 5.363 & 0.155 \\
\hline FDI & 0.413 & $(0.082)$ & 5.057 & 0.146 \\
\hline Debt & 0.328 & $(0.035)$ & 9.420 & 0.463 \\
\hline D: Net Exports & 0.013 & $(0.073)$ & 0.172 & 0.000 \\
\hline
\end{tabular}

Notes: The table reports the estimated slope coefficient, $\gamma$, the standard error, t-statistic, and $R^{2}$ statistic from regressions of log returns on the real effective depreciation rate for the dollar, $\Delta \varepsilon_{t}$, at the quarterly frequency over 1973:I2007:IV. Panel D reports the results from regressing the change in net exports, $\Delta n x_{t}^{*}$ on $\Delta \varepsilon_{t}$. Heteroskedastically consistent standard errors and t-statistics are computed from the White (1980) procedure.

The regression estimates in Panels $\mathrm{A}$ and $\mathrm{B}$ of Table 7 show that the exposure of U.S. foreign assets and liabilities to variations in the international value of the dollar are quite different from one another. In Panel A, the estimated slope coefficients are all positive and highly statistically significant. To interpret this finding, note that a rise in $\varepsilon_{t}$ represents a real depreciation of the dollar, or a fall in its international value. Thus, on average, the realized real return on foreign assets increased during quarters when there was a fall in the value of the dollar. ${ }^{17}$ The estimates in Panel

\footnotetext{
${ }^{17}$ For perspective, if the real returns on assets were constant when measured in terms of foreign consumption in a particular country, real returns measured in terms of U.S. consumption would move one-for-one with the real exchange rate measured on a bilateral basis. Here we are comparing returns on portfolios of assets from many foreign countries with the real deprecation rate computed from a trade-weighted basket, so there is no simple structural interpretation
} 
B show a different pattern. Here only the real returns on U.S. foreign debt liabilities display any statistically significant sensitivity to the real depreciation rate. Notice, too, that the $R^{2}$ statistics from these regressions are much lower than their counterparts in Panel A. Much more of the variation in the real returns on U.S. foreign assets are associated with variations in the international value of the dollar that the variation in the real returns on U.S. foreign liabilities.

Of course variations in the international value of the dollar affect the U.S. external position through returns differentials rather that through the returns on assets and liabilities individually. The estimates in Panel C quantify these effects. Here we see that the asymmetric exposures of asset and liability returns lead to significant exposures across all the differentials: all the estimates of $\gamma$ are positive and highly statistically significant. For example, a one percent real depreciation of the dollar is associated with an increase in the total return differential of 27 basis points, while the equity and FDI differentials rise by 62 and 41 basis points, respectively. These results contrast with the exposure of trade flows. Panel D shows that there is no statically significant relationship between the growth in net exports $\Delta n x_{t}^{*}$ and the real depreciation rate.

The results in Panel $\mathrm{C}$ of Table 7 establish that there was a strong statistical link between variations in the international value of the dollar and real return differentials between U.S. foreign assets and liabilities. Consequently, it is quite possible that the expectations concerning future differentials that drive the U.S. valuation component also embed expectations about changes in the future international value of the dollar. If this is the case, we can decompose the valuation component into two uncorrelated sub-components:

$$
x p_{t}^{\mathrm{VAL}}=\left\{-\sum_{i=1}^{\infty} \rho^{i} \mathbb{E}\left[\eta_{t+i} \mid \Omega_{t}\right]\right\}+\left\{-\gamma \sum_{i=1}^{\infty} \rho^{i} \mathbb{E}\left[\Delta \varepsilon_{t+i} \mid \Omega_{t}\right]\right\},
$$

where $r_{t}^{\mathrm{NFA}}=\gamma \Delta \varepsilon_{t}+\eta_{t} .{ }^{18}$ The first term on the right identifies the contribution of expectations concerning future return differentials that are uncorrelated with future real depreciation rates; the second term identifies the contribution from expected future changes in the value of the dollar. Clearly, non-zero values for $\gamma$ are necessary but not sufficient to produce valuation effects related to the value of the dollar.

Figure 13 plots the U.S. external position, $n x_{t}$, the valuation component, $x p_{t}^{\mathrm{VAL}}$, and the nondollar sub-component $-\sum_{i=1}^{\infty} \rho^{i} \mathbb{E}\left[\hat{\eta}_{t+i} \mid \Omega_{t}\right]$, computed from estimates of the baseline VAR with the residuals $\hat{\eta}_{t}=r_{t}^{\mathrm{NFA}}-\hat{\gamma} \Delta \varepsilon_{t}$ as an additional variable. These plots suggest that the historical variations in the valuation component embedded significant expectations concerning the future real depreciation of the dollar. Before 1984, for example, expectations of a real dollar appreciation increased the value of U.S. foreign assets relative to liabilities. This period was dominated by a very large rise in the international value of the dollar. More recently, dollar expectations have worked in the opposite direction. Since the late 1990's expectations about the future depreciation of the of $\gamma$.

${ }^{18}$ I ignore the regression constant, which is statistically insignificant. 
Figure 13: The U.S. Net External Position and the Role of the Dollar

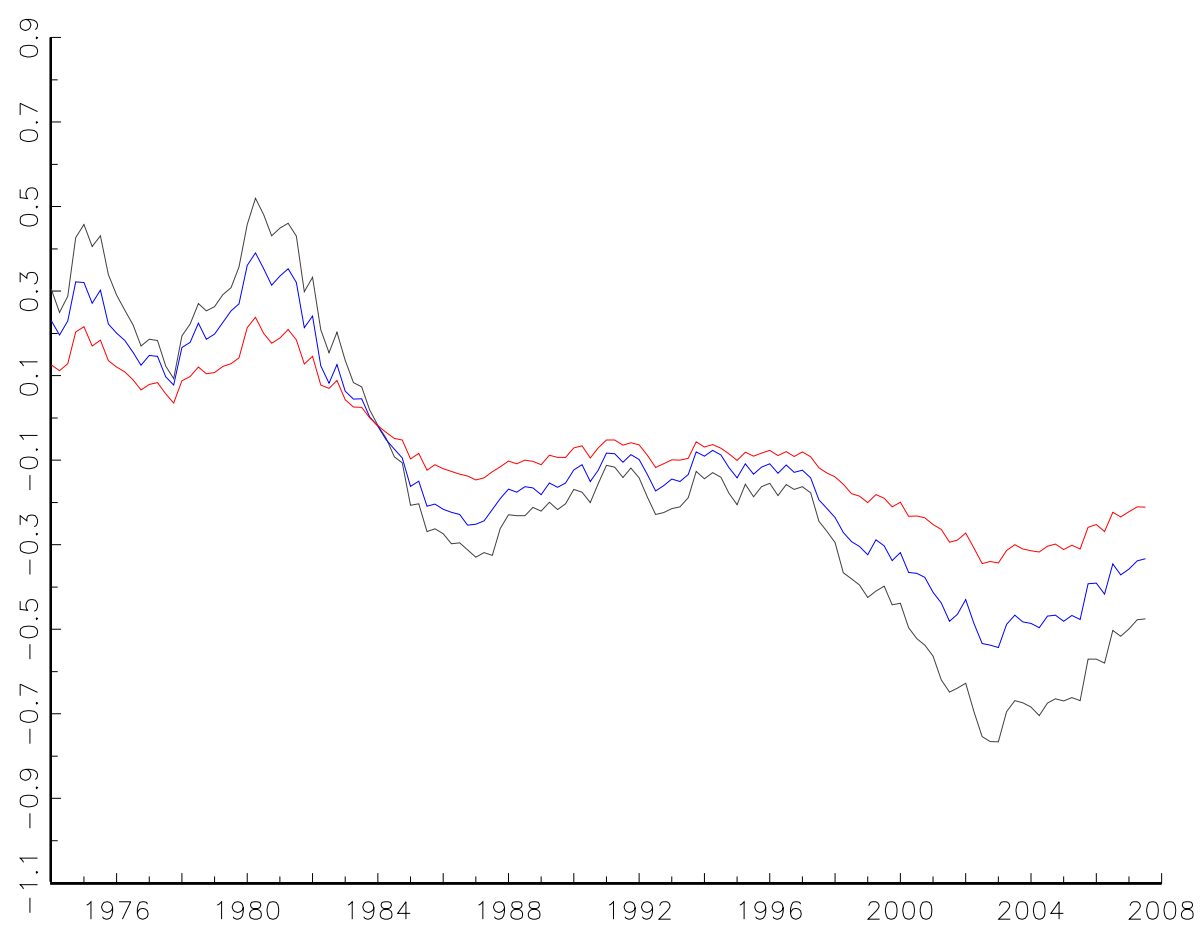

Key: U.S. external position $x p_{t}$ - black; valuation component $\widehat{n p}_{t}^{\mathrm{VAL}}$ - blue; and valuation without expected depreciation $-\sum_{i=1}^{\infty} \rho^{i} \mathbb{E}\left[\hat{\eta}_{t+i} \mid \Omega_{t}\right]$ - red.

dollar have pushed the valuation component well below the level of the non-dollar sub-component. In other words, much of the marked deterioration in the U.S. external position between 1998 and 2003 is attributable to expectations of a real dollar depreciation that was associated with higher expected future return differentials.

To summarize, Figures 12 and 13 provide a useful perspective on the view that the U.S. enjoyed an "exorbitant-privilege" in the post Bretton Woods era. My model estimates indicate that the dominant driver of the secular deterioration in the U.S. position during this period was the revaluation of U.S. foreign asset and liabilities positions as agents revised their expectations about future portfolio returns. While ex post returns were affected by portfolio composition effects, I find no evidence that the U.S. was able to sustain a significantly larger net debtor position because the composition of its foreign asset and liability portfolios were mismatched. Instead, the U.S. appears to have derived its greatest benefit since the mid-1990's from high expected returns on its equity and FDI asset holdings, that in turn appear significantly linked to expectations of a future real dollar depreciation. To be clear, these findings do not question the role the U.S. played in transforming savings from the rest of the world into risky capital, only the idea that the U.S. was able to become such a large international debtor because of this role. Similarly, my results do not provide direct evidence on the role of the dollar as a reserve currency, they simply quantify the importance of the dollar expectations as drivers of the U.S. external position. 


\section{Conclusion}

The requirements of international solvency link a country's foreign asset and liability positions to expectations concerning future trade flows and returns. The model developed in this paper uses these links to identify the determinants of gross asset and liability positions and their associated

trade flows. In so doing, I provide an integrated framework for examining the real and financial factors that affect the evolution of any country's external position.

Applying the model to U.S. data between 1973 and 2008 produces a number of striking results. First, revisions in the expected future return differential between foreign assets and liabilities were the dominant driver of the U.S. external position, even though the average differential was very small. Second, capital flows contribute significantly to changes in gross asset and liability positions but play a minor role in driving changes in the net external position. Third, there is no evidence that the U.S. was able to sustain a significantly larger net debtor position because the composition of its foreign asset and liability portfolios were mismatched. Instead, the U.S. appears to have derived its greatest benefit since the mid-1990's from high expected returns on its equity and FDI asset holdings, that in turn appear linked to expectations of a future real dollar depreciation.

Finally, let me offer a perspective on these findings. My empirical results are derived from the historical relationships between the U.S. external position, trade flows and returns as summarized by the VAR estimates. As such, there is no guarantee that the estimates of future expected trade flows and returns will be invariant to future policy and structural changes in the world economy. I focused on the pre 2008 crisis period for this very reason. Although the theoretical links between a country's asset and liability positions and expectations concerning future trade flows and returns identified by the model continue to hold under conditions of severe financial stress, estimating expectations from a simple VAR is more questionable. Similarly, while the theoretical framework can accommodate the presence of capital controls and other policy-induced frictions on international transactions, identifying how a future change in policy would affect capital flows and the external position requires the delicate task of estimating the effect on expectations.

\section{References}

Bertaut, C.C. and R.W. Tryon. 2007. "Monthly estimates of US cross-border securities positions." FRB International Finance Discussion Papers No. 910 .

Bosworth, B., S.M. Collins, and G. Chodorow-Reich. 2007. "Returns on Foreign Direct Investment: Does the United States Really Do Better?" In Brookings Trade Forum, vol. 2007. Brookings Institution Press, 177-210.

Campbell, J.Y. and R.J. Shiller. 1987. "Cointegration and tests of present value models." The Journal of Political Economy 95 (5). 
Coeurdacier, N., R. Kollmann, and P. Martin. 2010. "International portfolios, capital accumulation and foreign assets dynamics." Journal of International Economics 80 (1):100-112.

Curcuru, S.E., T. Dvorak, and F.E. Warnock. 2007. "Cross-border returns differentials." Quarterly Journal of Economics .

Devereux, Michael B. and Alan Sutherland. 2010. "Country portfolio dynamics." Journal of Economic Dynamics and Control 34 (7):1325 - 1342. URL http://www.sciencedirect.com/ science/article/pii/S0165188910000667.

ECB. 2006. "Financial Stability Review." Tech. rep., European Central Bank.

Evans, Martin D. D. 2012. "Exchange-Rate Dark Matter." IMF Working Papers 12/66, International Monetary Fund. URL http://ideas.repec.org/p/imf/imfwpa/12-66.html.

Evans, Martin D. D. and Viktoria Hnatkovska. 2005. "International Capital Flows, Returns and World Financial Integration." Working Paper 11701, National Bureau of Economic Research. URL http://www.nber.org/papers/w11701.

- 2007. "International Financial Integration and the Real Economy." IMF Staff Papers $54: 220-269$.

Forbes, K.J. 2009. "Why do foreigners invest in the United States?" Journal of International Economics .

Gohrband, C. and K. Howell. 2010. "US International Financial Flows and the US Net Investment Position: New Perspectives Arising from New International Standards." In NBER-CIW Conference on Wealth, Financial Intermediation and the Real Economy. National Bureau of Economic Research, Inc.

Gourinchas, Pierre-Olivier and Hélène Rey. 2005. "From World Banker to World Venture Capitalist: US External Adjustment and the Exorbitant Privilege." Working Paper 11563, National Bureau of Economic Research. URL http://www.nber.org/papers/w11563.

Gourinchas, P.O. and H. Rey. 2007a. "From world banker to world venture capitalist: US external adjustment and the exorbitant privilege." G7 Current Account Imbalances: Sustainability and Adjustment. University of Chicago Press.

—. 2007b. "International financial adjustment." Journal of Political Economy 115 (4):665-703.

Gros, D. 2006. "Foreign investment in the U.S. (II): Being taken to the cleaners?" Working Paper 243, Center for European Policy Studies.

Habib, Maurizio Michael. 2010. "Excess Returns on Net Foreign Assets: The Exorbitant Privilege From a Global Perspective." Tech. rep., ECB Working Paper No. 1158. 
Hausmann, R., F. Sturzenegger, John F. Kennedy School of Government, and Harvard University. Center for International Development. 2006. Global Imbalances Or Bad Accounting?: The Missing Dark Matter in the Wealth of Nations. John F. Kennedy School of Government, Harvard University.

Higgins, M., T. Klitgaard, and C. Tille. 2005. "The income implications of rising US international liabilities." Current Issues in Economics and Finance, Vol. 11, No. 12, December 2005.

Hnatkovska, Viktoria. 2010. "Home bias and high turnover: Dynamic portfolio choice with incomplete markets." Journal of International Economics 80 (1):113 - 128.

Hung, J.H. and A. Mascaro. 2004. "Return on cross-border investment: why does US investment abroad do better?" CBO Technical Paper Series 17.

Lane, Philip R. and Gian Maria Milesi-Ferretti. 2005. "A Global Perspective on External Positions." Working Paper 11589, National Bureau of Economic Research. URL http://www.nber.org/ papers/w11589.

Lane, P.R. and G.M. Milesi-Ferretti. 2009. "Where did all the borrowing go? A forensic analysis of the US external position." Journal of the Japanese and International Economies 23 (2):177-199.

Magud, N.E., C.M. Reinhart, and K.S. Rogoff. 2011. "Capital Controls: Myth and Reality-A Portfolio Balance Approach." Tech. rep., National Bureau of Economic Research.

Meissner, Christopher M. and Alan M. Taylor. 2006. "Losing our Marbles in the New Century? The Great Rebalancing in Historical Perspective." Working Paper 12580, National Bureau of Economic Research. URL http://www.nber.org/papers/w12580.

Obstfeld, M. and K. Rogoff. 1995. "The intertemporal approach to the current account." Handbook of international economics 3:1731-1799.

Obstfeld, M. and K.S. Rogoff. 2005. "Global current account imbalances and exchange rate adjustments." Brookings papers on economic activity 2005 (1):67-123.

Raymond Jr, J. 2000. "An examination of the low rates of return on foreign-owned US companies." Survey of Current Business 80 (3):55.

Tille, C. and E. Van Wincoop. 2010. "International Capital Flows." Journal of International Economics 80 (2):157-175.

White, H. 1980. "A heteroskedasticity-consistent covariance matrix estimator and a direct test for heteroskedasticity." Econometrica: Journal of the Econometric Society :817-838. 


\section{Appendix.}

I compute the bootstrap distribution for the Wald statistic in the following steps:

1. I draw a bootstrap sample of errors from the estimated VAR residuals equal to the length of the data sample $T$, and construct the sequence of error terms for the companion form: $\left\{\widetilde{U}_{t}\right\}_{t=1}^{T}$. I also draw a bootstrap sample from the estimated specification errors using the estimated value for $\rho, \hat{\rho}:\left\{\tilde{v}_{t}\right\}_{t=1}^{T}$.

2. I recursively compute a bootstrap sample for $\left\{\widetilde{Z}_{t}\right\}_{t=1}^{T}$ from $\widetilde{Z}_{t}=\widehat{A} \widetilde{Z}_{t-1}+\widetilde{U}_{t}$ with $\widetilde{Z}_{0}$ fixed at a vector of zeros. As part of this procedure, in each period $t$ I replace the fifth and sixth elements in $\widetilde{Z}_{t}$ (i.e., the unrestricted values for $\delta_{t}^{\mathrm{FA}}$ and $\delta_{t}^{\mathrm{FL}}$ with

$$
\begin{aligned}
\delta(\hat{\rho})_{t}^{\mathrm{FA}} & =\frac{1}{2}\left(\delta_{t}^{\mathrm{FA}}+\delta_{t}^{\mathrm{FL}}\right)+\frac{1}{2}\left\{\widetilde{r}_{t}^{\mathrm{FA}}-\widetilde{r}_{t}^{\mathrm{FL}}+\Delta \widetilde{x}_{t}^{*}-\Delta \widetilde{m}_{t}^{*}+\frac{1}{\hat{\rho}}\left(\delta(\hat{\rho})_{t-1}^{\mathrm{FA}}-\delta(\hat{\rho})_{t-1}^{\mathrm{FL}}\right)+\tilde{v}_{t}\right\} \quad \text { and } \\
\delta(\hat{\rho})_{t}^{\mathrm{FL}} & =\frac{1}{2}\left(\delta_{t}^{\mathrm{FA}}+\delta_{t}^{\mathrm{FL}}\right)-\frac{1}{2}\left\{\widetilde{r}_{t}^{\mathrm{FA}}-\widetilde{r}_{t}^{\mathrm{FL}}+\Delta \widetilde{x}_{t}^{*}-\Delta \widetilde{m}_{t}^{*}+\frac{1}{\hat{\rho}}\left(\delta(\hat{\rho})_{t-1}^{\mathrm{FA}}-\delta(\hat{\rho})_{t-1}^{\mathrm{FL}}\right)+\tilde{v}_{t}\right\} .
\end{aligned}
$$

By definition, $x p_{t}=\delta_{t}^{\mathrm{FA}}-\delta_{t}^{\mathrm{FL}}$, so combining these equations and iterating forward gives

$$
x p(\hat{\rho})_{t}=\delta(\hat{\rho})_{t}^{\mathrm{FA}}-\delta(\hat{\rho})_{t}^{\mathrm{FL}}=-\sum_{i=1}^{\infty} \hat{\rho}^{i}\left(\widetilde{r}_{t+i}^{\mathrm{NFA}}+\Delta n x_{t+i}+\tilde{v}_{t+i}\right) .
$$

By construction, $\mathbb{E}\left[\tilde{v}_{t+i} \mid \widetilde{Z}_{t}\right]=0$ and $\mathbb{E}\left[\widetilde{r}_{t+i}^{\mathrm{NFA}}+\Delta n x_{t+i} \mid \widetilde{Z}_{t}\right]=\left(\imath_{r}+\imath_{n x}\right) \widehat{A}^{i} \widetilde{Z}_{t}$ for $i>0$, so this expression implies that $x p(\hat{\rho})_{t}=-\left(\imath_{r}+\imath_{n x}\right) \hat{\rho} \widehat{A}(I-\hat{\rho} \widehat{A})^{-1} \widetilde{Z}_{t}$.

3. I estimate the VAR using $\left\{\widetilde{Z}_{t},\right\}_{t=1}^{T}$ and use the estimates to compute the companion matrix in $(25), \widetilde{A}$.

4. I compute a value for $\rho, \tilde{\rho}$, that minimizes the sample variance of the specification error,

$$
v_{t}=\widetilde{n x a}_{t}-\widetilde{n x a}_{t}^{\mathrm{VAL}}-\widetilde{n x a}_{t}^{\mathrm{TR}}=\left[\imath_{x p}+\left(\imath_{r}+\imath_{n x}\right) \rho \widetilde{A}(I-\rho \widetilde{A})^{-1}\right] \widetilde{Z}_{t}
$$

5. Finally, I use the bootstrap sample $\left\{\widetilde{Z}_{t},\right\}_{t=1 t=1}^{T}$ to compute the Wald statistic for the null

$$
\imath_{x p}=-\left(\imath_{r}+\imath_{n x}\right) \tilde{\rho} \widetilde{A}(I-\tilde{\rho} \widetilde{A})^{-1} .
$$

Steps 1 - 5 are repeated 10,000 times to build the bootstrap distribution for the Wald statistic for $\rho=0.989$. The p-values report the fraction of the 10,000 trials that generate Wald statistics larger than the value I compute in the data. 
Table A

\begin{tabular}{|c|c|c|c|c|}
\hline & CDW & Evans & Forbes & Evans \\
\hline & \multicolumn{2}{|c|}{$1994-2005$} & \multicolumn{2}{|c|}{$2002-2006$} \\
\hline & (i) & (ii) & (iii) & (iv) \\
\hline \multicolumn{5}{|l|}{ Equity } \\
\hline Assets & 9.59 & 7.05 & & \\
\hline Liabilities & 11.88 & 10.00 & & \\
\hline Differential & -2.29 & -2.95 & & \\
\hline \multicolumn{5}{|l|}{ Debt } \\
\hline Assets & 6.08 & 5.45 & & \\
\hline Liabilities & 5.89 & 5.49 & & \\
\hline Differential & 0.19 & -0.04 & & \\
\hline \multicolumn{5}{|l|}{ All } \\
\hline Assets & & & 11.20 & 11.05 \\
\hline Liabilities & & & 4.30 & 4.10 \\
\hline Differential & & & 6.90 & 6.94 \\
\hline $\begin{array}{l}\text { Notes: Colum } \\
\text { Dvorak, and } \\
\text { returns. Coluu } \\
\text { in my data se }\end{array}$ & $\begin{array}{l}\text { and (iii) s } \\
\text { ock (2007 } \\
\text { i) and (iv }\end{array}$ & $\begin{array}{l}\text { he sample } \\
\text { d Forbes } \\
\text { ort compa }\end{array}$ & $\begin{array}{l}\text { tics repor } \\
\text { for nom } \\
\text { tatistics }\end{array}$ & $\begin{array}{l}\text { Curcuru, } \\
\text { anualized } \\
\text { e returns }\end{array}$ \\
\hline
\end{tabular}

